WHPO Pub. $91-2$

Oug 1991
C.1

\title{
WORLD OCEAN CIRCULATION EXPERIMENT
}

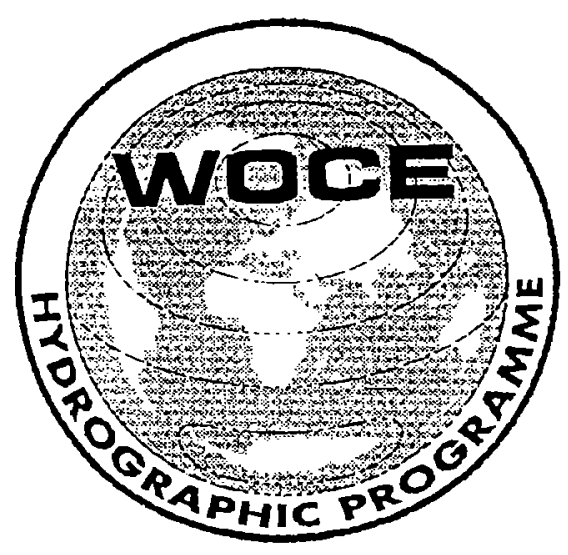

A Comparison of Methods for the Determination of Dissolved Oxygen in Seawater

\section{WHP Office Report WHPO 91-2 WOCE Report 73/91}

EC

228.5 .1663 $91-2$ c.l

August 1991

Woods Hole, Mass., USA

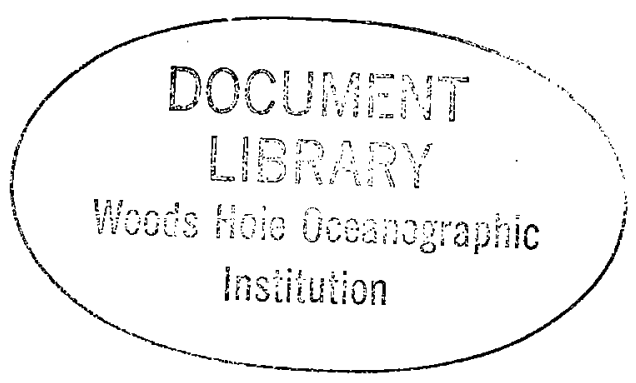




\title{
WHPO Publication 91-2
}

\section{A Comparison of Methods for the Determination of Dissolved Oxygen in Seawater}

\author{
Authors: \\ Charles H. Culberson \\ College of Marine Studies \\ University of Delaware \\ Newark, Delaware 19716 \\ George Knapp \\ Marvel C. Stalcup \\ Woods Hole Oceanographic Institution \\ Woods Hole, Massachusetts 02543 \\ Robert T. Williams \\ Oceanographic Data Facility \\ Scripps Institution of Oceanography \\ La Jolla, California 92093 \\ Frank Zemlyak \\ Marine Chemistry Division \\ Bedford Institute of Oceanography \\ Dartmouth, Nova Scotia \\ Canada B2Y 4A2 \\ WOCE Hydrographic Programme Office \\ Woods Hole Oceanographic Institution \\ Woods Hole, MA 02543 USA \\ Phone: (508) 457-2000 ext. 3374 \\ Fax: (508) 457-2181 \\ Telemail (Omnet): WHP.Office
}

\begin{abstract}
Prepared for the National Science Foundation under Grant OCE 89-07815, T. Joyce, Principal Investigator. Reproduction in whole or in part is permitted for any purpose. In citing this manuscript in a bibliography, the reference should be followed by the phrase: UNPUBLISHED MANUSCRIPT.
\end{abstract}

August 1991

WOCE Report 73/91 


\begin{tabular}{|c|c|}
\hline ABSTRACT & 1 \\
\hline INTRODUCTION & 3 \\
\hline METHODS & 5 \\
\hline $\begin{array}{l}\text { Water Sampling } \\
\text { Reagent Addition } \\
\text { Analytical Methods }\end{array}$ & $\begin{array}{l}5 \\
7 \\
7\end{array}$ \\
\hline CALCULATIONS & 12 \\
\hline $\begin{array}{l}\text { Whole Bottle Titration } \\
\text { Titration of an Aliquot }\end{array}$ & $\begin{array}{l}12 \\
13\end{array}$ \\
\hline RESULTS & 14 \\
\hline $\begin{array}{l}\text { Thiosulfate standardization } \\
\text { Blank Determination } \\
\text { Oxygen Measurements }\end{array}$ & $\begin{array}{l}14 \\
16 \\
18\end{array}$ \\
\hline DISCUSSION & 24 \\
\hline $\begin{array}{l}\text { Oxygen in the Reagents } \\
\text { The Seawater Blank }\end{array}$ & $\begin{array}{l}25 \\
25\end{array}$ \\
\hline RECOMMENDATIONS & 28 \\
\hline $\begin{array}{l}\text { Problems Needing Further Research } \\
\text { Techniques for Routine Oxygen Measurements }\end{array}$ & $\begin{array}{l}28 \\
29\end{array}$ \\
\hline REFERENCES & 32 \\
\hline LIST OF FIGURES & 34 \\
\hline $\begin{aligned} & \text { APPENDIX A - } \text { Measured oxygen concentrations from each } \\
& \text { institution }\end{aligned}$ & 35 \\
\hline $\begin{array}{l}\text { APPENDIX B - Bedford experimental data } \\
\text { APPENDIX C - Delaware experimental data } \\
\text { APPENDIX D - Scripps experimental data } \\
\text { APPENDIX E - Woods Hole experimental data }\end{array}$ & $\begin{array}{l}38 \\
40 \\
43 \\
46\end{array}$ \\
\hline
\end{tabular}




\section{ACKNOWLEDGMENTS}

We thank Andrew Dickson, Lou Gordon, Arnold Mantyla, and Peter Saunders for reviewing draft versions of this report. Henri Berteaux, principal investigator of the WOCE Sampler Program, supplied laboratory space and ship time for the intercalibration. We thank Bill Jenkins, chief scientist during R/V Oceanus cruise 219, for his support and help during the intercalibration.

This regearch was supported by National Science Foundation Grants OCE 8822542 and OCE 88-21977 and OCE 89-07815. Preparation and distribution of this report by the WHP Office, Woods Hole Oceanographic Institution, Woods Hole, MA. 02543 USA, was supported by NSF Grant OCE 89-07815. 


\section{ABSTRACT}

An intercalibration of dissolved oxygen methods was conducted at 2 stations in the Sargasso Sea between April 28 and May 3, 1990. The experiment compared three techniques using automated endpoint detection with the manual winkler method using a starch endpoint. Institutions participating in the intercomparison were the Bedford Institute of Oceanography (automated photometric titration), the University of Delaware (automated amperometric titration), the Scripps Institution of Oceanography (manual titration), and the Woods Hole Oceanographic Institution (automated amperometric titration).

Differences in measured oxygen concentrations between institutions were encouragingly small. However, small, systematic differences in dissolved oxygen between institutions did exist. The range between the highest and lowest oxygen values reported by the 4 institutions never exceeded $0.6 \%$ over the entire concentration range studied $(3.4$ to $6.2 \mathrm{ml} / 1)$. The good agreement is probably due to the use of the essentials of Carpenter's (1965) modification of the Winkler method by all institutions.

The intercalibration revealed several aspects of dissolved oxygen measurements that require further research: (1) the intercalibration should be extended to very low oxygen concentrations; (2) procedures for measuring and applying corrections for the seawater blank need to be formalized; (3) a simple procedure to measure the temperature of seawater at the time of sampling needs to be developed; and (4) the solubility of atmospheric oxygen in the Winkler reagents must be measured as a function of temperature.

The intercalibration also revealed that analytical techniques required for precise and accurate volumetric measurements were often not applied, even by experienced analysts. It was found that uncalibrated pipets were used to dispense standards, that the volumes of oxygen flasks were not corrected for buoyancy, and that corrections for the thermal expansion of aqueous solutions were often not applied. 


\section{INTRODUCTION}

This report describes an intercalibration of dissolved oxygen methods conducted between April 28 and May 3, 1990, during leg 3 of R/V Oceanus cruise 219. The experiment compared three techniques using automated endpoint detection with the manual winkler method using a starch endpoint. Institutions participating in the intercomparison were the Bedford Institute of oceanography (automated photometric titration), the University of Delaware (automated amperometric titration), the scripps Institution of Oceanography (manual titration), and the Woods Hole Oceanographic Institution (automated amperometric titration).

The purpose of the intercalibration was twofold:

1) to determine the precision of each technique under seagoing conditions; and

2) to check each method for systematic errors relative to the classic manual winkler titration using a starch endpoint.

The intercomparison was carried out at 2 stations in the sargasso sea (Figure 1 and Table 1). Vertical temperature, salinity, and oxygen profiles are shown in Figures 2 and 3 . Station 2 (casts $21,23,24$ ) is a repeat of KNORR 29 station 249 (9 July 1972), Geosecs station 121 (30 March 1973), and Transient Tracers station 005 (5 April 1981). 
Table 1. Station summary for oxygen intercalibration, R/V Oceanus cruise 219.

\begin{tabular}{|c|c|c|c|c|c|c|c|c|}
\hline \multirow[t]{2}{*}{ Cast } & \multirow[t]{2}{*}{ Date } & \multirow[t]{2}{*}{$\begin{array}{l}\text { Time } \\
\text { start }\end{array}$} & \multirow[t]{2}{*}{$\begin{array}{l}\text { (GMT) } \\
\text { End }\end{array}$} & $\begin{array}{l}\text { Lat i tude } \\
\left({ }^{\circ} \mathrm{N}\right)\end{array}$ & $\begin{array}{l}\text { Longi tude } \\
\left({ }^{\circ} \mathrm{W}\right)\end{array}$ & $\begin{array}{c}\text { Pressure } \\
\text { Range } \\
\text { Sampled } \\
\text { (dB) }\end{array}$ & \multirow[t]{2}{*}{$\begin{array}{l}\text { Water } \\
\text { Depth } \\
(m)\end{array}$} & \multirow[t]{2}{*}{$\begin{array}{l}\text { Number } \\
\text { of Depths } \\
\text { Sampled }\end{array}$} \\
\hline & & & & \multicolumn{2}{|c|}{ Station 1} & & & \\
\hline 13 & 29 April 90 & $07: 25$ & $08: 36$ & $33^{\circ} 46.78^{\prime}$ & $65^{\circ} 54.591$ & $0020-5195$ & 5111 & 11 \\
\hline 15 & 29 April 90 & 20:02 & $20: 22$ & $33^{\circ} 10.05^{\prime}$ & $65^{\circ} 44.971$ & $0896-0896$ & 5111 & 10 \\
\hline 16 & 29 April 90 & 22: 19 & 23:09 & $33^{\circ} 49.09^{\prime}$ & $65^{\circ} 52.99 !$ & $3549-3550$ & 5111 & 10 \\
\hline 20 & 30 April 90 & $16: 24$ & $17: 29$ & $33^{\circ} 49.68^{\prime}$ & $65^{\circ} 53.85^{\prime}$ & $0022-5109$ & 5122 & 10 \\
\hline \multicolumn{9}{|c|}{ Station 2} \\
\hline 21 & 1 May 90 & $13: 48$ & $15: 30$ & $35^{\circ} 55.391$ & $67^{\circ} 50.47^{\prime}$ & $3040-4945$ & 4926 & 10 \\
\hline 23 & 1 May 90 & $23: 30$ & $23: 50$ & $35^{\circ} 55.97$ & $67^{\circ} 52.02^{\prime}$ & $0011-0909$ & 4846 & 10 \\
\hline 24 & 2 May 90 & $01: 45$ & $02: 24$ & $35^{\circ} 58.20^{\prime}$ & $67^{\circ} 55.02 !$ & $1014-2840$ & 4950 & 10 \\
\hline \multicolumn{9}{|c|}{ KNORR 29} \\
\hline 249 & 7 July 72 & & & $35^{\circ} 54^{\prime}$ & $67^{\circ} 56^{\prime}$ & & 4931 & \\
\hline \multicolumn{9}{|c|}{ Geosecs } \\
\hline 121 & 30 March 73 & & & $35^{\circ} 591$ & $67^{\circ} 59^{\prime}$ & & 4933 & \\
\hline \multicolumn{9}{|c|}{ Transient Tracers } \\
\hline 005 & 5 April 81 & & & $35^{\circ} 59^{\prime}$ & $68^{\circ} 00^{\prime}$ & & 4928 & \\
\hline
\end{tabular}


Seawater samples were collected with a General Oceanics rosette sampler equipped with 10 liter PVC Niskin bottles and a Neil Brown Mark III CTD. Samples were collected on the open deck, in an area with no overhead covering. At night the lighting was poor in this area, and, at certain positions around the rosette, it was impossible to check the oxygen drawing tubes for trapped air bubbles. The exposed sampling position became a problem after cast 24 when the ship was underway. As samples were drawn after this cast, the deck was often underwater to such an extent that cases containing the oxygen flasks were floating and in danger of being lost over the side. In addition, spray which had collected on the deck above dripped steadily onto the area in which the reagent dispensers were mounted; occasionally drops from the deck above would fall into an oxygen flask as it was being pickled. The digital thermometer used to measure sampling temperatures was flooded with seawater and damaged while cast 24 was being sampled.

Oxygen samples from Bedford, Delaware, and scripps were collected in calibrated iodine flasks (Erlenmeyer flasks with a ground glass stopper and a lip to provide a water seal). Ground glass stoppers on the Bedford flasks contained long nipples which extended into the flask and displaced enough volume so that titrations did not overflow the flask (Green and Carritt, 1966). The Woods Hole samples were collected in calibrated narrow mouth amber reagent bottles with flat head ground glass stoppers (147.5 ml nominal volume).

Duplicate oxygen samples were drawn by each institution. The second of the two samples was drawn immediately after the first. The order in which samples were drawn was deliberately staggered, to detect possible systematic errors, as the head space in the Niskin bottles increased during sampling. The order in which samples were drawn from each Niskin bottle is listed in Table 2.

To minimize errors due to contamination from atmospheric oxygen, all oxygen samples from Niskin bottles 2-4 were drawn before the air vents on bottles 5-8 were opened. All samples from Niskin bottles 5-8 were then drawn before bottles 9-12 were opened. About 15 minutes was required to draw the 4 sets of duplicate oxygen samples from each Niskin bottle. About 45 minutes elapsed between the time the first and last samples were drawn from the rosette.

Oxygen samples were the first samples drawn from the Niskin bottles at station 1. At station 2, a freon sample (about $300 \mathrm{ml}$ including rinse) was drawn before the first oxygen sample.

Oxygen flasks were copiously flushed with seawater before pickling reagents were added. The volume of seawater remaining in the Niskin bottles after all oxygen samples had been drawn was measured during cast 20 . Between 1.5 and 3.0 liters of seawater remained in the 10 liter Niskin bottles. This indicates that about 1 liter of seawater was used to rinse and flush each 
Table 2. Order of sampling for each Niskin bottle. Bottle 1 (and usually bottle 2) was used for other purposes during the cruise and was not sampled as part of the intercalibration.

\begin{tabular}{|c|c|c|c|c|c|}
\hline $\begin{array}{l}\text { Niskin } \\
\text { bottle } \\
\text { number }\end{array}$ & $\begin{array}{l}\text { Relative } \\
\text { position } \\
\text { in cast }\end{array}$ & $\begin{array}{l}----\infty \\
\text { First }\end{array}$ & $\begin{array}{l}\text { of sampling } \\
\text { second }\end{array}$ & $\begin{array}{l}\text { by institut } \\
\text { Third }\end{array}$ & $\begin{array}{l}\text { Fourth } \\
\text { Four }\end{array}$ \\
\hline $\begin{array}{l}2 \\
3 \\
4\end{array}$ & deep & $\begin{array}{l}\text { Bedford } \\
\text { Woods Hole } \\
\text { Delaware }\end{array}$ & $\begin{array}{l}\text { Scripps } \\
\text { Bedford } \\
\text { Woods Hole }\end{array}$ & $\begin{array}{l}\text { Delaware } \\
\text { Scripps } \\
\text { Bedford }\end{array}$ & $\begin{array}{l}\text { Woods Hole } \\
\text { Delaware } \\
\text { Scripps }\end{array}$ \\
\hline $\begin{array}{l}5 \\
6 \\
7 \\
8\end{array}$ & & $\begin{array}{l}\text { Scripps } \\
\text { Bedford } \\
\text { Woods Hole } \\
\text { Delaware }\end{array}$ & $\begin{array}{l}\text { Delaware } \\
\text { Scripps } \\
\text { Bedford } \\
\text { Woods Hole }\end{array}$ & $\begin{array}{l}\text { Woods Hole } \\
\text { Delaware } \\
\text { Scripps } \\
\text { Bedford }\end{array}$ & $\begin{array}{l}\text { Bedford } \\
\text { Woods Hole } \\
\text { Delaware } \\
\text { Scripps }\end{array}$ \\
\hline $\begin{array}{r}9 \\
10 \\
11 \\
12\end{array}$ & shallow & $\begin{array}{l}\text { Scripps } \\
\text { Bedford } \\
\text { Woods Hole } \\
\text { Delaware }\end{array}$ & $\begin{array}{l}\text { Delaware } \\
\text { Scripps } \\
\text { Bedford } \\
\text { Woods Hole }\end{array}$ & $\begin{array}{l}\text { Woods Hole } \\
\text { Delaware } \\
\text { Scripps } \\
\text { Bedford }\end{array}$ & $\begin{array}{l}\text { Bedford } \\
\text { Woods Hole } \\
\text { Delaware } \\
\text { Scripps }\end{array}$ \\
\hline
\end{tabular}

Table 3. Source of reagents used by each institution.

$\begin{array}{llll}\text { Institution } & \mathrm{MnCl}_{2} & \mathrm{NaOH} / \mathrm{NaI} & \mathrm{H}_{2} \mathrm{SO}_{4} \\ \text { Woods Hole } & \text { Batch 1 } & \text { Batch 1 } & \text { Batch 1 } \\ \text { Delaware } & \text { Batch 2 } & \text { Batch 2 } & \text { Batch 1 } \\ \text { Scripps } & \text { Batch 2 } & \text { Batch 2 } & \text { Batch 2 } \\ \text { Bedford } & \text { Batch 2 } & \text { Batch 2 } & \text { Batch 2 }\end{array}$


flask, since 8 oxygen flasks were filled from each Niskin bottle. The 1 liter seawater rinse corresponds to approximately 7-10 complete flushes of each oxygen
flask. This degree of flask. This degree of flushing is much greater than the $1 / 3$ bottle volume recommended by Strickland and Parsons (1965), the 1 bottle volume by Carpenter (1965), and the 2 bottle volumes by Horibe et al (1972) and by Grasshoff (1976).

It is our opinion that the use of proper water sampling techniques is the single most important factor in obtaining high quality oxygen measurements.

\section{Reagent Addition}

Reagents used to pickle and acidify the samples were prepared at Woods Hole, using concentrations specified by carpenter (1965). Two liters of each reagent were prepared and filtered through a glass fiber filter (Gelman type A/E, $1.6 \mu \mathrm{m}$ pore size, or Whatman type GF-F, $0.7 \mu \mathrm{m}$ pore size) to remove particulates. The reagents were dispensed with all glass and teflon Dispensette. Bottle-Top Dispensers, 0-2 ml capacity, from Brinkmann Instruments. The volume of each dispenser was adjusted to $1 \mathrm{ml}$ by dispensing 10 portions into a $10 \mathrm{ml}$ graduated
cylinder.

The length of the tips of the $\mathrm{MnCl}_{2}$ and $\mathrm{NaOH} / \mathrm{NaI}$ reagent dispensers used by Bedford, Delaware, and Scripps was increased from 1 to 3 inches by an additional length of small diameter plastic tubing. The tips were lengthened to ensure that manganese hydroxide did not precipitate in the necks of the oxygen flasks before they were stoppered. Erroneously high oxygen concentrations would be calculated if oxidized precipitate from the neck of the flask settled into the interior of the flask before it was stoppered.

Because the analysts were located in 2 different locations aboard ship, it was necessary to divide the reagents into 2 batches. Table 3 lists the batch of reagents used by each institution. Reagent blanks for both sets of reagents were measured by each institution.

After copious flushing, the filled oxygen flasks were carried to a nearby rack containing the $\mathrm{MnCl}_{2}$ and $\mathrm{NaOH} / \mathrm{NaI}$ pickling reagents, which were immediately injected into the samples. The flasks were stoppered and then inverted and shaken to $\mathrm{mix}$ the reagents. The flasks were not stoppered during the short interval between sampling and reagent addition.

The pickled oxygen samples were returned to the laboratory; once the precipitate had settled, the flasks were shaken a second time, and the precipitate allowed to settle before titration.

\section{Analytical Methods}

Details of the methods used by each of the four institutions are listed in Table 4. All standards and blanks were prepared and run in distilled water. All institutions used Carpenter's (1965) method of reverse $1 \mathrm{ml}$ reagent additions to
determine the reagent blank. 
Table 4. Details of oxygen methods used on R/V Oceanus Cruise 219

$$
\text { Bedford Delaware Scripps Woods Hole }
$$

Endpoint: photometric amperometric starch amperometric

Volumes:

Flask volume (ml) Aliquot volume (ml)

Size of buret (ml)

Smallest measurable volume increment $(\mu l)$

Reagent concentrations:

$\mathrm{MnCl}$

$\mathrm{NaOH} / \mathrm{NaI}$

$\mathrm{H}_{2} \mathrm{SO}_{4}$

$\mathrm{KIO}_{3}$ or $\mathrm{KH}\left(\mathrm{IO}_{3}\right)_{2}$

$\mathrm{KIO}_{3}$ volume $(\mathrm{ml})$

Thiosulfate normality

$\mathrm{MnCl}_{2}$ in standards

Wetting agent added
131

$-$

5

1

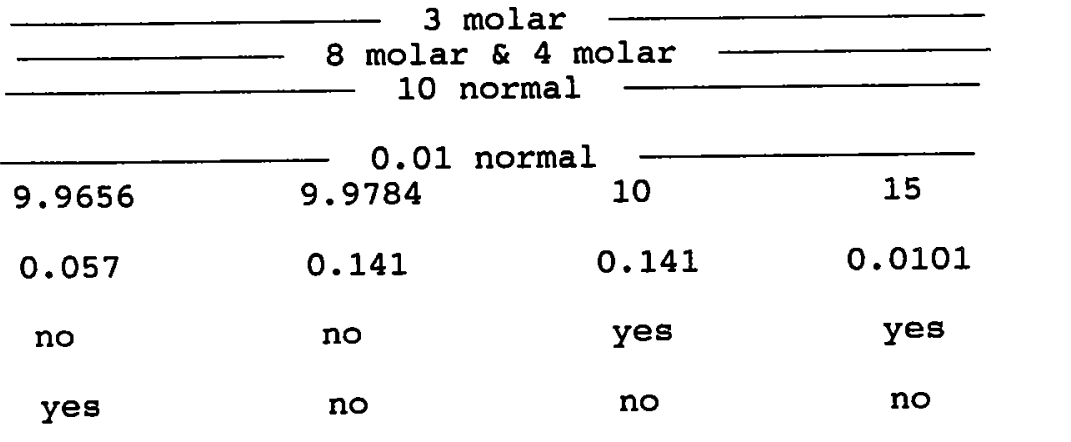




\section{Bedford}

The automated titration used by the Bedford Institute of Oceanography was a modification of the manual Winkler titration previously employed at Bedford (Levy et al, 1977a,b). The automated titration differed from Carpenter's (1965) method in four respects: (1) the starch endpoint was replaced by a photometric endpoint; (2) the $1 \mathrm{ml}$ manual microburet was replaced by a $5 \mathrm{ml}$ Metrohm Dosimat E655 digital piston buret; (3) the thiosulfate normality was reduced from 0.14 to 0.06 ; and (4) 1 drop of wetting agent was added to all samples, standards, and blanks just prior to titration to prevent bubble formation.

The photometric endpoint was detected at a wavelength of $420 \mathrm{~nm}$ with a Brinkmann model PC 800 digital fiber optic probe colorimeter. The titration program was written in Pascal; the titration was controlled by an IBM compatible microcomputer.

Standards were dispensed with a $10 \mathrm{ml}$, class A, calibrated hand pipet; blanks with a $1 \mathrm{ml}$, class $A$, hand pipet. The standard kIo solution was a commercially prepared 0.01 normal solution (BDH R02592, lot 9001142) distributed in $100 \mathrm{ml}$ polyethylene bottles. A freshly opened bottle was used for each standardization.

The Bedford automatic titrator developed erratic behavior after cast 20, apparently due to an incompatibility between the microcomputer and the ship's power supply. Consequently, only Bedford data from casts 13 through 20 are included in this report.

\section{Delaware}

The automated titration used by the University of Delaware differed from Carpenter's (1965) method in two respects: (1) the starch endpoint was replaced by an amperometric endpoint; and (2) the $1 \mathrm{ml}$ manual microburet was replaced by a $5 \mathrm{ml}$ Metrohm Dosimat $\mathrm{E} 535$ digital piston buret.

The titration program was written in Commodore Basic; the titration was controlled by a Commodore CBM 8032 microcomputer using the procedure described by Culberson and Huang (1987). The average analysis time per sample, including acidification, sample changing, and titration was 4.8 minutes.

Standards were dispensed with a $10 \mathrm{ml}$, class A, calibrated hand pipet; blanks with a $1 \mathrm{ml}$ Eppendorf pipet. The standard $\mathrm{KIO}_{3}$ solution was a 2 liter batch of $\mathrm{KIO}_{3}$ prepared on 11 April 1990. Fisher reagent grade $\mathrm{KIO}_{3}$ (P253-100, lot 897675 , assay 99.98 ) was dried at $135^{\circ} \mathrm{C}$ for 12 hours, cooled in a desiccator, and weighed to $0.1 \mathrm{mg}$. The weighed salt was transferred to a 2 liter, class $A$, volumetric flask and made up to volume at $22.5^{\circ} \mathrm{C}$. The calculated normality was 0.010140 . The weight of $\mathrm{KIO}_{3}$ was corrected for buoyancy assuming a density of 3.89 (Hodgman, 1958); the molecular weight of $\mathrm{KIO}_{3}$ was taken as 214.001 . 


\section{Scripps}

The manual titration with starch endpoint used by scripps (Dickson and Anderson, 1990) was identical to that described by Carpenter (1965) with one exception. In addition to the $1 \mathrm{ml}$ of $\mathrm{H}_{2} \mathrm{SO}_{4}$ and $1 \mathrm{ml}$ of $\mathrm{NaOH} / \mathrm{NaI}$ specified by Carpenter (1965), Scripps also added $1 \mathrm{ml}^{4}$ of $\mathrm{MnCl}_{2}$ to their standards. The average analysis time per sample, including acidification, sample changing, and titration was 4.0 minutes.

Standards were dispensed with an uncalibrated $10 \mathrm{ml}$ automatic pipet; blanks with a $1 \mathrm{ml}$ Eppendorf pipet. The standard iodate solution was prepared, during the cruise, in 1 liter batches from pre-weighed (to $0.1 \mathrm{mg}$ ) vials of Fisher reagent grade $\mathrm{KIO}_{3}$ (P253-100, lot 870977 , assay $100.2 \%$ ). The normality of the standard was assumed to be exactly 0.010000 . Two 1 liter batches of standard were prepared during the cruise, their thiosulfate titers differed by $0.04 \%$.

The $10 \mathrm{ml}$ automatic pipet used to dispense standards had not been calibrated prior to the cruise, and was broken, after the cruise, before it could be calibrated. The volumes of 8 similar pipets, previously calibrated at Scripps, ranged from 9.9957 to $9.9726 \mathrm{ml}$, and averaged $9.985 \pm 0.007(1 \sigma) \mathrm{ml}$.

\section{Woods Hole}

The automated titration used by Woods Hole Oceanographic Institution (Knapp, Stalcup, and Stanley, 1989, 1990) differed from Carpenter's (1965) method in several respects: (1) an aliquot of the acidified sample, rather than the entire contents of the sample bottle, was titrated; (2) the starch endpoint was replaced by an amperometric endpoint; (3) the $1 \mathrm{ml}$ manual microburet was replaced by a 10 $\mathrm{ml}$ Metrohm Dosimat E665 digital piston buret; (4) the thiosulfate normality was reduced from 0.14 to 0.01 normal; and (5) $1 \mathrm{ml}$ of the $\mathrm{MnCl}_{2}$ reagent was added to their standards.

In the Woods Hole procedure, a $50 \mathrm{ml}$ aliquot of the acidified sample is added to a $100 \mathrm{ml}$ beaker and the contents titrated with 0.01 normal thiosulfate. The average analysis time per sample, including acidification, sample changing, and titration was 2.5 minutes.

The standardization procedure used by woods Hole differs from that of carpenter (1965). In the Woods Hole procedure, $150 \mathrm{ml}$ of distilled water was added to a $200 \mathrm{ml}$ Erlenmeyer flask; $1 \mathrm{ml}$ each of the $\mathrm{H}_{2} \mathrm{SO}_{4}, \mathrm{MnCl}_{2}$, and $\mathrm{NaOH} / \mathrm{NaI}$ reagents were then added with stirring; and finally, $15 \mathrm{ml}$ of the iodate standard was added to the flask. A $50 \mathrm{ml}$ aliquot of this solution was titrated as if it were an unknown. This procedure was adopted to minimize errors due to iodine volatilization. 
Standards and blanks were dispensed with a $20 \mathrm{ml}$ Metrohm Dosimat E665 digital piston buret. The standard iodate solution was a 1 liter batch of $\mathrm{KH}\left(\mathrm{IO}_{3}\right)_{2}$ prepared on 20 March 1990. Fisher purified $\mathrm{KH}\left(\mathrm{IO}_{3}\right)_{2}$ (P190-100, lot 893220, assay 100.1\%) was dried in a desiccator and weighed to $0.1 \mathrm{mg}$. The weighed salt was transferred to a 1 liter, class A, volumetric flask and made up to volume with distilled water. 


\section{CALCULATIONS}

The following equations were used to calculate the concentration of dissolved oxygen in the seawater samples. All volumes are expressed in milliliters.

$$
\begin{aligned}
& \mathrm{V}_{\mathrm{x}}=\text { thiosulfate titer of sample (ml) } \\
& \mathrm{V}_{\mathrm{blk}, \mathrm{dw}}=\text { thiosulfate titer of pure water blank (ml) } \\
& \mathrm{V}_{\text {std }}=\text { thiosulfate titer of standard (ml) } \\
& \mathrm{V}_{\text {bot }}=\text { volume of sample bottle }(\mathrm{ml}) \\
& \mathrm{V}_{\text {aliq }}=\text { volume of aliquot }(50 \mathrm{ml}) \\
& \mathrm{V}_{\text {reg }}=\text { volume }(2 \mathrm{ml}) \text { of sample displaced by reagents } \\
& v_{3}=\text { volume of reagents }(3 \mathrm{ml}) \text { used to prepare standards } \\
& \mathrm{V}_{150}=\text { volume of distilled water }(150 \mathrm{ml}) \text { used to prepare } \\
& \text { standards in aliquot method } \\
& \mathrm{V}_{103}=\text { volume of iodate standard (ml) } \\
& \mathrm{N}_{103}=\text { normality of iodate standard }(=6 \cdot \text { molarity }) \\
& \mathrm{DO}_{\text {reg }}=\text { absolute amount of oxygen added with reagents, } \\
& 0.0017 \mathrm{ml} \text { (Murray, Riley, and Wilson, 1968) } \\
& \mathrm{O}_{2}=\text { oxygen concentration in sample }(\mathrm{ml} / \mathrm{l})
\end{aligned}
$$

Whole Bottle Titration

Dissolved oxygen calculations for whole bottle titrations performed by Bedford, Delaware, and Scripps were calculated from the following modification of Carpenter's (1965) equation,

$$
O_{2}=\frac{\frac{\left(v_{x}-v_{b l k, d w}\right) \cdot v_{I 03} \cdot N_{I 03} \cdot 5598}{\left(v_{s t d}-v_{b l k, d w}\right)}-1000 \cdot D O_{r e g}}{\left(v_{b o t}-v_{\text {reg }}\right)}
$$

Equation 1 differs from Carpenter's (1965) equation for whole bottle titrations in the correction for oxygen added with the reagents. In equation 1 , the correction for oxygen added with the reagents is a function of the flask volume; whereas, in Carpenter's equation, a constant correction, $0.018 \mathrm{ml} / 1$, is used. The use of a constant value for the concentration of oxygen added with the reagents is only correct if all flasks have identical volumes. 
The normality of thiosulfate used to titrate the Woods Hole samples was calculated from equation 2,

$$
N_{\text {thio }}=\frac{v_{103} \cdot N_{103}}{\left(v_{\text {std }} \cdot \frac{\left(v_{150}+v_{103}+v_{3}\right)}{v_{\text {aliq }}}-v_{b(k, d w}\right)}
$$

Dissolved oxygen calculations for titrations performed by woods Hole were calculated from equation 3 ,

$$
O_{2}=\frac{\left(v_{x} \cdot \frac{v_{\text {bot }}}{v_{\text {aliq }}}-v_{b l k, d w}\right) \cdot N_{\text {thio }} \cdot 5598-1000 \cdot D_{\text {reg }}}{\left(v_{\text {bot }}-v_{\text {reg }}\right)}
$$


Measurement of dissolved oxygen concentration involves several steps: (1) water sampling; (2) addition of reagents; (3) standardization of the thiosulfate titrant; (4) determination of the reagent and sample blanks; and (5) titration of the seawater sample. Items (1) and (2) were discussed under METHODS. The last 3 items represent the titration of samples, standards, and blanks and will be discussed in this section.

\section{Thiosulfate standardization}

The standards run by each institution were prepared by dispensing a precise, known volume of iodate into $a$; adding the $\mathrm{H}_{2} \mathrm{SO}_{4}$ and $\mathrm{NaOH} / \mathrm{NaI}$ (and sometimes $\mathrm{MnCl}_{2}$ ) reagents; and titrating the liberated iodine with thiosulfate. statistical analysis of replicate standards provides a measure of the best possible precision of a particular analytical technique. The actual precision of oxygen analyses may be worse than the precision calculated from replicate standards, due to the presence of sampling errors which occur when oxygen samples are drawn.

The average thiosulfate titer and its associated standard deviation, for each set of standards run by each institution, is shown in Figures 4 through 7 . A statistical analysis of this data is given in Table 5 .

Table 5. Precision of replicate standards run by different institutions during $R / V$ Oceanus cruise 219 . Standard deviation calculated by pooling the variances of the individual sets of standards (Youden, 1951). This table contains some data not shown in Figures 4 through 7 .

Institution

Bedford

Delaware

Scripps

Woods Hole

$$
\begin{aligned}
& \text { Sets of } \\
& \text { replicate } \\
& \text { standards }
\end{aligned}
$$

$$
\begin{aligned}
& \text { Number of } \\
& \text { replicates } \\
& \text { per set }
\end{aligned}
$$

$$
\begin{aligned}
& \text { Relative } \\
& \text { standard } \\
& \text { deviation }
\end{aligned}
$$


An examination of the results in Table 5 and Figures 4 through 7 , shows that standards run by Woods Hole and Scripps are considerably more precise than those of Bedford and Delaware. The difference between the precisions of the Woods Hole and Delaware standards, both of which use Metrohm Dosimat titrators and amperometric endpoints, may be due to the non-diffusive buret tip used by Woods Hole, but not by Delaware. The one-way valve in this buret tip eliminates diffusion of thiosulfate into the solution between additions of titrant. On a subsequent cruise in which a non-diffusive buret tip was used, the relative standard deviation of Delaware standards was 0.078 for 9 sets of 5 replicates measured over a 2 week period.

The normality of the standard used by each institution was checked after cast 24. The thiosulfate titer of five replicates of each standard was measured by the automated amperometric titration used by Delaware (Table 6). Although this experiment cannot yield the absolute normality of each standard, it does provide information on their relative concentrations.

\begin{tabular}{|c|c|c|c|c|c|}
\hline Cable 6 . & $\begin{array}{l}\text { Comparison of stan } \\
\text { replicates of each } \\
\text { autotitrator. The } \\
\text { standard deviation } \\
\text { given in Table } 5 \text {. }\end{array}$ & $\begin{array}{l}\text { dards fro } \\
\text { standarc } \\
\text { t-statis } \\
\text { for the }\end{array}$ & $\begin{array}{l}\text { different i } \\
\text { were titrate } \\
\text { ic was calcu } \\
\text { elaware stan }\end{array}$ & $\begin{array}{l}\text { istitutions. } \\
\text { with the Del } \\
\text { lated from the } \\
\text { lards, } 0.00065\end{array}$ & $\begin{array}{l}\text { Five } \\
\text { laware } \\
\text { e overall } \\
5(=0.098),\end{array}$ \\
\hline Institutio & $\begin{array}{l}\text { Nominal } \\
\text { normality }\end{array}$ & $\begin{array}{l}\text { Average } \\
\text { titer }\end{array}$ & $\begin{array}{l}\text { Standard } \\
\text { deviation }\end{array}$ & $\begin{array}{l}\text { Ratio to } \\
\text { woods Hole }\end{array}$ & $t_{\text {statistic }}^{t}$ \\
\hline Bedford & 0.01000 & $0.7046_{6}$ & 0.0003 & 0.99497 & 12.23 \\
\hline Scripps & 0.01000 & $0.7083_{4}$ & 0.0009 & 1.00017 & 0.41 \\
\hline Woods Hole & 0.01000 & $0.7082_{2}$ & 0.0007 & 1.00000 & -- \\
\hline Delaware & $(0.71762 / 1.014=)$ & $\begin{array}{l}0.7176_{2} \\
0.70771\end{array}$ & 0.0006 & 0.99928 & 1.75 \\
\hline
\end{tabular}

Since the nominal normalities of the Bedford, Scripps, and Woods Hole standards were all 0.01 , there should be no difference between the average titers listed in Table 6 . The 0.028 difference between the titers of the scripps and Woods Hole standards is not significant $(P=69 \%)$. Furthermore, the $0.07 \%$ difference in titer between the Delaware (normalized to 0.01 ) and Woods Hole standards is not significant $(P=12 \%)$. However, the $0.5 \%$ difference between the Bedford and Woods Hole titers is highly significant ( $P<0.5 \%$ ). 
Since the normalities of the Delaware, Scripps, and Woods Hole standards are consistent with each other, it appears that the true normality of the Bedford standard is lower than the nominal value. The correct normality of the Bedford standard, calculated from the average titer of the Delaware, Scripps, and Woods Hole standards $([0.7077+0.7083+0.7082] / 3=0.7081)$, is $0.009952(=$ $0.01 * 0.7047 / 0.7081)$. The oxygen concentrations listed for Bedford in this report are calculated using an iodate normality of 0.009952 .

\section{Blank Determination}

Three factors may contribute to the blank measured by Carpenter's (1965) procedure of successive $1 \mathrm{ml} \mathrm{KIO}_{3}$ additions:

1) any difference between the measured end-point and the equivalence point, $\mathrm{V}_{b / k, \text { ep }}$

2) the presence of oxidants or reductants in the reagents, $\mathrm{V}_{\mathrm{blk}, \mathrm{reg}}$; and

3) the presence of oxidants or reductants (other than oxygen) in the sample, $v_{b l k, x}$.

Blanks measured during this intercalibration were determined in deionized water. These pure water blanks are the sum of factors 1 and 2 above; they measure the concentration of redox species in the pickling reagents plus any bias in the measured end-point.

$$
\mathrm{V}_{\mathrm{blk}, \mathrm{dw}}=\mathrm{V}_{\mathrm{blk,ep}}+\mathrm{V}_{\mathrm{blk,reg}} \cdot
$$

Blanks determined in pure water do not measure the concentration of oxidants or reductants in the seawater samples.

For a given method, the end-point, $V_{b l k, e p}$ and reagent, $v_{b l k}$ reg, blanks are

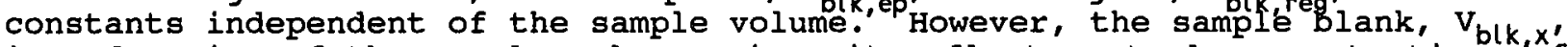
is a function of the sample volume, since it reflects actual concentrations of redox species in the sample.

Seawater blanks were not measured during the intercalibration. In hindsight, this was a mistake.

A practical difficulty in using seawater blanks, is that, rigorously, sample blanks should be measured for each seawater sample, to allow for variation in the concentrations of oxidants and reductants.

Each of the ingtitutions participating in the intercalibration, determined the pure water blank using Carpenter's (1965) procedure. The blanks measured by each institution cannot be directly compared because the normality of thiosulfate differed between institutions. Consequently in Table 7, we have converted the blank measured by each institution into the equivalent amount of dissolved oxygen using the following modification of equation 1.

$$
O_{2, b l k, d w}=\frac{v_{b l k, d w} \cdot N_{t h i o} \cdot 5598}{125}
$$



The oxygen concentration corresponding to a given blank is calculated for a
nominal volume of $125 \mathrm{ml}$.

Table 7. Comparison of pure water blanks measured by different institutions on 2 May. Blanks calculated from equation 5, and expressed as oxygen concentrations in $\mathrm{ml} / \mathrm{l}$.

Woods Hole Reagents (batch 1 )

Bedford Delaware Scripps Woods Hole

$\begin{array}{lllrr}\text { Average blank }(\mathrm{ml} / 1) & +0.0282 & 0.0088 & -0.0088 & 0.0056 \\ \text { Std deviation }(\mathrm{ml} / \mathrm{l}) & 0.0050 & 0.0019 & 0.0025 & 0.0013\end{array}$

Bedford/Scripps Reagents (batch 2)

$\begin{array}{lllrr}\text { Average blank }(\mathrm{ml} / \mathrm{l}) & 0.0332 & 0.0006 & -0.0044 & 0.0050 \\ \text { Std deviation }(\mathrm{ml} / \mathrm{l}) & 0.0132 & 0.0025 & 0.0025 & 0.0013\end{array}$

Several features are evident in Table 7. First, blanks determined by Bedford are considerably larger than those of the other institutions. Second, Delaware and woods Hole blanks are roughly equal. Third, scripps blanks are slightly less than the Delaware and Woods Hole blanks. Scripps blanks being more negative than Delaware and Woods Hole blanks is consistent with the fact that the starch endpoint occurs slightly before the amperometric endpoint (Bradbury and Hambly, 1952; Knowles and Lowden, 1953; Culberson and Huang, 1987). 


\section{Oxygen Measurements}

A complete list of the oxygen concentrations measured by each institution is given in Appendices A through $E$.

\section{Precision of Individual Methods}

The precision of oxygen measurements from each institution was calculated by pooling differences between duplicates (Youden, 1951, page 16). The data from each institution is highly precise, with standard deviations ranging from 0.005 to $0.010 \mathrm{ml} / \mathrm{l}$ (Table 8$)$. If the few duplicates with differences $>0.05 \mathrm{ml} / 1(10$ standard deviations of the most precise method) are excluded, the precision of the Delaware, Scripps, and Woods Hole techniques are all between 0.004 and 0.005 $\mathrm{ml} / \mathrm{l}$.

Table 8. Precision ( 1 standard deviation) of oxygen measurements from different institutions, as measured by the difference between the oxygen concentrations of duplicate samples.

Bedford Delaware Scripps Woods Hole calculated using all measured values

$\begin{array}{rcccc}\text { Precision (ml/l): } & 0.010 & 0.005 & 0.007 & 0.008 \\ \text { Number of duplicates: } & 35 & 67 & 70 & 70\end{array}$

using duplicates with differences $<0.05 \mathrm{ml} / \mathrm{l}$
Precision (ml/l):
0.010
0.005
0.004
0.005

35

67

69

Number of duplicates:

69

Plots of the difference between duplicates versus the oxygen concentration (Figures 8 - 11) indicate that the precision of each method is independent of concentration over the range of concentrations measured.

For each institution, the order in which oxygen samples were titrated matched the order in which they were drawn. If the measured concentrations were independent of the order in which the samples were drawn, the differences between duplicates should be symmetrical about the origin. Histograms (Figures 12 - 15 ) show that this is true. 


\section{Systematic Differences between Institutions}

Comparison of the oxygen concentrations in Appendix $A$ shows that there are small systematic differences between the concentrations reported by different institutions. The average difference between oxygen concentrations reported by each pair of institutions is summarized in Table 9.

Table 9. Average difference ( $\mathrm{ml} / \mathrm{l})$ between oxygen concentrations reported by pairs of institutions (institution A minus institution B). The average difference was calculated by summing the individual differences and dividing by the total number of samples. The number of common samples is given in parenthesis after each difference.

Institution B

$\longrightarrow$

Delaware

Scripps

Woods Hole
Institution A

\begin{tabular}{cccc}
\hline Bedford & Delaware & Scripps & Woods Hole \\
& $-0.010(35)$ & $0.013(35)$ & $-0.007(35)$ \\
& $0.020(71)$ & $0.002(71)$ \\
& & & $-0.019(71)$
\end{tabular}

Close examination of the systematic differences between methods (Figures 16 - 21) shows that they are not constant, but tend to increase with increasing oxygen concentration. With one exception (Table 10), the slopes and intercepts of the regression lines plotted in Figures 16 through 21 are significantly different from zero at a $99 \%$ confidence interval.

To facilitate comparison of the systematic differences between institutions, regression lines from Figures 16 through 21 are plotted on Figure 22 .

The fact that the bias between institutions increases with increasing concentration (regression lines in Figure 22 have positive slopes) could be due to small errors in constant factors, such as $V_{103}$ and $\mathrm{N}_{103}$, used in equations 1 
Table 10. Regression analysis of systematic differences between oxygen concentrations $(\mathrm{ml} / \mathrm{l})$ reported by different institutions. Rows labeled Probability are the probability of the intercept or slope equaling zero.

Institutions

\begin{tabular}{rcccccc} 
& DEL-BIO & SIO-BIO & WHOI-BIO & SIO-DEL & SIO-WHOI & WHOI-DEL \\
\cline { 2 - 7 } Intercept: & -0.0354 & -0.0415 & -0.0510 & -0.0052 & 0.0098 & -0.0149 \\
Standard deviation: & $\mathbf{0 . 0 0 5 4}$ & 0.0050 & 0.0058 & 0.0031 & 0.0034 & 0.0037 \\
t-statistic: & 6.61 & 8.27 & 8.75 & 1.70 & 2.92 & 4.05 \\
Probability: & $<0.5 \%$ & $<0.5 \%$ & $<0.5 \%$ & $<10 \%$ & $<1 \%$ & $<0.5 \%$ \\
& & & & & & \\
Slope: & 0.0054 & 0.0113 & 0.0092 & 0.0050 & 0.0017 & 0.0032 \\
Standard deviation: & 0.0011 & 0.0010 & 0.0012 & 0.0006 & 0.0006 & 0.0007 \\
t-statistic: & 4.98 & 11.12 & 7.77 & 8.48 & 2.71 & 4.59 \\
Probability: & $<0.5 \%$ & $<0.5 \%$ & $<0.5 \%$ & $<0.5 \%$ & $<1 \%$ & $<0.5 \%$
\end{tabular}


Systematic differences between methods are unlikely due to errors in $\mathrm{N}_{103}$, since the normalities of the iodate standards used in the oxygen calculations were intercompared (Table 6 ) and adjusted where necessary.

However, as mentioned in the Methods section, the automatic $10 \mathrm{ml}$ pipet used by Scripps to dispense iodate standards was broken before it could be calibrated. scripps oxygen concentrations in this report have been calculated assuming a volume $\left(V_{1}\right)$ of exactly $10 \mathrm{ml}$ for the iodate pipet. A -0.38 error in the assumed volume of the Scripps pipet would account for the difference in reported oxygen concentrations between Scripps and Delaware/Woods Hole (Table 9). The volumes of 8 similar $10 \mathrm{ml}$ pipets, previously calibrated by Scripps (see Methods section), averaged -0.158 low. Consequently, it is possible that much of the difference between the Scripps and Delaware/Woods Hole oxygen concentrations is due to the volume of the scripps pipet being less than the assumed $10 \mathrm{ml}$.

For comparison, the volumes of the $10 \mathrm{ml}$ hand pipets used by Bedford and Delaware to dispense iodate standards (Table 4) were 0.348 and 0.228 too low,
respectively.

The non-zero intercepts shown in Figures 16 through 21 may be due to differences between the starch, amperometric, and colorimetric end-points, and the true equivalence point in the titration of iodine with thiosulfate.

\section{Effect of Drawing Order on Oxygen Concentrations}

Since 70-90\% of the seawater in each 10 liter Niskin bottle was used during sampling, it is possible that the last samples collected from the Niskin bottles were contaminated with atmospheric oxygen. The order in which institutions sampled each Niskin bottle was deliberately staggered to detect atmospheric contamination (see Table 2).

The statistical analysis of sampling order in Table 11 indicates that there was no detectable difference between oxygen concentrations of the first and last
samples drawn.

\section{Conversion of Volumetric Concentrations to Weight Concentrations}

The analytical methods used to determine dissolved oxygen during this intercalibration were volumetric techniques. They determine the amount of dissolved oxygen per unit volume of seawater.

Current oceanographic practice requires data to be reported as weight concentrations, on a per kilogram of seawater basis. Dividing the volumetric concentration by the density of seawater yields the weight concentration. Since oxygen samples are pickled immediately after being drawn, the density of seawater used in the conversion should be calculated at the temperature of the seawater at the time of sampling. This temperature is not routinely measured. Instead, it is assumed that the water samples do not warm as they are brought onboard, and the density is calculated at the potential temperature of the 
Table 11. Effect of drawing order on measured oxygen concentration. The column labeled Number of Samples is the number of samples available for comparison. The column labeled Average oxygen is the oxygen concentration averaged over the given number of samples. The column labeled Average Difference is the average difference in oxygen concentrations reported by the two institutions, for the given number of samples. If the last samples drawn are subject to atmospheric contamination, the Average Difference for the first row of the comparison should be significantly different than the Average Difference for the second row of the comparison.

\begin{tabular}{|c|c|c|c|c|c|}
\hline ........... Sampling Order & $\begin{array}{l}\text { Number of } \\
\text { Samples }\end{array}$ & $\begin{array}{l}\text { Average } \\
\text { Oxygen } \\
(\mathrm{ml} / \mathrm{l})\end{array}$ & $\begin{array}{l}\text { Average } \\
\text { Difference } \\
(\mathrm{ml} / \mathrm{l})\end{array}$ & \multicolumn{2}{|c|}{$\begin{array}{l}\text { Standard Deviation } \\
\text { of } \mathrm{Differences} \\
(\mathrm{ml} / \mathrm{l})\end{array}$} \\
\hline $\begin{array}{l}\text { Rosette positions } 3,7,11 \text {; } \\
\text { Hoods Hole first, Delaware last: }\end{array}$ & 21 & 5.055 & 0.002 & & 0.009 \\
\hline \multirow[t]{2}{*}{$\begin{array}{l}\text { Rosette positions } 4,8,12 \text {; } \\
\text { Delaware first, Hoods Hole second: }\end{array}$} & 21 & 5.044 & 0.000 & & 0.005 \\
\hline & Combined & :andard dev & tion for both & sets: & 0.008 \\
\hline t-statistic for $c$ & difference & ween posit & ns $3,7,11$ and & $4,8,12:$ & 0.84 \\
\hline $\begin{array}{l}\text { Rosette positions } 4,8,12 ; \\
\text { Delaware first, Scripps last: }\end{array}$ & 21 & 5.063 & 0.019 & & 0.006 \\
\hline $\begin{array}{l}\text { Rosette positions } 5,9 \text {; } \\
\text { Scripps first, Delaware second: }\end{array}$ & 14 & 5.124 & 0.020 & & 0.007 \\
\hline
\end{tabular}

$t$-statistic for difference between positions $4,8,12$ and $5,9: \quad 0.44$ 
sample. If the sampling and potential temperatures are different, weight concentrations calculated from the potential density will be in error, by as much as 0.58 for a $25^{\circ} \mathrm{C}$ difference (Kester, 1975).

To assess the difference between the sampling and potential temperatures, the sampling temperature was determined at several stations by $R$. T. Williams. Temperatures were measured with a platinum resistance thermometer attached to a digital thermometer readable to $0.1^{\circ} \mathrm{C}$. The platinum resistance thermometer was embedded in a short piece of plastic tubing which fit over the Niskin bottle outlet. Seawater temperatures in the Niskin bottles were measured immediately before the first oxygen sample was drawn, and immediately after the last sample was drawn. The air temperature was $20 \pm 1^{\circ} \mathrm{C}$ during these experiments.

Figure 23 shows the experimental results. The coldest seawater had warmed 2 to $6^{\circ} \mathrm{C}$ by the time of first sampling; it had warmed 5 to $10^{\circ} \mathrm{C}$ by the time the last sample was drawn. Sampling each Niskin bottle took approximately 15 minutes. Since only 1 set of oxygen samples are normally drawn, the temperature changes occurring at the time of first sampling are probably most representative of temperature differences that would be encountered in routine measurements. Extrapolating these results to locations with significantly different vertical temperature profiles and air temperatures is not recommended.

The change in seawater temperature between the beginning of sampling and the end of sampling is shown in Figure 24. The coldest seawater warmed about $4^{\circ} \mathrm{C}$ in the 15 minutes required to draw all oxygen samples from a single Niskin bottle.

The maximum $4^{\circ} \mathrm{C}$ temperature increase in Figure 24 , represents a $0.06 \%$ decrease in the seawater density. Theoretically, this density decrease during the course of sampling would cause the volumetric oxygen concentration of the last sample drawn to be $0.06 \%$ lower than that of the first sample drawn. For North Atlantic Deep Water with oxygen concentrations of $6 \mathrm{ml} / \mathrm{l}$, the theoretical change in the volumetric oxygen concentration would be $0.004 \mathrm{ml} / \mathrm{l}$.

The results of the oxygen intercalibration have not been converted from volumetric to weight concentrations for the following reasons:

1) systematic errors caused by neglecting temperature changes during sampling are small $(<0.068)$; and

2) sampling temperatures were not measured for every station and/or sample. 


\section{DISCUSSION}

Systematic differences in dissolved oxygen (Figure 22) between the institutions participating in the intercalibration were encouragingly small. The largest difference, that between Woods Hole and Bedford at low concentrations, was $-0.6 \%$. All other differences were within $\pm 0.5 \%$ over the concentration range studied $(3.4$ to $6.2 \mathrm{ml} / \mathrm{l})$. Relative differences between institutions at the lowest and highest oxygen concentrations measured are listed in Table 12 .

Table 12. Systematic differences in dissolved oxygen between institutions calculated from the regression lines in Figures 16 through 21 . The listed values are the percent difference in dissolved oxygen between ingtitutions for a given oxygen concentration.

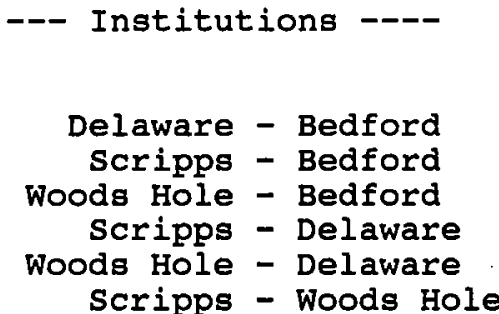

$\begin{array}{rr}\text { Percent difference at } \\ 3.4 \mathrm{ml} / \mathrm{l} & 6.2 \mathrm{ml} / 1 \\ -0.58 & 0.08 \\ -0.18 & 0.58 \\ -0.68 & 0.18 \\ 0.38 & 0.48 \\ -0.18 & 0.18 \\ 0.58 & 0.38\end{array}$

Systematic differences between Scripps and Delaware/Woods Hole were approximately constant at $0.3 \%$ to $0.5 \%$ over the entire concentration range studied. Differences between Woods Hole and Delaware were much less; averaging only $0.002 \mathrm{ml} / \mathrm{l}$ (Table 9).

As mentioned above, Scripps results higher than those of Delaware and Woods Hole may be due to the uncalibrated pipet used to deliver the Scripps standard.

The good agreement between methods is probably due to the use of the essentials of Carpenter's (1965) method by all institutions. In a previous intercomparison between 11 institutions (Carritt and Carpenter, 1966) before adoption of Carpenter's (1965) technique, the range of concentrations reported for air saturated seawater was $9 \%$.

The oxygen concentrations measured during the intercalibration varied between $53 \%$ and 1048 saturation (Figures 2 and 3 ). Consequently, it was not possible to intercalibrate at low concentrations where errors due to sampling, blanks, and oxygen in the reagents will be most important. However, the non-zero intercepts of the regression lines in Figure 22 suggest that systematic errors between some of the methods may increase at low concentrations. The extrapolated values at zero oxygen are particularly large for differences involving the Bedford Institute of Oceanography. 
Because the precision $(\sigma<=0.010 \mathrm{ml} / \mathrm{l}$ ) of the present methods is high, other sources of error in equations 1 and 3 become important, particularly at low oxygen concentrations. Two potential sources of error are (1) the concentration of dissolved oxygen in the reagents and (2) the seawater blank.

\section{Oxygen in the Reagents}

For a nominal oxygen volume of $125 \mathrm{ml}$, the amount of oxygen added with the reagents is $0.014 \mathrm{ml} / \mathrm{l}(=0.0017 / 0.123)$. This value is 3 times the standard deviation of the most precise of the present methods. Variation of the amount of oxygen added with the reagents is, potentially, a major source of error in calculated oxygen concentrations. The amount of oxygen dissolved in the reagents, $0.0017 \mathrm{ml}$, was determined at $25.5^{\circ} \mathrm{C}$ (Murray et al, 1968). Reagents stored at lower temperatures will presumably contain more oxygen. Ideally, the $\mathrm{MnCl}_{2}$ and $\mathrm{NaOH} / \mathrm{NaI}$ reagents should be stripped of oxygen and stored under an oxygen free atmosphere. Since this does not appear feasible under shipboard conditions, we recommend that the reagents be stored in the ship's laboratory and not brought on deck until needed. This procedure should minimize large changes in the concentration of oxygen in the reagents.

The reagents used during the intercalibration were divided into 2 batches since the analysts were in different laboratories aboard ship. It is possible that the concentration of oxygen in the 2 batches of reagents differed slightly due to small differences in storage temperature $\left(22 \pm 3^{\circ} \mathrm{C}\right)$.

\section{The Seawater Blank}

A potential source of error in equations 1 and 3 is the value of the seawater contribution to the blank. During the course of the intercalibration it became apparent that there was almost no information available on the magnitude and variability of seawater blanks. Pure water $\left(V_{b l k, d w}\right)$ and seawater blanks $\left(V_{b l k, s w}\right)$ can be represented by
equations 4 and 6,

$$
\begin{aligned}
& v_{b l k, d w}= \\
& v_{b l k, s w}=v_{b l k, x}+v_{b l k, e p}+v_{b l k, r e g}
\end{aligned}
$$

where

$$
\begin{aligned}
\mathrm{V}_{\mathrm{blk}, \mathrm{ep}}= & \begin{array}{c}
\text { blank due to differences between the measured end-point and } \\
\text { the equivalence point; }
\end{array} \\
\mathrm{V}_{\mathrm{blk}, \mathrm{reg}}= & \text { blank due to oxidants or reductants in the reagents; and } \\
\mathrm{V}_{\mathrm{b}(\mathrm{k}, \mathrm{x}}= & \begin{array}{c}
\text { blank due to presence of oxidants or reductants (other than } \\
\text { oxygen) in the sample. }
\end{array}
\end{aligned}
$$

Rigorously, it is the seawater blank ( $\left.V_{b / k, s w}\right)$ which should be subtracted from $v_{x}$, the thiosulfate titer of the sample, $i_{n}$ equations 1 and 3 .

In practice, blanks used in equations 1 and 3 have been estimated by two different approaches. 
1) Seawater and pure water blanks are assumed equal, and the pure water blank is used throughout equations 1 and 3 . This approach is used by Bedford, Delaware, Woods Hole, and sometimes scripps, and was adopted for the intercalibration.

2) The seawater blank is assumed constant, independent of position, and a single batch of seawater is used to prepare all standards and blanks. This procedure has been used by Scripps. For a given oxygen method, the end-point ( $\left.V_{b l k, e p}\right)$ and reagent ( $V_{b} \mid k_{1}$ reg)
blanks are constants independent of the sample volume. However, the sample blank $\left(V_{b l k}\right)$ is a function of the sample volume, since it reflects actual concentrations of redox species in seawater.

If we assume that the end-point blank ( $\left.V_{b / k, p}\right)$ is identical in pure water and in seawater, the difference in blanks or standards determined in seawater and in water is,

$$
v_{b l k, s w}-v_{b l k, d w}=v_{b l k, x^{*}}
$$

We could find only 13 measurements from which the sample blank $\left(V_{b l k}\right)$ could be calculated (Table 13). Iodate is probably one of the major contributora to the seawater blank, and values of $\mathrm{O}_{2}$,blk corresponding to various iodate concentrations are included in Table 13 . Seawater of 35 ppt contains approximately 450 nanomolar iodate (Wong and Brewer, 1974). Iodate is not conservative and 30 ppt coastal seawater may contain as little as 200 nanomolar iodate. Based on the few available measurements, it appears that the sample blank in the open ocean, Sargasso Sea, and standard seawaters analyzed by scripps and Woods Hole is close to the seawater iodate blank. Sample blanks in the 2 coastal samples analyzed by Woods Hole and Delaware are less than the iodate blank.

The range between the highest and lowest seawater blanks, $0.03 \mathrm{ml} / 1$ (Table 13). amounts to 18 of an oxygen concentration of $3 \mathrm{ml} / 1$ and $0.5 \%$ of a concentration of $6 \mathrm{ml} / \mathrm{l}$. Clearly, failure to apply the proper seawater blank in equations 1 and 3 may cause errors in the calculated concentration much larger than those due to analytical imprecision. 
Table 13. Measurements of the sample blank $\left(v_{b l k}\right)$ in seawater. Since the blanks measured by different institutions used differing seawater volumes and thiosulfate normalities, measured values have been converted to an equivalent concentration of oxygen using the following equation,

$$
\mathrm{o}_{2, \mathrm{blk}}=\frac{\mathrm{v}_{\mathrm{blk}, \mathrm{x}} \cdot \mathrm{N}_{\text {thio }} \cdot 5598}{\mathrm{v}_{\text {seawater }}}
$$

In some cases, $V_{b l k}$ was calculated from the difference in volumes of standards determined in seawater and in pure water.

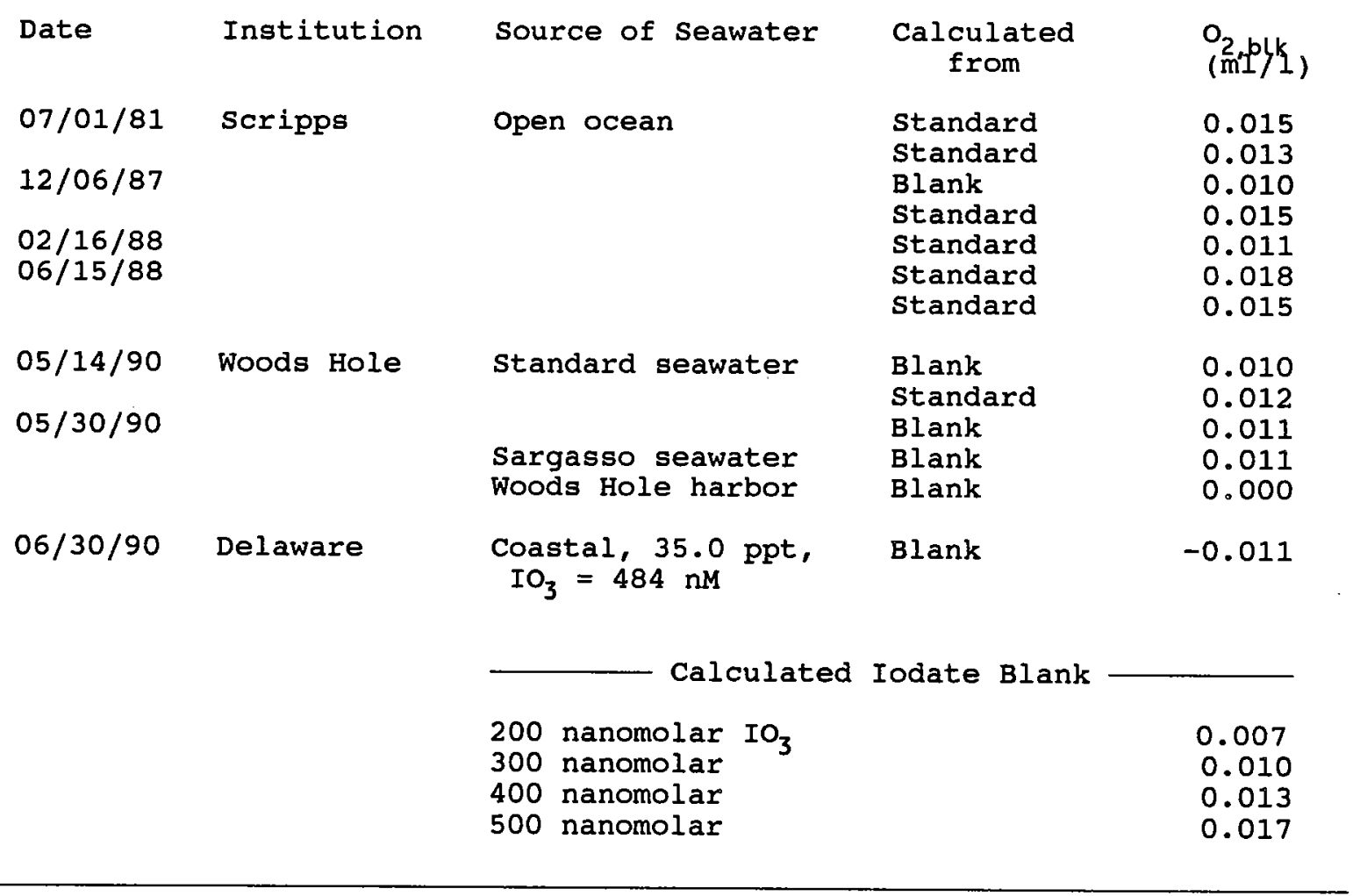




\title{
RECOMMENDATIONS
}

\author{
Problems Needing Further Research
}

Based on the results of this intercalibration, we feel that the following items require additional study before methods can be guaranteed accurate to $\pm 0.5 \%$ over the entire oceanic range of oxygen concentrations.

\section{Low oxygen intercalibration}

The intercalibration of oxygen methods should be extended to include very low oxygen concentrations. Intercalibration at low concentrations could be performed in the laboratory (Carritt and Carpenter, 1966), or at sea off the West coast of the United States. Intercalibration at low concentrations will provide a severe test of sampling techniques.

The intercomparison should include a sample of oxygen free water prepared by purging the sample with gas free of oxygen. Measurements on oxygen free water will serve to check the values for oxygen in the reagents and for the blank used in equations 1 and 3 .

\section{Endpoint bias in pure and sea waters}

The starch endpoint occurs slightly before the amperometric endpoint (Bradbury and Hambly, 1952; Knowles and Lowden, 1953). There is some evidence (Culberson and Huang, 1987) that the difference between the two endpoints varies with salinity. If the difference between the starch and amperometric endpoints does depend on salinity, there will be a systematic difference between the two methods when standards are run in pure water, and the samples are seawater.

The effect of salinity on endpoint bias between the starch, amperometric, and photometric endpoints should be studied. The simplest way to determine endpoint bias would be to determine standards and blanks in pure water and in seawater, using the same reagents for each analytical method. This study could be performed during the low oxygen intercalibration.

\section{Seawater blanks}

A systematic study of the difference between seawater and pure water blanks should be undertaken using Carpenter's (1965) blank procedure. The study should include seawater from both coastal and open ocean locations. Depths sampled should include the surface, the oxygen minimum, the nutrient maximum, and the bottom. 
To increase precision, dilute thiosulfate $(0.01 \mathrm{~N})$ should be used in this study, since blanks determined with $0.14 \mathrm{~N}$ thiosulfate (Carpenter, 1965) are small and near the limit of detection.

\section{Temperature warming in water bottles}

The measurements of sampling temperature begun during this intercalibration should be extended to other areas of the ocean, and to other seasons. Measurements in the tropics, an area with high $\left(30^{\circ} \mathrm{C}\right)$ air and surface seawater temperatures, are particularly important. The sampling temperature should be measured just prior to drawing the oxygen sample. Additional information required are the air temperature, the time of sampling, and the time the water bottles were brought on deck. This information would allow estimation of the error involved in conversion of volumetric to weight concentrations.

If possible, a simple technique for determining and recording the sampling temperature, that does not require operator assistance, should be devised.

\section{Oxygen dissolved in the reagents}

The solubility of atmospheric oxygen in the $\mathrm{MnCl}_{2}$ and $\mathrm{NaOH} / \mathrm{NaI}$ reagents should be measured (or at least calculated) as a function of temperature. If possible a technique for storing the reagents free of oxygen should be devised.

\section{Techniques for Routine Oxygen Measurements}

The following procedures should be made mandatory for all wock oxygen measurements. Although these are standard procedures for high precision measurements, our experience is that many oceanographic laboratories do not implement all of them.

\section{Sampling procedure}

All oxygen samples must be flushed with at least 2 volumes of seawater. The $\mathrm{MnCl}_{2}$ and $\mathrm{NaOH} / \mathrm{NaI}$ reagents should be added immediately after the sample is drawn, and before the oxygen is stoppered. Stoppering the oxygen s before adding the pickling reagents increases the chance of contamination with atmospheric oxygen.

The $\mathrm{MnCl}_{2}, \mathrm{NaOH} / \mathrm{NaI}$, and $\mathrm{H}_{2} \mathrm{SO}_{4}$ reagents must have the concentrations specified by carpenter (1965). Use of these reagents will minimize uncertainties due to the amount of oxygen added with the reagents. 
It is our opinion that the use of proper water sampling techniques is the single most important factor in obtaining high quality oxygen measurements.

\section{Calculation of dissolved oxygen}

Equations 1 or 3 must be used to calculate the concentration of dissolved oxygen from the measured parameters.

\section{Calibration of glassware}

The pipet used to dispense iodate standards, the volumetric used to prepare the iodate standard, and oxygen $s$ used in whole bottle titrations must be calibrated by weighing the weight of pure water dispensed or contained. The calibration must include a buoyancy correction.

None of the volumetric $\mathbf{s}$ used in the present intercomparison were calibrated.

\section{Effect of temperature on mass of thiosulfate and iodate dispensed}

Due to the thermal expansion of water, the mass, of the thiosulfate titrant and of the iodate standard dispensed by volumetric apparatus, depends on the solution temperature. Consequently, the temperature of the thiosulfate and iodate solutions at the time of delivery must be recorded, so that the solution concentrations can be reduced to a uniform temperature of $20^{\circ} \mathrm{C}$.

\section{Preparation of iodate standard}

The standard should be prepared from reagent grade (primary standard grade if available) $\mathrm{KIO}_{3}$ or $\mathrm{KH}\left(\mathrm{IO}_{3}\right)_{2}$. If possible, a common batch of $\mathrm{KIO}_{3}$ should be distributed for use as a standard. Commercial iodate solutions must not be used as standards.

The weight of solids should be corrected for buoyancy, and 1987 atomic weights used to calculate the concentration $\left(\mathrm{KIO}_{3}=214.001 ; \mathrm{KH}\left(\mathrm{IO}_{3}\right)_{2}=389.912\right)$.

The volumetric concentration of the standard must be reduced to $20^{\circ} \mathrm{C}$; this requires knowledge of the temperature at which the standard was prepared. Furthermore, the temperature at which the standard is dispensed must be measured so that the volume dispensed can be reduced to $20^{\circ} \mathrm{C}$. 


\section{Standardization}

Carpenter's (1965) recommended standardization procedure should be modified to include the addition of $1 \mathrm{ml}$ of the $\mathrm{MnCl}_{2}$ reagent after the $1 \mathrm{ml} \mathrm{NaOH} / \mathrm{NaI}$ addition. The solution should be stirred between the $\mathrm{NaOH} / \mathrm{NaI}$ and $\mathrm{MnCl} 2$
additions.

Use of seawater blanks

Until more is known about the magnitude and variability of seawater blanks, only pure water blanks should be used in equations 1 and 3 . Although this will cause small errors in the calculated oxygen concentration, it will insure that oxygens from different institutions are internally consistent.

\section{Set of test calculations}

Every institution performing wocE oxygen measurements should be required to complete a set of test calculations, to check the accuracy of their data reduction techniques.

This set of test calculations should include: (1) data for calibration of a volumetric pipet; (2) data for calibration of an oxygen ; (3) data for calculation of the concentration of an iodate standard; and (4) sample titration data for low, medium, and high oxygen concentrations. Successful completion of the test calculations will insure that calculated results from all institutions are compatible. 


\section{REFERENCES}

J. H. Bradbury and A. N. Hambly. 1952. An investigation of errors in the amperometric and starch indicator methods for the titration of millinormal solutions of iodine and thiosulfate. Australian Journal of Scientific Research, Series A, 5:541-554.

J. H. Carpenter. 1965. The Chesapeake Bay Institute technique for the winkler dissolved oxygen titration. Limnology and Oceanography 10:141-143.

D. E. Carritt and J. H. Carpenter. 1966. Comparison and evaluation of currently employed modifications of the Winkler method for determining dissolved oxygen in seawater; a NASCO report. Journal of Marine Research $24(3): 286-318$.

C. H. Culberson and S.-I. Huang. 1987. Automated amperometric oxygen titration. Deep-Sea Research 34(5/6):875-880.

A. Dickson. 1990. Calibration of oxygen bottles from the weight of the contained water when weighed in air. Unpublished notes. 4 pages.

A. Dickson and G. Anderson. 1990. Marine Technicians Handbook: Oxygen Analysis. Scripps Institution of Oceanography Reference No. 71-8; preliminary revision, August 21, 1990.

K. Grasshoff. 1976. Chapter 4, page 67, in: Methods of Seawater Analysis. Verlag Chemie, Weinheim.

E. J. Green and D. E. Carritt. 1966. An improved iodine determination for whole-bottle titrations. Analyst 91:207-208.

C. D. Hodgman, editor. 1958. Handbook of Chemistry and Physics, 39th edition. Chemical Rubber Publishing Company, Cleveland, Ohio.

Y. Horibe, Y. Kodama, and K. Shigehara. 1972. Errors in sampling procedure for the determination of dissolved oxygen by Winkler method. Journal of the Oceanographical Society of Japan 28:203-206.

D. R. Kester. 1975. Dissolved Gases other than $\mathrm{CO}_{2}$. Chapter 8 , page 503, in: Chemical Oceanography, Volume 1, second edition, J. P. Riley and G. Skirrow, editors. Academic Press, London.

G. P. Knapp, M. C. Stalcup, R. J. Stanley. 1989. Dissolved oxygen measurements in sea water at the Woods Hole Oceanographic Institution. Woods Hole Oceanographic Institution, Technical Report WHOI-89-23.

G. P. Knapp, M. C. Stalcup, R. J. Stanley. 1990. Automated oxygen titration and salinity determination. Woods Hole Oceanographic Institution, Technical Report WHOI-90-35. 
G. Knowles and G. F. Lowden. 1953. Methods for detecting the end-point in the titration of iodine with thiosulfate. Analyst 78:159-164.

E. M. Levy, C. C. Cunningham, C. D. W. Conrad, and J. D. Moffatt. 1977a. The determination of dissolved oxygen in sea water. Bedford Institute of Oceanography, Report Series BI-R-77-9, August 1977, 17 pages.

E. M. Levy, C. C. Cunningham, C. D. W. Conrad, and J. D. Moffatt. 1977b. A titration apparatus for the determination of dissolved oxygen in seawater. Journal of the Fisheries Research Board of Canada 34(11):2218-2220.

C. N. Murray, J. P. Riley, and T. R. S. Wilson. 1968. The solubility of oxygen in winkler reagents used for the determination of dissolved oxygen. Deep-Sea Research 15:237-238.

J. D. H. Strickland and T. R. Parsons. 1965. A manual of sea water analysis. Fisheries Research Board of Canada, Bulletin No. 125. Second edition,
revised. Ottawa.

G. T. F. Wong and P. G. Brewer. 1974. The determination and distribution of iodate in South Atlantic Waters. Journal of Marine Research 32:25-36.

W. J. Youden. 1951. Statistical Methods for Chemists. John Wiley \& Sons, Inc., New York. 126 pages. 


\section{Iist of Figures}

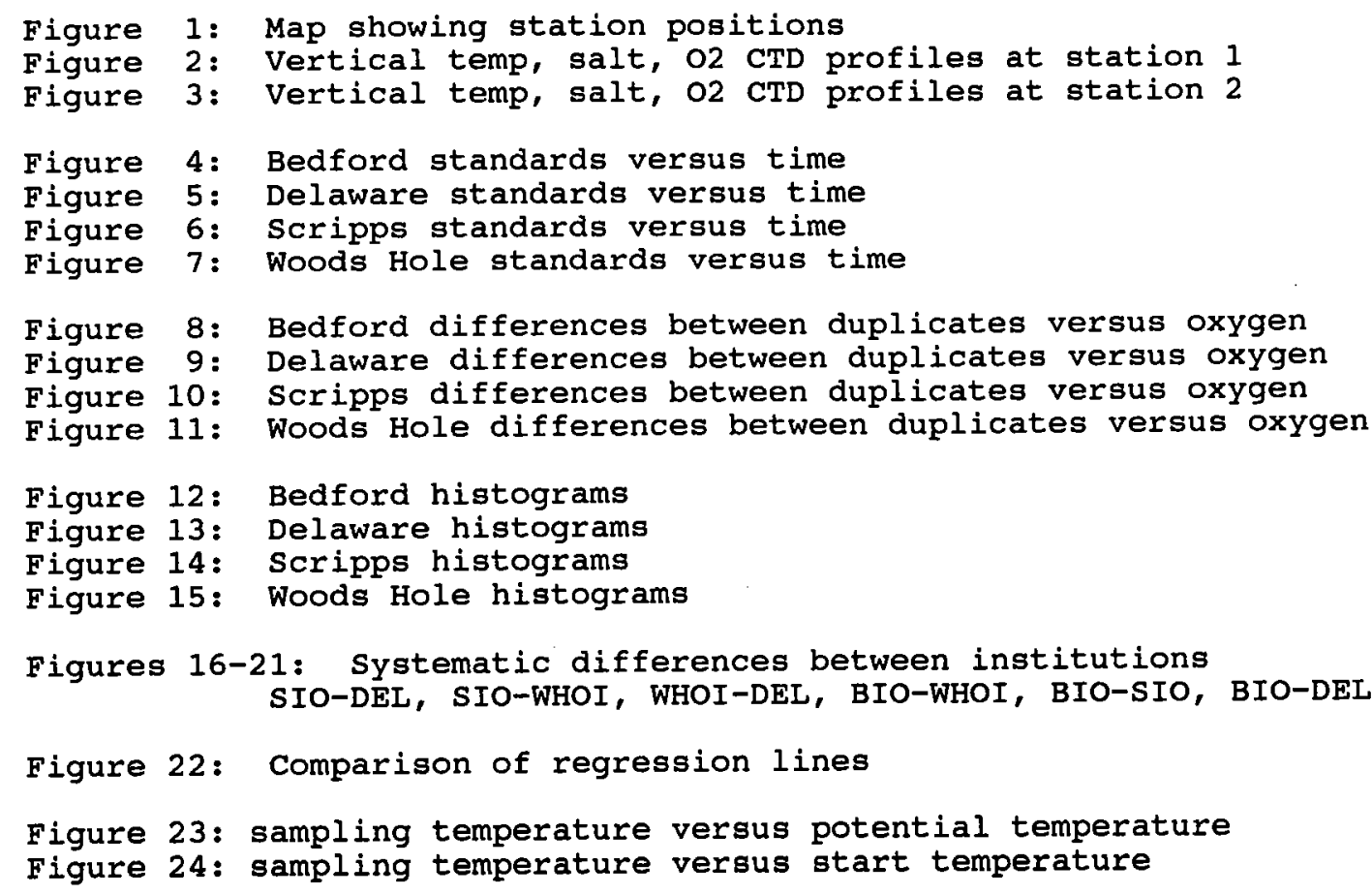




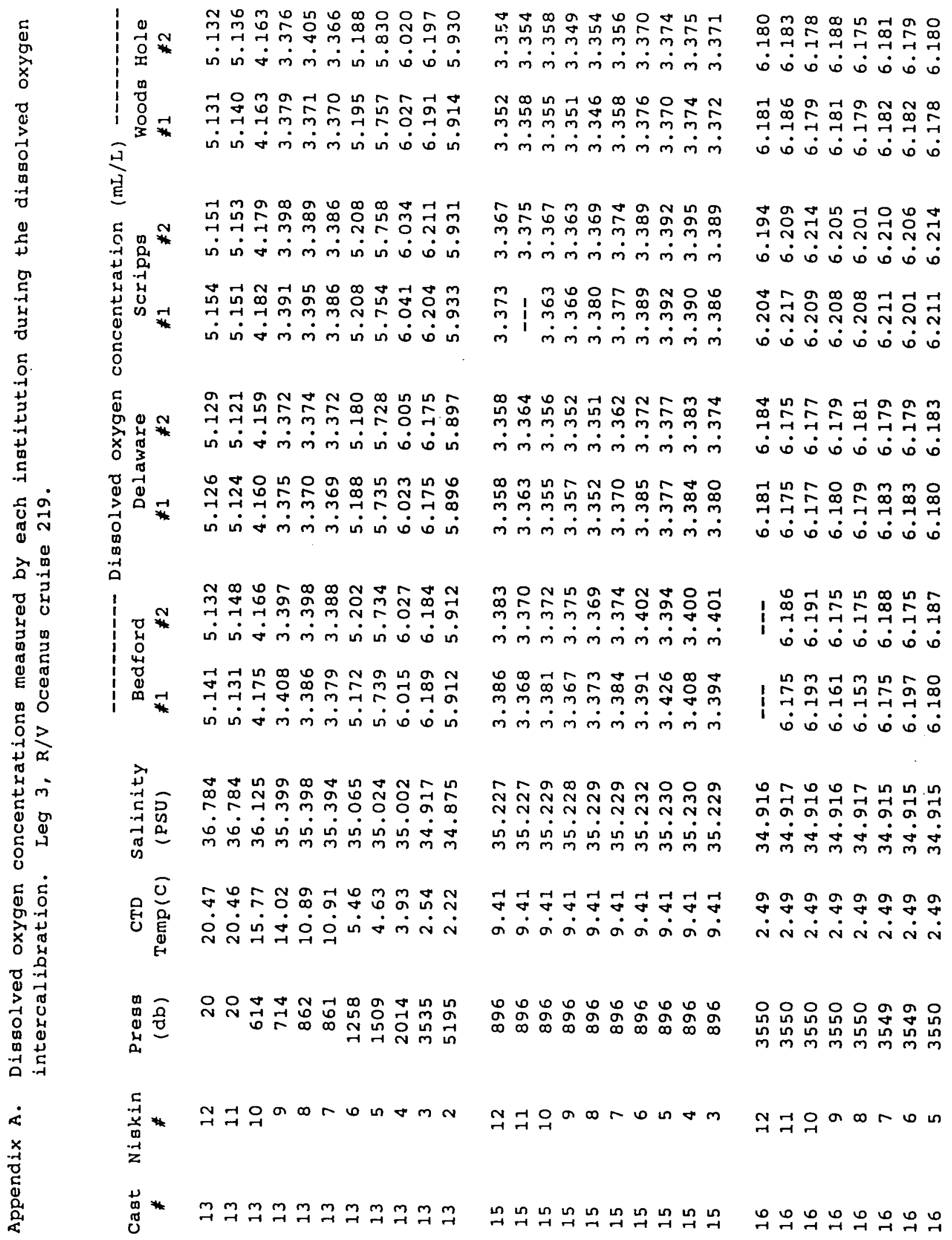




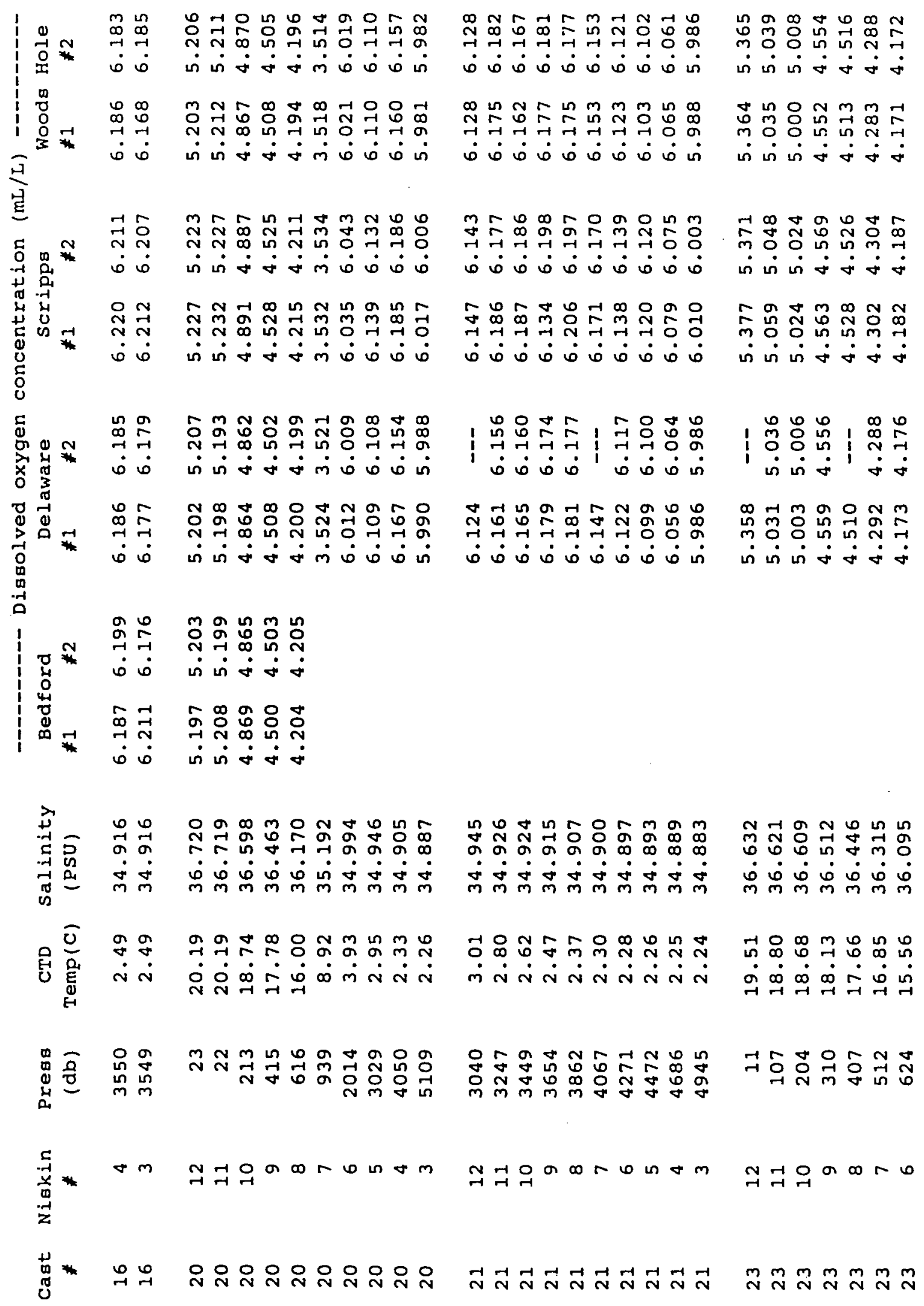




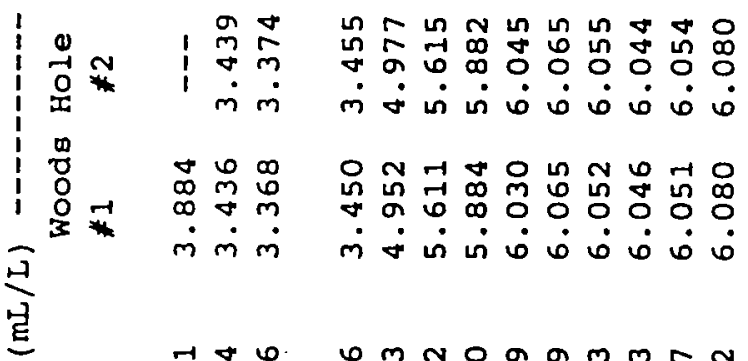

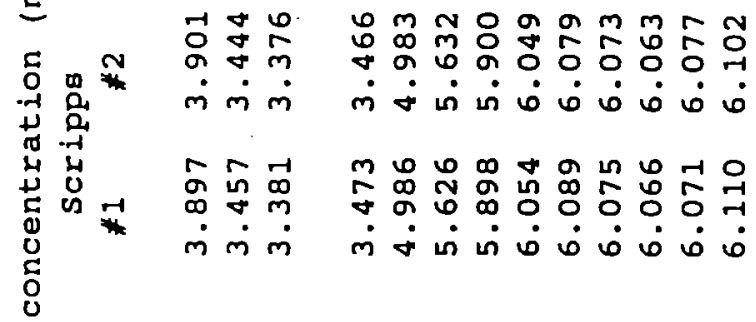

Ð

厌出

ช

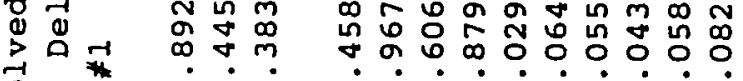

$\dot{m} \dot{m} \dot{m} \dot{m} \dot{\sim} \dot{\sim} \dot{\omega} \dot{\omega} \dot{0} \dot{0} \dot{0}$

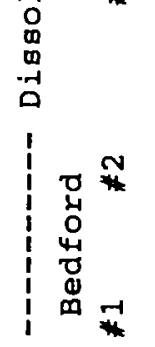

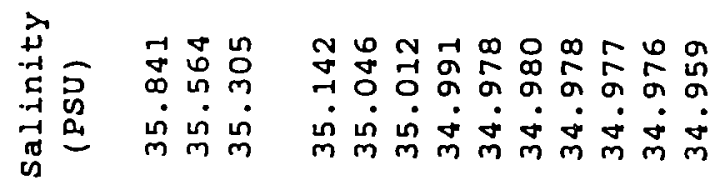

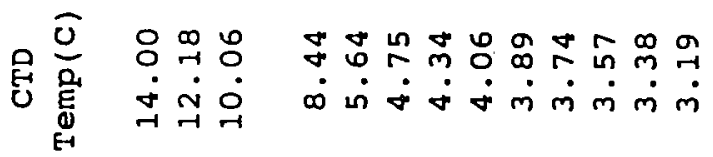

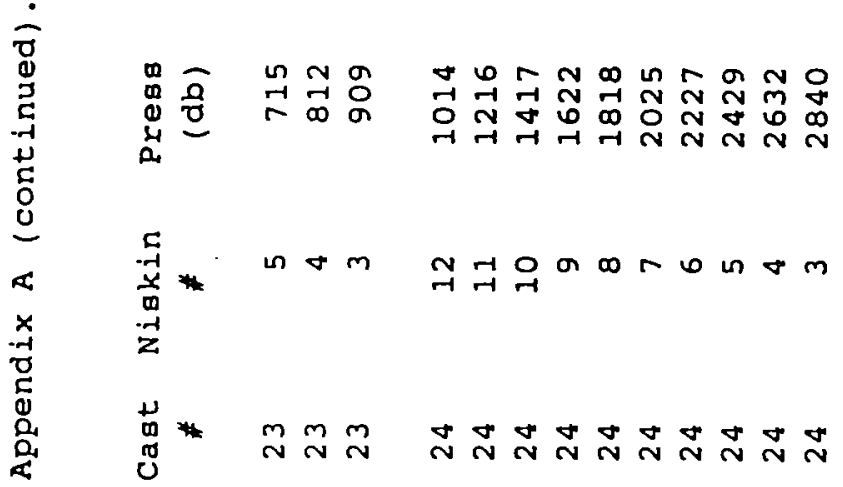


Appendix B. Bedford Institute of Oceanography. Experimental data for the calculation of dissolved oxygen. Leg 3 , $\mathrm{R} / \mathrm{V}$ Oceanus cruise 219.

$\begin{array}{rr}\text { Iodate normality: } & 0.009952 \\ \text { Iodate pipet volume (mL): } & 9.96560 \\ \text { Thiosulfate titer (mL) for standards: } & 1.74900 \\ \text { Thiosulfate titer (mL) for blanks: } & 0.01275\end{array}$

\begin{tabular}{|c|c|c|c|c|c|c|}
\hline Cast & Niskin & $\begin{array}{l}\text { Pressure } \\
(\mathrm{db})\end{array}$ & $\begin{array}{l}\text { Oxygen } \\
(\mathrm{mL} / \mathrm{L})\end{array}$ & $\begin{array}{l}\text { Thiosulfate } \\
\text { Titer (mL) }\end{array}$ & $\underset{*}{--} F$ & $\begin{array}{c}\text { ask -- } \\
\text { Volume } \\
\text { (mL) }\end{array}$ \\
\hline 13 & 12 & 20 & 5.141 & 2.1052 & 728 & 131.82 \\
\hline 13 & 12 & 20 & 5.132 & 2.1013 & 773 & 131.80 \\
\hline 13 & 11 & 20 & 5.131 & 2.0994 & 737 & 131.71 \\
\hline 13 & 11 & 20 & 5.148 & 2.1269 & 781 & 133.00 \\
\hline 13 & 10 & 614 & 4.175 & 1.6813 & 700 & 129.40 \\
\hline 13 & 10 & 614 & 4.166 & 1.7050 & 740 & 131.47 \\
\hline 13 & 9 & 714 & 3.408 & 1.3984 & 736 & 131.50 \\
\hline 13 & 9 & 714 & 3.397 & 1.3567 & 382 & 128.02 \\
\hline 13 & 8 & 862 & 3.386 & 1.3454 & 524 & 127.35 \\
\hline 13 & 8 & 862 & 3.398 & 1.3994 & 705 & 132.00 \\
\hline 13 & 7 & 861 & 3.379 & 1.3709 & 835 & 130.01 \\
\hline 13 & 7 & 861 & 3.388 & 1.3980 & 844 & 132.26 \\
\hline 13 & 6 & 1258 & 5.172 & 2.1416 & 362 & 133.29 \\
\hline 13 & 6 & 1258 & 5.202 & 2.1159 & 767 & 130.95 \\
\hline 13 & 5 & 1509 & 5.739 & 2.3510 & 704 & 131.99 \\
\hline 13 & 5 & 1509 & 5.734 & 2.2976 & 761 & 129.11 \\
\hline 13 & 4 & 2014 & 6.015 & 2.4646 & 756 & 132.07 \\
\hline 13 & 4 & 2014 & 6.027 & 2.4247 & 758 & 129.68 \\
\hline 13 & 3 & 3535 & 6.189 & 2.4748 & 817 & 128.93 \\
\hline 13 & 3 & 3535 & 6.184 & 2.5056 & 608 & 130.62 \\
\hline 13 & 2 & 5195 & 5.912 & 2.4414 & 678 & 133.07 \\
\hline 13 & 2 & 5195 & 5.912 & 2.3820 & 853 & 129.86 \\
\hline 15 & 12 & 896 & 3.386 & 1.4084 & 362 & 133.29 \\
\hline 15 & 12 & 896 & 3.383 & 1.3821 & 767 & 130.95 \\
\hline 15 & 11 & 896 & 3.368 & 1.3629 & 758 & 129.68 \\
\hline 15 & 11 & 896 & 3.370 & 1.3888 & 756 & 132.07 \\
\hline 15 & 10 & 896 & 3.381 & 1.3779 & 608 & 130.62 \\
\hline 15 & 10 & 896 & 3.372 & 1.3565 & 817 & 128.93 \\
\hline 15 & 9 & 896 & 3.367 & 1.3980 & 678 & 133.07 \\
\hline 15 & 9 & 896 & 3.375 & 1.3675 & 853 & 129.86 \\
\hline 15 & 8 & 896 & 3.373 & 1.3403 & 524 & 127.35 \\
\hline 15 & 8 & 896 & 3.369 & 1.3875 & 705 & 132.00 \\
\hline 15 & 7 & 896 & 3.384 & 1.3919 & 728 & 131.82 \\
\hline 15 & 7 & 896 & 3.374 & 1.3877 & 773 & 131.80 \\
\hline 15 & 6 & 896 & 3.391 & 1.4071 & 781 & 133.00 \\
\hline 15 & 6 & 896 & 3.402 & 1.3979 & 737 & 131.71 \\
\hline 15 & 5 & 896 & 3.426 & 1.4050 & 740 & 131.47 \\
\hline 15 & 5 & 896 & 3.394 & 1.3705 & 700 & 129.40 \\
\hline 15 & 4 & 896 & 3.408 & 1.3980 & 736 & 131.50 \\
\hline 15 & 4 & 896 & 3.400 & 1.3579 & 382 & 128.02 \\
\hline 15 & 3 & 896 & 3.394 & 1.3817 & 848 & 130.48 \\
\hline 15 & 3 & 896 & 3.401 & 1.4071 & 709 & 132.59 \\
\hline
\end{tabular}




\begin{tabular}{|c|c|c|c|c|c|c|}
\hline $\begin{array}{c}\text { Cast } \\
\star\end{array}$ & $\begin{array}{c}\text { Niskin } \\
\#\end{array}$ & $\begin{array}{c}\text { Pressure } \\
(\mathrm{db})\end{array}$ & $\begin{array}{l}\text { Oxygen } \\
(m L / L)\end{array}$ & $\begin{array}{l}\text { Thiosulfate } \\
\text { Titer (mL) }\end{array}$ & -- & $\begin{array}{c}\text { ask --- } \\
\text { Volume } \\
\text { (mL) }\end{array}$ \\
\hline 16 & 11 & 3550 & 6.175 & 2.5476 & 781 & 133.00 \\
\hline 16 & 11 & 3550 & 6.186 & 2.5274 & 737 & 131.71 \\
\hline 16 & 10 & 3550 & 6.193 & 2.5470 & 709 & 132.59 \\
\hline 16 & 10 & 3550 & 6.191 & 2.5055 & 848 & 130.48 \\
\hline 16 & 9 & 3550 & 6.161 & 2.5125 & 740 & 131.47 \\
\hline 16 & 9 & 3550 & 6.175 & 2.4784 & 700 & 129.40 \\
\hline 16 & 8 & 3550 & 6.153 & 2.5195 & 704 & 131.99 \\
\hline 16 & 8 & 3550 & 6.175 & 2.472 .7 & 761 & 129.11 \\
\hline 16 & 7 & 3549 & 6.175 & 2.5534 & 362 & 133.29 \\
\hline 16 & 7 & 3549 & 6.188 & 2.5135 & 767 & 130.95 \\
\hline 16 & 6 & 3549 & 6.197 & 2.5387 & 756 & 132.07 \\
\hline 16 & 6 & 3549 & 6.175 & 2.4837 & 758 & 129.68 \\
\hline 16 & 5 & 3550 & 6.180 & 2.5354 & 844 & 132.26 \\
\hline 16 & 5 & 3550 & 6.187 & 2.4950 & 835 & 130.01 \\
\hline 16 & 4 & 3550 & 6.187 & 2.4741 & 817 & 128.93 \\
\hline 16 & 4 & 3550 & 6.199 & 2.5114 & 608 & 130.62 \\
\hline 16 & 3 & 3549 & 6.211 & 2.5639 & 678 & 133.07 \\
\hline 16 & 3 & 3549 & 6.176 & 2.4876 & 853 & 129.86 \\
\hline 20 & 12 & 23 & 5.197 & 2.1318 & 756 & 132.07 \\
\hline 20 & 12 & 23 & 5.203 & 2.0956 & 758 & 129.68 \\
\hline 20 & 11 & 22 & 5.208 & 2.1350 & 704 & 131.99 \\
\hline 20 & 11 & 22 & 5.199 & 2.0848 & 761 & 129.11 \\
\hline 20 & 10 & 213 & 4.869 & 1.9507 & 817 & 128.93 \\
\hline 20 & 10 & 213 & 4.865 & 1.9634 & 853 & 129.86 \\
\hline 20 & 9 & 415 & 4.500 & 1.8281 & 608 & 130.62 \\
\hline 20 & 9 & 415 & 4.503 & 1.8640 & 678 & 133.07 \\
\hline 20 & 8 & 616 & 4.204 & 1.6930 & 700 & 129.40 \\
\hline 20 & 8 & 616 & 4.205 & 1.7207 & 740 & 131.47 \\
\hline
\end{tabular}


Appendix C. University of Delaware. Experimental data for the calculation of dissolved oxygen. Leg $3, R / V$ Oceanus cruise 219.

$$
\begin{aligned}
\text { Iodate normality: } & 0.010140 \\
\text { Iodate pipet volume (mL): } & 9.97840
\end{aligned}
$$

Thiosulfate titer (mL) for standards: 0.71800

\begin{tabular}{|c|c|c|c|c|c|c|}
\hline Cast & $\underset{*}{\text { Nigkin }}$ & $\begin{array}{c}\text { Pressure } \\
\text { (db) }\end{array}$ & $\begin{array}{l}\text { oxygen } \\
(\mathrm{mL} / \mathrm{L})\end{array}$ & $\begin{array}{l}\text { Thiosulfate } \\
\text { Titer (mL) }\end{array}$ & -- & $\begin{array}{c}\text { lask -- } \\
\text { Volume } \\
\text { (mL) }\end{array}$ \\
\hline 13 & 12 & 20 & 5.126 & 0.9232 & 35 & 143.73 \\
\hline 13 & 12 & 20 & 5.129 & 0.9468 & 36 & 147.26 \\
\hline 13 & 11 & 20 & 5.124 & 0.9581 & 41 & 149.16 \\
\hline 13 & 11 & 20 & 5.121 & 0.9431 & 43 & 146.92 \\
\hline 13 & 10 & 614 & 4.160 & 0.7733 & 39 & 148.23 \\
\hline 13 & 10 & 614 & 4.159 & 0.7633 & 40 & 146.38 \\
\hline 13 & 9 & 714 & 3.375 & 0.6265 & 37 & 147.93 \\
\hline 13 & 9 & 714 & 3.372 & 0.6228 & 38 & 147.22 \\
\hline 13 & 8 & 862 & 3.370 & 0.5850 & 17 & 138.47 \\
\hline 13 & 8 & 862 & 3.374 & 0.6202 & 19 & 146.53 \\
\hline 13 & 7 & 861 & 3.369 & 0.5880 & 30 & 139.20 \\
\hline 13 & 7 & 861 & 3.372 & 0.6188 & 34 & 146.26 \\
\hline 13 & 6 & 1258 & 5.188 & 0.9059 & 23 & 139.41 \\
\hline 13 & 6 & 1258 & 5.180 & 0.9540 & 24 & 146.93 \\
\hline 13 & 5 & 1509 & 5.735 & 1.0031 & 20 & 139.66 \\
\hline 13 & 5 & 1509 & 5.728 & 1.0538 & 21 & 146.81 \\
\hline 13 & 4 & 2014 & 6.023 & 1.1123 & 1 & 147.38 \\
\hline 13 & 4 & 2014 & 6.005 & 1.1068 & 2 & 147.09 \\
\hline 13 & 3 & 3535 & 6.175 & 1.0892 & 11 & 140.85 \\
\hline 13 & 3 & 3535 & 6.175 & 1.1197 & 13 & 144.74 \\
\hline 13 & 2 & 5195 & 5.896 & 1.0261 & 4 & 138.97 \\
\hline 13 & 2 & 5195 & 5.897 & 1.0886 & 7 & 147.30 \\
\hline 15 & 12 & 896 & 3.358 & 0.5861 & 30 & 139.20 \\
\hline 15 & 12 & 896 & 3.358 & 0.6161 & 34 & 146.26 \\
\hline 15 & 11 & 896 & 3.363 & 0.6255 & 39 & 148.23 \\
\hline 15 & 11 & 896 & 3.364 & 0.6178 & 40 & 146.38 \\
\hline 15 & 10 & 896 & 3.355 & 0.6228 & 37 & 147.93 \\
\hline 15 & 10 & 896 & 3.356 & 0.6199 & 38 & 147.22 \\
\hline 15 & 9 & 896 & 3.357 & 0.6052 & 35 & 143.73 \\
\hline 15 & 9 & 896 & 3.352 & 0.6194 & 36 & 147.26 \\
\hline 15 & 8 & 896 & 3.352 & 0.5921 & 11 & 140.85 \\
\hline 15 & 8 & 896 & 3.351 & 0.6085 & 13 & 144.74 \\
\hline 15 & 7 & 896 & 3.370 & 0.5890 & 23 & 139.41 \\
\hline 15 & 7 & 896 & 3.362 & 0.6198 & 24 & 146.93 \\
\hline 15 & 6 & 896 & 3.385 & 0.5927 & 20 & 139.66 \\
\hline 15 & 6 & 896 & 3.372 & 0.6211 & 21 & 146.81 \\
\hline 15 & 5 & 896 & 3.377 & 0.5862 & 17 & 138.47 \\
\hline 15 & 5 & 896 & 3.377 & 0.6208 & 19 & 146.53 \\
\hline 15 & 4 & 896 & 3.384 & 0.6257 & 1 & 147.38 \\
\hline 15 & 4 & 896 & 3.383 & 0.6243 & 2 & 147.09 \\
\hline 15 & 3 & 896 & 3.380 & 0.5890 & 4 & 138.97 \\
\hline 15 & 3 & 896 & 3.374 & 0.6236 & 7 & 147.30 \\
\hline
\end{tabular}

Thiosulfate titer (mL) for blanks: -0.00040 


\begin{tabular}{|c|c|c|c|c|c|c|}
\hline $\begin{array}{c}\text { Cast } \\
\#\end{array}$ & $\begin{array}{l}\text { Niskin } \\
*\end{array}$ & $\begin{array}{l}\text { Pressure } \\
(\mathrm{db})\end{array}$ & $\begin{array}{l}\text { oxygen } \\
(\mathrm{mL} / \mathrm{L})\end{array}$ & $\begin{array}{l}\text { Thiosulfate } \\
\text { Titer (mL) }\end{array}$ & 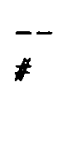 & $\begin{array}{c}\text { Flask -- } \\
\text { Volume } \\
\text { (mL) }\end{array}$ \\
\hline 16 & 12 & 3550 & 6.181 & 1.0773 & 30 & 139.20 \\
\hline 16 & 12 & 3550 & 6.184 & 1.1333 & 34 & 146.26 \\
\hline 16 & 11 & 3550 & 6.175 & 1.1470 & 39 & 148.23 \\
\hline 16 & 11 & 3550 & 6.175 & 1.1325 & 40 & 146.38 \\
\hline 16 & 10 & 3550 & 6.177 & 1.1450 & 37 & 147.93 \\
\hline 16 & 10 & 3550 & 6.177 & 1.1395 & 38 & 147.22 \\
\hline 16 & 9 & 3550 & 6.180 & 1.1126 & 35 & 143.73 \\
\hline 16 & 9 & 3550 & 6.179 & 1.1401 & 36 & 147.26 \\
\hline 16 & 8 & 3550 & 6.179 & 1.0900 & 11 & 140.85 \\
\hline 16 & 8 & 3550 & 6.181 & 1.1207 & 13 & 144.74 \\
\hline 16 & 7 & 3549 & 6.183 & 1.0793 & 23 & 139.41 \\
\hline 16 & 7 & 3549 & 6.179 & 1.1376 & 24 & 146.93 \\
\hline 16 & 6 & 3549 & 6.183 & 1.0813 & 20 & 139.66 \\
\hline 16 & 6 & 3549 & 6.179 & 1.1366 & 21 & 146.81 \\
\hline 16 & 5 & 3550 & 6.180 & 1.0715 & 17 & 138.47 \\
\hline 16 & 5 & 3550 & 6.183 & 1.1352 & 19 & 146.53 \\
\hline 16 & 4 & 3550 & 6.186 & 1.1424 & 1 & 147.38 \\
\hline 16 & 4 & 3550 & 6.185 & 1.1400 & 2 & 147.09 \\
\hline 16 & 3 & 3549 & 6.177 & 1.0749 & 4 & 138.97 \\
\hline 16 & 3 & 3549 & 6.179 & 1.1405 & 7 & 147.30 \\
\hline 20 & 12 & 23 & 5.202 & 0.9070 & 30 & 139.20 \\
\hline 20 & 12 & 23 & 5.207 & 0.9545 & 34 & 146.26 \\
\hline 20 & 11 & 22 & 5.198 & 0.9658 & 39 & 148.23 \\
\hline 20 & 11 & 22 & 5.193 & 0.9528 & 40 & 146.38 \\
\hline 20 & 10 & 213 & 4.864 & 0.9020 & 37 & 147.93 \\
\hline 20 & 10 & 213 & 4.862 & 0.8973 & 38 & 147.22 \\
\hline 20 & 9 & 415 & 4.508 & 0.8122 & 35 & 143.73 \\
\hline 20 & 9 & 415 & 4.502 & 0.8312 & 36 & 147.26 \\
\hline 20 & 8 & 616 & 4.200 & 0.7414 & 11 & 140.85 \\
\hline 20 & 8 & 616 & 4.199 & 0.7619 & 13 & 144.74 \\
\hline 20 & 7 & 939 & 3.524 & 0.6159 & 23 & 139.41 \\
\hline 20 & 7 & 939 & 3.521 & 0.6490 & 24 & 146.93 \\
\hline 20 & 6 & 2014 & 6.012 & 1.0514 & 20 & 139.66 \\
\hline 20 & 6 & 2014 & 6.009 & 1.1055 & 21 & 146.81 \\
\hline 20 & 5 & 3029 & 6.109 & 1.0592 & 17 & 138.47 \\
\hline 20 & 5 & 3029 & 6.108 & 1.1215 & 19 & 146.53 \\
\hline 20 & 4 & 4050 & 6.167 & 1.1389 & 1 & 147.38 \\
\hline 20 & 4 & 4050 & 6.154 & 1.1343 & 2 & 147.09 \\
\hline 20 & 3 & 5109 & 5.990 & 1.0423 & 4 & 138.97 \\
\hline 20 & 3 & 5109 & 5.988 & 1.1052 & 7 & 147.30 \\
\hline 21 & 12 & 3040 & 6.124 & 1.1223 & 34 & 146.26 \\
\hline 21 & 11 & 3247 & 6.161 & 1.1445 & 39 & 148.23 \\
\hline 21 & 11 & 3247 & 6.156 & 1.1290 & 40 & 146.38 \\
\hline 21 & 10 & 3449 & 6.165 & 1.1429 & 37 & 147.93 \\
\hline 21 & 10 & 3449 & 6.160 & 1.1364 & 38 & 147.22 \\
\hline 21 & 9 & 3654 & 6.179 & 1.1125 & 35 & 143.73 \\
\hline 21 & 9 & 3654 & 6.174 & 1.1393 & 36 & 147.26 \\
\hline 21 & 8 & 3862 & 6.181 & 1.0903 & 11 & 140.85 \\
\hline 21 & 8 & 3862 & 6.177 & 1.1201 & 13 & 144.74 \\
\hline
\end{tabular}


Appendix C (continued).

\begin{tabular}{|c|c|c|c|c|c|c|}
\hline Cast & $\underset{*}{\text { Niskin }}$ & $\begin{array}{l}\text { Pressure } \\
\text { (db) }\end{array}$ & $\begin{array}{l}\text { Oxygen } \\
(\mathrm{mL} / \mathrm{L})\end{array}$ & $\begin{array}{l}\text { Thiosulfate } \\
\text { Titer (mL) }\end{array}$ & - & $\begin{array}{c}\text { Lask -- } \\
\text { Volume } \\
\text { (mL) }\end{array}$ \\
\hline 21 & 7 & 4067 & 6.147 & 1.1317 & 24 & 146.93 \\
\hline 21 & 6 & 4271 & 6.122 & 1.0707 & 20 & 139.66 \\
\hline 21 & 6 & 4271 & 6.117 & 1.1252 & 21 & 146.81 \\
\hline 21 & 5 & 4472 & 6.099 & 1.0574 & 17 & 138.47 \\
\hline 21 & 5 & 4472 & 6.100 & 1.1200 & 19 & 146.53 \\
\hline 21 & 4 & 4686 & 6.056 & 1.1184 & 1 & 147.38 \\
\hline 21 & 4 & 4686 & 6.064 & 1.1177 & 2 & 147.09 \\
\hline 21 & 3 & 4945 & 5.986 & 1.0416 & 4 & 138.97 \\
\hline 21 & 3 & 4945 & 5.986 & 1.1049 & 7 & 147.30 \\
\hline 23 & 12 & 11 & 5.358 & 0.9822 & 34 & 146.26 \\
\hline 23 & 11 & 107 & 5.031 & 0.9348 & 39 & 148.23 \\
\hline 23 & 11 & 107 & 5.036 & 0.9239 & 40 & 146.38 \\
\hline 23 & 10 & 204 & 5.003 & 0.9278 & 37 & 147.93 \\
\hline 23 & 10 & 204 & 5.006 & 0.9238 & 38 & 147.22 \\
\hline 23 & 9 & 310 & 4.559 & 0.8213 & 35 & 143.73 \\
\hline 23 & 9 & 310 & 4.556 & 0.8412 & 36 & 147.26 \\
\hline 23 & 8 & 407 & 4.510 & 0.8308 & 24 & 146.93 \\
\hline 23 & 7 & 512 & 4.292 & 0.7512 & 20 & 139.66 \\
\hline 23 & 7 & 512 & 4.288 & 0.7894 & 21 & 146.81 \\
\hline 23 & 6 & 624 & 4.173 & 0.7241 & 17 & 138.47 \\
\hline 23 & 6 & 624 & 4.176 & 0.7673 & 19 & 146.53 \\
\hline 23 & 5 & 715 & 3.892 & 0.6872 & 11 & 140.85 \\
\hline 23 & 5 & 715 & 3.893 & 0.7065 & 13 & 144.74 \\
\hline 23 & 4 & 812 & 3.445 & 0.6370 & $i$ & 147.38 \\
\hline 23 & 4 & 812 & 3.444 & 0.6356 & 2 & 147.09 \\
\hline 23 & 3 & 909 & 3.383 & 0.5894 & 4 & 138.97 \\
\hline 23 & 3 & 909 & 3.425 & 0.6329 & 7 & 147.30 \\
\hline 24 & 12 & 1014 & 3.458 & 0.6035 & 30 & 139.20 \\
\hline 24 & 12 & 1014 & 3.457 & 0.6342 & 34 & 146.26 \\
\hline 24 & 11 & 1216 & 4.967 & 0.9288 & 41 & 149.16 \\
\hline 24 & 11 & 1216 & 4.967 & 0.9147 & 43 & 146.92 \\
\hline 24 & 10 & 1417 & 5.606 & 1.0394 & 37 & 147.93 \\
\hline 24 & 10 & 1417 & 5.604 & 1.0340 & 38 & 147.22 \\
\hline 24 & 9 & 1622 & 5.879 & 1.0586 & 35 & 143.73 \\
\hline 24 & 9 & 1622 & 5.873 & 1.0838 & 36 & 147.26 \\
\hline 24 & 8 & 1818 & 6.029 & 1.0635 & 11 & 140.85 \\
\hline 24 & 8 & 1818 & 6.026 & 1.0927 & 13 & 144.74 \\
\hline 24 & 7 & 2025 & 6.064 & 1.0586 & 23 & 139.41 \\
\hline 24 & 7 & 2025 & 6.061 & 1.1158 & 24 & 146.93 \\
\hline 24 & 6 & 2227 & 6.055 & 1.0589 & 20 & 139.66 \\
\hline 24 & 6 & 2227 & 6.050 & 1.1129 & 21 & 146.81 \\
\hline 24 & 5 & 2429 & 6.043 & 1.0477 & 17 & 138.47 \\
\hline 24 & 5 & 2429 & 6.045 & 1.1099 & 19 & 146.53 \\
\hline 24 & 4 & 2632 & 6.058 & 1.1188 & 1 & 147.38 \\
\hline 24 & 4 & 2632 & 6.055 & 1.1160 & 2 & 147.09 \\
\hline 24 & 3 & 2840 & 6.082 & 1.0584 & 4 & 138.97 \\
\hline 24 & 3 & 2840 & 6.077 & 1.1217 & 7 & 147.30 \\
\hline
\end{tabular}


Appendix D. Scrippo Institution of Oceanography. Experimental data for the calculation of dissolved oxygen. Leg 3 , $R / V$ Oceanus cruise 219 .

Iodate normality: 0.010000 Iodate pipet volume $(\mathrm{mL}): 10.00000$

Thiosulfate titer ( $\mathrm{mL}$ ) for standards: 0.70935 Thiosulfate titer (mL) for blanks: -0.00065

\begin{tabular}{|c|c|c|c|c|c|c|}
\hline Cast & $\underset{*}{\text { Nigkin }}$ & $\begin{array}{l}\text { Pressure } \\
\text { (db) }\end{array}$ & $\begin{array}{l}\text { Oxygen } \\
(\mathrm{mL} / \mathrm{L})\end{array}$ & $\begin{array}{l}\text { Thiosulfate } \\
\text { Titer (mL) }\end{array}$ & 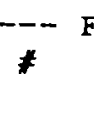 & $\begin{array}{c}\text { ask -- } \\
\text { Volume } \\
\text { (mL) }\end{array}$ \\
\hline 13 & 12 & 20 & 5.154 & 0.6612 & 560 & 102.92 \\
\hline 13 & 12 & 20 & 5.151 & 0.6503 & 577 & 101.31 \\
\hline 13 & 11 & 20 & 5.151 & 0.6738 & 557 & 104.90 \\
\hline 13 & 11 & 20 & 5.153 & 0.6586 & 576 & 102.54 \\
\hline 13 & 10 & 614 & 4.182 & 0.5287 & 556 & 101.40 \\
\hline 13 & 10 & 614 & 4.179 & 0.5362 & 573 & 102.88 \\
\hline 13 & 9 & 714 & 3.391 & 0.4438 & 555 & 104.83 \\
\hline 13 & 9 & 714 & 3.398 & 0.4403 & 572 & 103.82 \\
\hline 13 & 8 & 862 & 3.395 & 0.4251 & 554 & 100.37 \\
\hline 13 & 8 & 862 & 3.389 & 0.4602 & 571 & 108.71 \\
\hline 13 & 7 & 861 & 3.386 & 0.4426 & 552 & 104.70 \\
\hline 13 & 7 & 861 & 3.386 & 0.4150 & 569 & 98.29 \\
\hline 13 & 6 & 1258 & 5.208 & 0.6889 & 551 & 106.07 \\
\hline 13 & 6 & 1258 & 5.208 & 0.6519 & 568 & 100.47 \\
\hline 13 & 5 & 1509 & 5.754 & 0.7517 & 514 & 104.79 \\
\hline 13. & 5 & 1509 & 5.758 & 0.7327 & 567 & 102.13 \\
\hline 13 & 4 & 2014 & 6.041 & 0.8224 & 513 & 109.14 \\
\hline 13 & 4 & 2014 & 6.034 & 0.7578 & 565 & 100.82 \\
\hline 13 & 3 & 3535 & 6.204 & 0.7836 & 490 & 101.40 \\
\hline 13 & 3 & 3535 & 6.211 & 0.7804 & 564 & 100.87 \\
\hline 13 & 2 & 5195 & 5.933 & 0.7243 & 418 & 98.05 \\
\hline 13 & 2 & 5195 & 5.931 & 0.7503 & 563 & 101.54 \\
\hline 15 & 12 & 896 & 3.373 & 0.4332 & 560 & 102.92 \\
\hline 15 & 12 & 896 & 3.367 & 0.4256 & 577 & 101.31 \\
\hline 15 & 11 & 896 & 3.375 & 0.4319 & 576 & 102.54 \\
\hline 15 & 10 & 896 & 3.363 & 0.4255 & 556 & 101.40 \\
\hline 15 & 10 & 896 & 3.367 & 0.4323 & 573 & 102.88 \\
\hline 15 & 9 & 896 & 3.366 & 0.4405 & 555 & 104.83 \\
\hline 15 & 9 & 896 & 3.363 & 0.4358 & 572 & 103.82 \\
\hline 15 & 8 & 896 & 3.380 & 0.4232 & 554 & 100.37 \\
\hline 15 & 8 & 896 & 3.369 & 0.4575 & 571 & 108.71 \\
\hline 15 & 7 & 896 & 3.377 & 0.4414 & 552 & 104.70 \\
\hline 15 & 7 & 896 & 3.374 & 0.4135 & 569 & 98.29 \\
\hline 15 & 6 & 896 & 3.389 & 0.4489 & 551 & 106.07 \\
\hline 15 & 6 & 896 & 3.389 & 0.4248 & 568 & 100.47 \\
\hline 15 & 5 & 896 & 3.392 & 0.4437 & 514 & 104.79 \\
\hline 15 & 5 & 896 & 3.392 & 0.4322 & 567 & 102.13 \\
\hline 15 & 4 & 896 & 3.390 & 0.4621 & 513 & 109.14 \\
\hline 15 & 4 & 896 & 3.395 & 0.4270 & 565 & 100.82 \\
\hline 15 & 3 & 896 & 3.386 & 0.4284 & 490 & 101.40 \\
\hline 15 & 3 & 896 & 3.389 & 0.4265 & 564 & 100.87 \\
\hline
\end{tabular}




\begin{tabular}{|c|c|c|c|c|c|c|}
\hline $\begin{array}{l}\text { Cast } \\
\#\end{array}$ & $\underset{\#}{\text { Nigkin }}$ & $\begin{array}{l}\text { Pressure } \\
\cdot(\mathrm{db})\end{array}$ & $\begin{array}{l}\text { oxygen } \\
(m L / L)\end{array}$ & $\begin{array}{l}\text { Thiosulfate } \\
\text { Titer (mL) }\end{array}$ & $\underset{\#}{---} \mathrm{F}$ & $\begin{array}{c}\text { ask -- } \\
\text { Volume } \\
\text { (mL) }\end{array}$ \\
\hline 16 & 12 & 3550 & 6.204 & 0.8785 & 273 & 113.45 \\
\hline 16 & 12 & 3550 & 6.194 & 0.7669 & 15 & 99.42 \\
\hline 16 & 11 & 3550 & 6.217 & 0.7794 & 207 & 100.66 \\
\hline 16 & 11 & 3550 & 6.209 & 0.8472 & 340 & 109.39 \\
\hline 16 & 10 & 3550 & 6.209 & 0.7603 & 176 & 98.35 \\
\hline 16 & 10 & 3550 & 6.214 & 0.7743 & 333 & 100.06 \\
\hline 16 & 9 & 3550 & 6.208 & 0.8307 & 166 & 107.31 \\
\hline 16 & 9 & 3550 & 6.205 & 0.8723 & 332 & 112.65 \\
\hline 16 & 8 & 3550 & 6.208 & 0.7908 & 152 & 102.25 \\
\hline 16 & 8 & 3550 & 6.201 & 0.7828 & 331 & 101.34 \\
\hline 16 & 7 & 3549 & 6.211 & 0.8558 & 150 & 110.45 \\
\hline 16 & 7 & 3549 & 6.210 & 0.7575 & 329 & 97.99 \\
\hline 16 & 6 & 3549 & 6.201 & 0.8489 & 143 & 109.74 \\
\hline 16 & 6 & 3549 & 6.206 & 0.7596 & 327 & 98.32 \\
\hline 16 & 5 & 3550 & 6.211 & 0.7899 & 87 & 102.09 \\
\hline 16 & 5 & 3550 & 6.214 & 0.7975 & 315 & 102.99 \\
\hline 16 & 4 & 3550 & 6.220 & 0.7730 & 44 & 99.80 \\
\hline 16 & 4 & 3550 & 6.211 & 0.7943 & 303 & 102.65 \\
\hline 16 & 3 & 3549 & 6.212 & 0.8671 & 32 & 111.87 \\
\hline 16 & 3 & 3549 & 6.207 & 0.8451 & 297 & 109.16 \\
\hline 20 & 12 & 23 & 5.227 & 0.6706 & 560 & 102.92 \\
\hline 20 & 12 & 23 & 5.223 & 0.6594 & 577 & 101.31 \\
\hline 20 & 11 & 22 & 5.232 & 0.6844 & 557 & 104.90 \\
\hline 20 & 11 & 22 & 5.227 & 0.6680 & 576 & 102.54 \\
\hline 20 & 10 & 213 & 4.891 & 0.6181 & 556 & 101.40 \\
\hline 20 & 10 & 213 & 4.887 & 0.6268 & 573 & 102.88 \\
\hline 20 & 9 & 415 & 4.528 & 0.5921 & 555 & 104.83 \\
\hline 20 & 9 & 415 & 4.525 & 0.5859 & 572 & 103.82 \\
\hline 20 & 8 & 616 & 4.215 & 0.5274 & 554 & 100.37 \\
\hline 20 & 8 & 616 & 4.211 & 0.5714 & 571 & 108.71 \\
\hline 20 & 7 & 939 & 3.532 & 0.4616 & 552 & 104.70 \\
\hline 20 & 7 & 939 & 3.534 & 0.4331 & 569 & 98.29 \\
\hline 20 & 6 & 2014 & 6.035 & 0.7981 & 551 & 106.07 \\
\hline 20 & 6 & 2014 & 6.043 & 0.7562 & 568 & 100.47 \\
\hline 20 & 5 & 3029 & 6.139 & 0.8018 & 514 & 104.79 \\
\hline 20 & 5 & 3029 & 6.132 & 0.7802 & 567 & 102.13 \\
\hline 20 & 4 & 4050 & 6.185 & 0.8419 & 513 & 109.14 \\
\hline 20 & 4 & 4050 & 6.186 & 0.7768 & 565 & 100.82 \\
\hline 20 & 3 & 5109 & 6.017 & 0.7601 & 490 & 101.40 \\
\hline 20 & 3 & 5109 & 6.006 & 0.7547 & 564 & 100.87 \\
\hline 21 & 12 & 3040 & 6.147 & 0.8704 & 273 & 113.45 \\
\hline 21 & 12 & 3040 & 6.143 & 0.7606 & 15 & 99.42 \\
\hline 21 & 11 & 3247 & 6.186 & 0.7756 & 207 & 100.66 \\
\hline 21 & 11 & 3247 & 6.177 & 0.8428 & 340 & 109.39 \\
\hline 21 & 10 & 3449 & 6.187 & 0.7576 & 176 & 98.35 \\
\hline 21 & 10 & 3449 & 6.186 & 0.7708 & 333 & 100.06 \\
\hline 21 & 9 & 3654 & 6.134 & 0.8207 & 166 & 107.31 \\
\hline 21 & 9 & 3654 & 6.198 & 0.8713 & 332 & 112.65 \\
\hline 21 & 8 & 3862 & 6.206 & 0.7906 & 152 & 102.25 \\
\hline 21 & 8 & 3862 & 6.197 & 0.7823 & 331 & 101.34 \\
\hline
\end{tabular}


Appendix D (continued).

\begin{tabular}{|c|c|c|c|c|c|c|}
\hline Cast & $\underset{*}{\text { Nigkin }}$ & $\begin{array}{l}\text { Pressure } \\
\text { (db) }\end{array}$ & $\begin{array}{l}\text { oxygen } \\
(\mathrm{mL} / \mathrm{L})\end{array}$ & $\begin{array}{l}\text { Thiosulfate } \\
\text { Titer (mL) }\end{array}$ & ---1 & $\begin{array}{c}\text { vok } \\
\text { (mL) }\end{array}$ \\
\hline 21 & 7 & 4067 & 6.171 & 0.8503 & 150 & 110.45 \\
\hline 21 & 7 & 4067 & 6.170 & 0.7526 & 329 & 97.99 \\
\hline 21 & 6 & 4271 & 6.138 & 0.8402 & 143 & 109.74 \\
\hline 21 & 6 & 4271 & 6.139 & 0.7514 & 327 & 98.32 \\
\hline 21 & 5 & 4472 & 6.120 & 0.7784 & 87 & 102.09 \\
\hline 21 & 5 & 4472 & 6.120 & 0.7854 & 315 & 102.99 \\
\hline 21 & 4 & 4686 & 6.079 & 0.7555 & 44 & 99.80 \\
\hline 21 & 4 & 4686 & 6.075 & 0.7770 & 303 & 102.65 \\
\hline 21 & 3 & 4945 & 6.010 & 0.8390 & 32 & 111.87 \\
\hline 21 & 3 & 4945 & 6.003 & 0.8174 & 297 & 109.16 \\
\hline 23 & 12 & 11 & 5.377 & 0.7616 & 273 & 113.45 \\
\hline 23 & 12 & 11 & 5.371 & 0.6652 & 15 & 99.42 \\
\hline 23 & 11 & 107 & 5.059 & 0.6346 & 207 & 100.66 \\
\hline 23 & 11 & 107 & 5.048 & 0.6890 & 340 & 109.39 \\
\hline 23 & 10 & 204 & 5.024 & 0.6154 & 176 & 98.35 \\
\hline 23 & 10 & 204 & 5.024 & 0.6263 & 333 & 100.06 \\
\hline 23 & 9 & 310 & 4.563 & 0.6110 & 166 & 107.31 \\
\hline 23 & 9 & 310 & 4.569 & 0.6428 & 332 & 112.65 \\
\hline 23 & 8 & 407 & 4.528 & 0.5772 & 152 . & 102.25 \\
\hline 23 & 8 & 407 & 4.526 & 0.5718 & 331 & 101.34 \\
\hline 23 & 7 & 512 & 4.302 & 0.5932 & 150 & 110.45 \\
\hline 23 & 7 & 512 & 4.304 & 0.5255 & 329 & 97.99 \\
\hline 23 & 6 & 624 & 4.182 & 0.5730 & 143 & 109.74 \\
\hline 23 & 6 & 624 & 4.187 & 0.5130 & 327 & 98.32 \\
\hline 23 & 5 & 715 & 3.897 & 0.4962 & 87 & 102.09 \\
\hline 23 & 5 & 715 & 3.901 & 0.5012 & 315 & 102.99 \\
\hline 23 & 4 & 812 & 3.457 & 0.4303 & 44 & 99.80 \\
\hline 23 & 4 & 812 & 3.444 & 0.4412 & 303 & 102.65 \\
\hline 23 & 3 & 909 & 3.381 & 0.4727 & 32 & 111.87 \\
\hline 23 & 3 & 909 & 3.376 & 0.4604 & 297 & 109.16 \\
\hline 24 & 12 & 1014 & 3.473 & 0.4461 & 560 & 102.92 \\
\hline 24 & 12 & 1014 & 3.466 & 0.4381 & 577 & 101.31 \\
\hline 24 & 11 & 1216 & 4.986 & 0.6523 & 557 & 104.90 \\
\hline 24 & 11 & 1216 & 4.983 & 0.6369 & 576 & 102.54 \\
\hline 24 & 10 & 1417 & 5.626 & 0.7108 & 556 & 101.40 \\
\hline 24 & 10 & 1417 & 5.632 & 0.7221 & 573 & 102.88 \\
\hline 24 & 9 & 1622 & 5.898 & 0.7707 & 555 & 104.83 \\
\hline 24 & 9 & 1622 & 5.900 & 0.7634 & 572 & 103.82 \\
\hline 24 & 8 & 1818 & 6.054 & 0.7568 & 554 & 100.37 \\
\hline 24 & 8 & 1818 & 6.049 & 0.8202 & 571 & 108.71 \\
\hline 24 & 7 & 2025 & 6.089 & 0.7946 & 552 & 104.70 \\
\hline 24 & 7 & 2025 & 6.079 & 0.7439 & 569 & 98.29 \\
\hline 24 & 6 & 2227 & 6.075 & 0.8034 & 551 & 106.07 \\
\hline 24 & 6 & 2227 & 6.073 & 0.7600 & 568 & 100.47 \\
\hline 24 & 5 & 2429 & 6.066 & 0.7924 & 514 & 104.79 \\
\hline 24 & 5 & 2429 & 6.063 & 0.7715 & 567 & 102.13 \\
\hline 24 & 4 & 2632 & 6.071 & 0.8264 & 513 & 109.14 \\
\hline 24 & 4 & 2632 & 6.077 & 0.7632 & 565 & 100.82 \\
\hline 24 & 3 & 2840 & 6.110 & 0.7718 & 490 & 101.40 \\
\hline 24 & 3 & 2840 & 6.102 & 0.7667 & 564 & 100.87 \\
\hline
\end{tabular}


Appendix E. Woods Hole Oceanographic Institution. Experimental data for the calculation of dissolved oxygen. Leg 3, R/V Oceanus cruise 219. 
winkler titration values

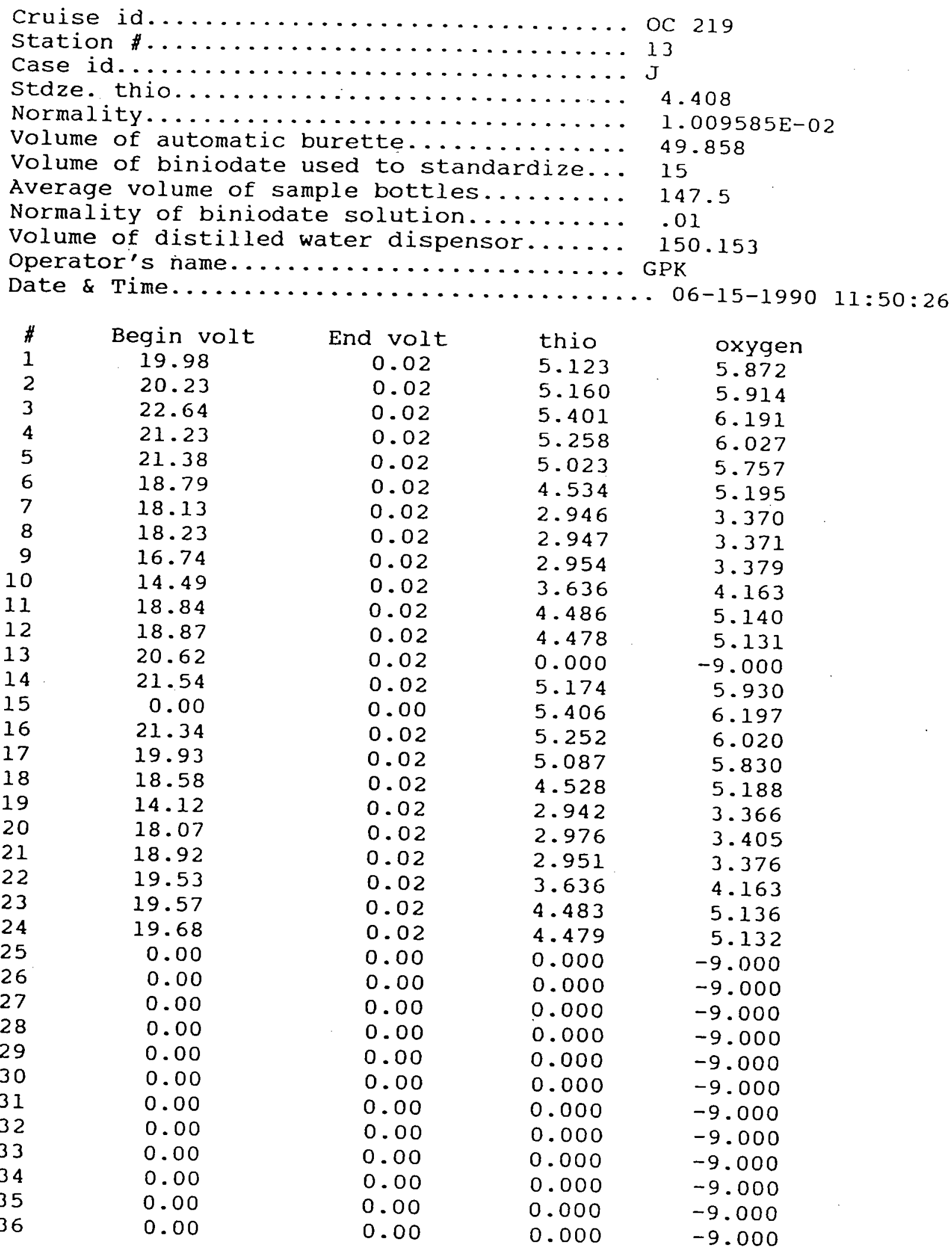




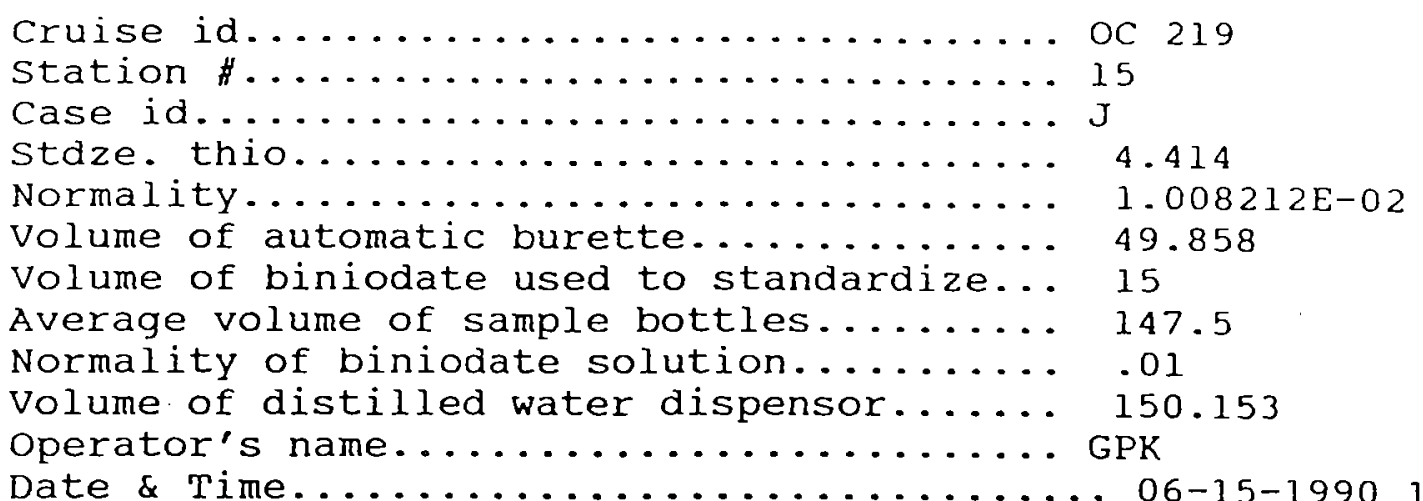

$11: 50: 03$

\begin{tabular}{|c|c|c|c|c|}
\hline$\#$ & Begin volt & End volt & thio & oxygen \\
\hline 1 & 18.48 & 0.02 & 3.009 & 3.438 \\
\hline 2 & 17.53 & 0.02 & 2.947 & 3.367 \\
\hline 3 & 18.05 & 0.02 & 2.952 & 3.372 \\
\hline 4 & 16.09 & 0.02 & 2.953 & 3.374 \\
\hline 6 & 16.96 & 0.02 & 2.955 & 3.376 \\
\hline 7 & 15.65 & 0.02 & 2.939 & 3.358 \\
\hline 8 & 19.86 & 0.02 & 2.929 & 3.346 \\
\hline 9 & 20.22 & 0.02 & 2.933 & 3.351 \\
\hline 10 & 15.19 & 0.02 & 2.937 & 3.355 \\
\hline 11 & 17.91 & 0.02 & 2.939 & 3.358 \\
\hline 12 & 18.11 & 0.02 & 2.934 & 3.352 \\
\hline 13 & 15.86 & 0.02 & 0.000 & -9.000 \\
\hline 14 & 0.00 & 0.00 & 0.000 & -9.000 \\
\hline 15 & 0.00 & 0.00 & 2.951 & 3.371 \\
\hline 16 & 14.29 & 0.02 & 2.954 & 3.375 \\
\hline 17 & 18.65 & 0.02 & 2.953 & 3.374 \\
\hline 18 & 17.46 & 0.02 & 2.950 & 3.370 \\
\hline 19 & 18.02 & 0.02 & 2.938 & 3.356 \\
\hline 20 & 15.97 & 0.02 & 2.936 & 3.354 \\
\hline 21 & 16.58 & 0.02 & 2.932 & 3.349 \\
\hline 22 & 16.42 & 0.02 & 2.939 & 3.358 \\
\hline 23 & 17.62 & 0.02 & 2.936 & 3.354 \\
\hline 24 & 17.99 & 0.02 & 2.936 & 3.354 \\
\hline 25 & 0.00 & 0.00 & 0.000 & -9.000 \\
\hline 26 & 0.00 & 0.00 & 0.000 & -9.000 \\
\hline 27 & 0.00 & 0.00 & 0.000 & -9.000 \\
\hline 28 & 0.00 & 0.00 & 0.000 & -9.000 \\
\hline 29 & 0.00 & 0.00 & 0.000 & -9.000 \\
\hline 30 & 0.00 & 0.00 & 0.000 & -9.000 \\
\hline 31 & 0.00 & 0.00 & 0.000 & -9.000 \\
\hline 32 & 0.00 & 0.00 & 0.000 & -9.000 \\
\hline 33 & 0.00 & 0.00 & 0.000 & -9.000 \\
\hline 34 & 0.00 & 0.00 & 0.000 & -9.000 \\
\hline 35 & 0.00 & 0.00 & 0.000 & -9.000 \\
\hline 36 & 0.00 & 0.00 & 0.000 & -9.000 \\
\hline
\end{tabular}




\section{winkler titration values}

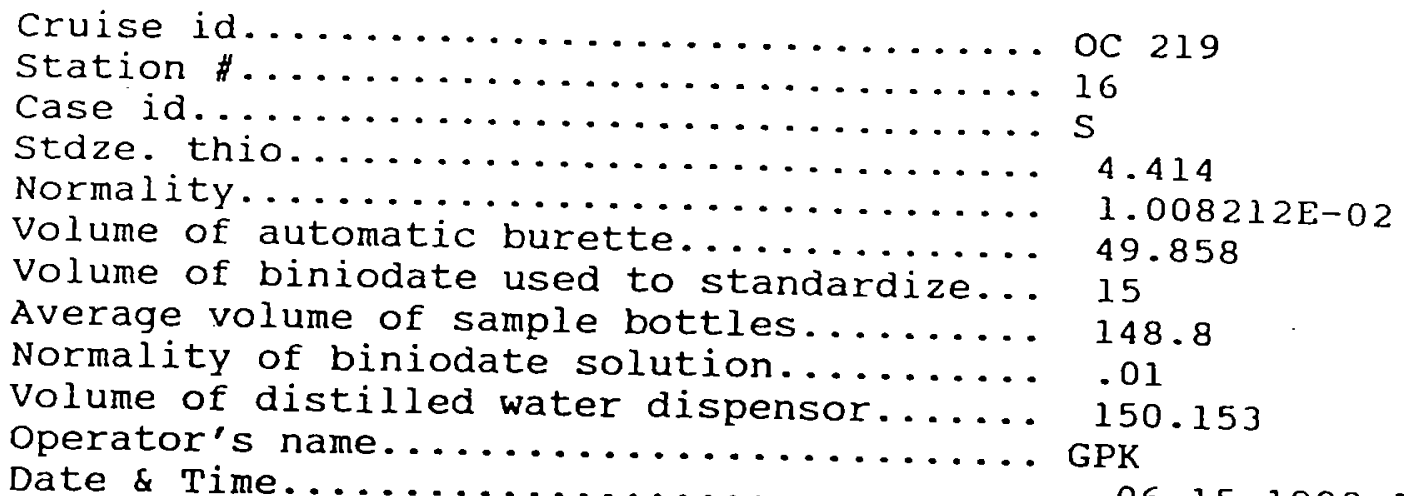

Date \& Time.......................... 06-15-1990 11:49:42

\begin{tabular}{|c|c|c|c|c|}
\hline$\#$ & Begin volt & End volt & thio & oxygen \\
\hline 1 & 0.00 & 0.00 & 0.000 & -9.000 \\
\hline 2 & 0.00 & 0.00 & 0.000 & -9.000 \\
\hline 3 & 19.59 & 0.02 & 5.389 & 6.168 \\
\hline 4 & 22.60 & 0.02 & 5.404 & 6.186 \\
\hline 5 & 19.32 & 0.02 & 5.397 & 6.178 \\
\hline 6 & 15.84 & 0.02 & 5.401 & 6.182 \\
\hline 7 & 23.40 & 0.02 & 5.401 & 6.182 \\
\hline 8 & 22.73 & 0.02 & 5.398 & 6.179 \\
\hline 9 & 21.16 & 0.02 & 5.400 & 6.181 \\
\hline 10 & 21.58 & 0.02 & 5.398 & 6.179 \\
\hline 11 & 20.03 & 0.02 & 5.404 & 6.186 \\
\hline 12 & 22.34 & 0.02 & 5.400 & 6.181 \\
\hline 13 & 0.00 & 0.00 & 0.000 & -9.000 \\
\hline 14 & 0.00 & 0.00 & 0.000 & -9.000 \\
\hline 15 & 21.14 & 0.02 & 5.403 & 6.185 \\
\hline 16 & 20.23 & 0.02 & 5.402 & 6.183 \\
\hline 17 & 21.26 & 0.02 & 5.399 & 6.180 \\
\hline 18 & 20.01 & 0.02 & 5.398 & 6.179 \\
\hline 19 & 22.09 & 0.02 & 5.400 & 6.181 \\
\hline 20 & 23.24 & 0.02 & 5.395 & 6.175 \\
\hline 21 & 22.57 & 0.02 & 5.406 & 6.188 \\
\hline 22 & 21.34 & 0.02 & 5.397 & 6.178 \\
\hline 23 & 22.30 & 0.02 & 5.402 & 6.183 \\
\hline 24 & 22.17 & 0.02 & 5.399 & 6.180 \\
\hline 25 & 0.00 & 0.00 & 0.000 & -9.000 \\
\hline 26 & 0.00 & 0.00 & 0.000 & -9.000 \\
\hline 27 & 0.00 & 0.00 & 0.000 & -9.000 \\
\hline 28 & 0.00 & 0.00 & 0.000 & -9.000 \\
\hline 29 & 0.00 & 0.00 & 0.000 & -9.000 \\
\hline 30 & 0.00 & 0.00 & 0.000 & -9.000 \\
\hline 31 & 0.00 & 0.00 & 0.000 & -9.000 \\
\hline 32 & 0.00 & 0.00 & 0.000 & -9.000 \\
\hline 33 & 0.00 & 0.00 & 0.000 & -9.000 \\
\hline 34 & 0.00 & 0.00 & 0.000 & -9.000 \\
\hline 35 & 0.00 & 0.00 & 0.000 & -9.000 \\
\hline 36 & 0.00 & 0.00 & 0.000 & -9.000 \\
\hline
\end{tabular}


winkler titration values

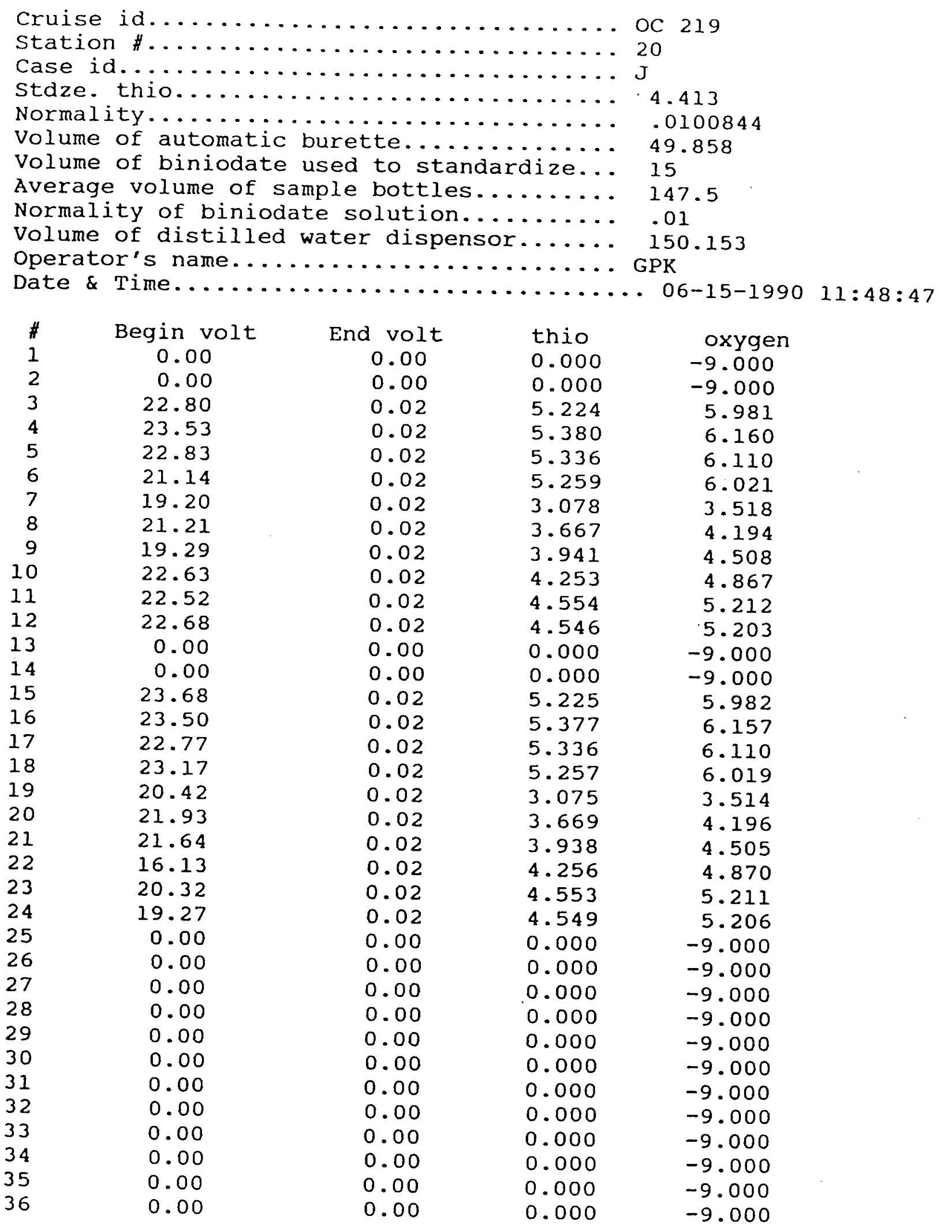


winkler titration values

\begin{tabular}{|c|c|c|c|c|c|}
\hline \multicolumn{6}{|c|}{ Cruise id....................... OC 219} \\
\hline \multirow{2}{*}{\multicolumn{6}{|c|}{ 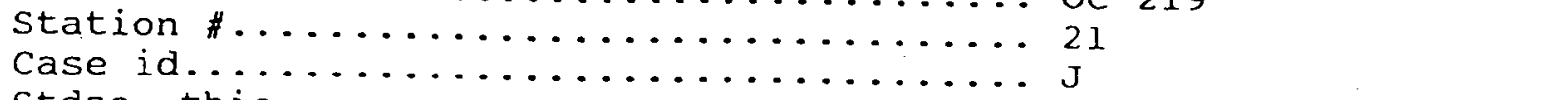 }} \\
\hline \multirow{2}{*}{\multicolumn{6}{|c|}{ 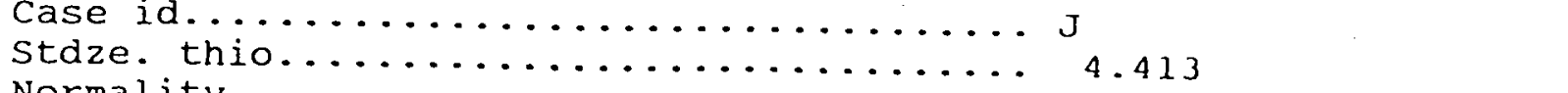 }} \\
\hline & & & & & \\
\hline \multirow{2}{*}{\multicolumn{6}{|c|}{ 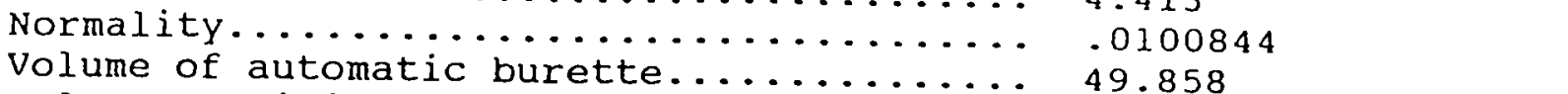 }} \\
\hline & & & & 49.858 & \\
\hline & of biniodat & sed to sta & dize... & 15 & \\
\hline \multicolumn{6}{|c|}{ Average volume of sample bottles....... 147.5} \\
\hline \multirow{2}{*}{\multicolumn{6}{|c|}{$\begin{array}{l}\text { Normality of biniodate solution.............. } \\
\text { Volume of distilled water disnensor }\end{array}$}} \\
\hline \multirow{2}{*}{\multicolumn{6}{|c|}{ 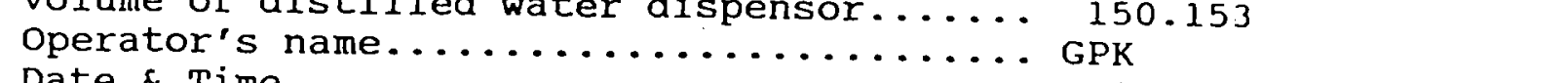 }} \\
\hline & & & & & \\
\hline Dat & Time...... & $\ldots \ldots \ldots$ & $\ldots \ldots$ & $06-15-1990$ & $11: 48: 20$ \\
\hline$\#$ & Begin volt & End volt & thio & oxygen & \\
\hline 1 & 20.48 & 0.02 & 5.195 & 5.948 & \\
\hline 2 & 21.75 & 0.02 & 5.228 & 5.986 & \\
\hline 3 & 20.10 & 0.02 & 5.230 & 5.988 & \\
\hline 4 & 19.89 & 0.02 & 5.297 & 6.065 & \\
\hline 5 & 20.52 & 0.02 & 5.330 & 6.103 & \\
\hline 6 & 22.09 & 0.02 & 5.348 & 6.123 & \\
\hline 7 & 22.58 & 0.02 & 5.374 & 6.153 & \\
\hline 8 & 23.76 & 0.02 & 5.393 & 6.175 & \\
\hline 9 & 17.06 & 0.02 & 5.395 & 6.177 & \\
\hline 10 & 20.05 & 0.02 & 5.382 & 6.162 & \\
\hline 11 & 19.43 & 0.02 & 5.393 & 6.175 & \\
\hline 12 & 22.42 & 0.02 & 5.352 & 6.128 & \\
\hline 13 & 0.00 & 0.00 & 0.000 & -9.000 & \\
\hline 14 & 0.00 & 0.00 & 0.000 & -9.000 & \\
\hline 15 & 20.83 & 0.02 & 5.228 & 5.986 & \\
\hline 16 & 21.00 & 0.02 & 5.294 & 6.061 & $\cdot$ \\
\hline 17 & 20.92 & 0.03 & 5.329 & 6.102 & \\
\hline 18 & 23.24 & 0.02 & 5.346 & 6.121 & \\
\hline 19 & 17.43 & 0.02 & 5.374 & 6.153 & \\
\hline 20 & 20.35 & 0.02 & 5.395 & 6.177 & \\
\hline 21 & 17.35 & 0.02 & 5.398 & 6.181 & \\
\hline 22 & 20.65 & 0.02 & 5.386 & 6.167 & \\
\hline 23 & 21.64 & 0.02 & 5.399 & 6.182 & \\
\hline 24 & 20.60 & 0.02 & 5.352 & 6.128 & \\
\hline 25 & 0.00 & 0.00 & 0.000 & -9.000 & \\
\hline 26 & 0.00 & 0.00 & 0.000 & -9.000 & \\
\hline 27 & 0.00 & 0.00 & 0.000 & -9.000 & \\
\hline 28 & 0.00 & 0.00 & 0.000 & -9.000 & \\
\hline 29 & 0.00 & 0.00 & 0.000 & -9.000 & \\
\hline 30 & 0.00 & 0.00 & 0.000 & -9.000 & \\
\hline 31 & 0.00 & 0.00 & 0.000 & -9.000 & \\
\hline 32 & 0.00 & 0.00 & 0.000 & -9.000 & \\
\hline 33 & 0.00 & 0.00 & 0.000 & -9.000 & \\
\hline 34 & 0.00 & 0.00 & 0.000 & -9.000 & \\
\hline 35 & 0.00 & 0.00 & 0.000 & -9.000 & \\
\hline 36 & 0.00 & 0.00 & 0.000 & -9.000 & \\
\hline
\end{tabular}


winkler titration values

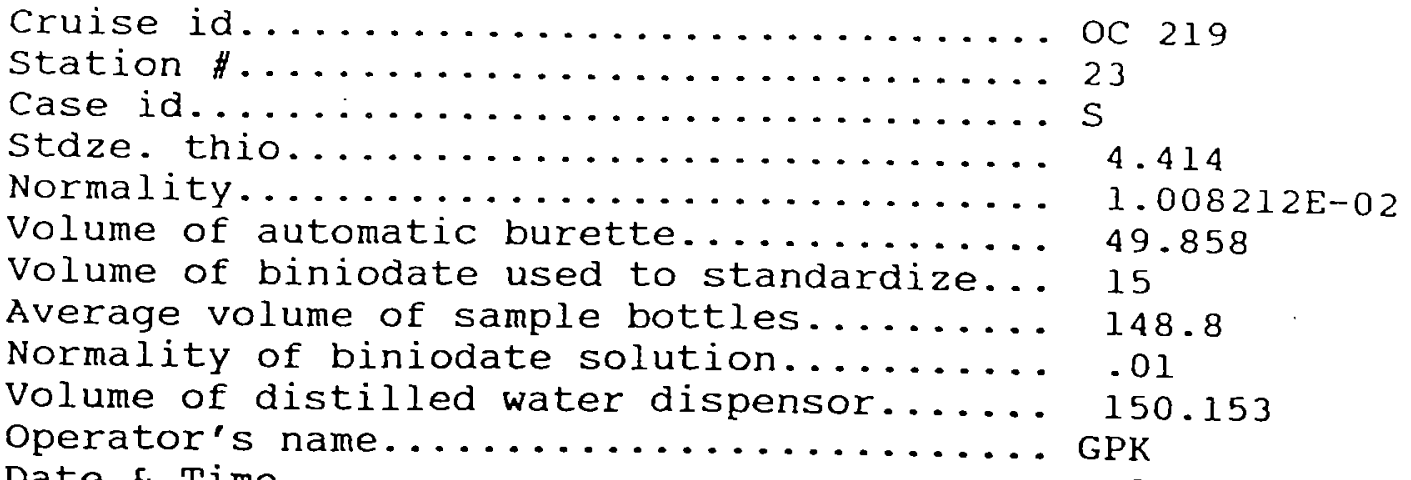

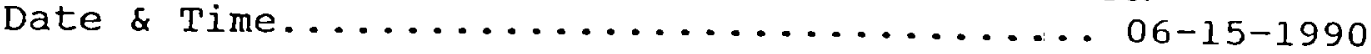

$11: 47: 32$

$\begin{array}{rrrrr}\# & \text { Begin volt } & \text { End volt } & \text { thio } & \text { oxygen } \\ 1 & 17.17 & 0.02 & 2.993 & 3.419 \\ 2 & 17.25 & 0.02 & 2.956 & 3.377 \\ 3 & 17.71 & 0.02 & 2.948 & 3.368 \\ 4 & 16.64 & 0.02 & 3.008 & 3.436 \\ 5 & 17.10 & 0.02 & 3.398 & 3.884 \\ 6 & 17.54 & 0.02 & 3.648 & 4.171 \\ 7 & 14.90 & 0.02 & 3.746 & 4.283 \\ 8 & 16.51 & 0.02 & 3.946 & 4.513 \\ 9 & 20.48 & 0.02 & 3.980 & 4.552 \\ 10 & 22.94 & 0.02 & 4.371 & 5.000 \\ 11 & 19.96 & 0.02 & 4.401 & 5.035 \\ 12 & 21.30 & 0.02 & 4.688 & 5.364 \\ 13 & 0.00 & 0.00 & 0.000 & -9.000 \\ 14 & 0.00 & 0.00 & 0.000 & -9.000 \\ 15 & 16.91 & 0.02 & 2.954 & 3.374 \\ 16 & 16.96 & 0.02 & 3.010 & 3.439 \\ 17 & 0.00 & 0.00 & 0.000 & -9.000 \\ 18 & 18.77 & 0.02 & 3.649 & 4.172 \\ 19 & 17.86 & 0.02 & 3.750 & 4.288 \\ 20 & 20.63 & 0.02 & 3.949 & 4.516 \\ 21 & 19.37 & 0.02 & 3.982 & 4.554 \\ 22 & 20.28 & 0.02 & 4.378 & 5.008 \\ 23 & 18.15 & 0.02 & 4.405 & 5.039 \\ 24 & 19.41 & 0.02 & 4.689 & 5.365 \\ 25 & 0.00 & 0.00 & 0.000 & -9.000 \\ 26 & 0.00 & 0.00 & 0.000 & -9.000 \\ 27 & 0.00 & 0.00 & 0.000 & -9.000 \\ 28 & 0.00 & 0.00 & 0.000 & -9.000 \\ 29 & 0.00 & 0.00 & 0.000 & -9.000 \\ 30 & 0.00 & 0.00 & 0.000 & -9.000 \\ 31 & 0.00 & 0.00 & 0.000 & -9.000 \\ 32 & 0.00 & 0.00 & 0.000 & -9.000 \\ 33 & 0.00 & 0.00 & 0.000 & -9.000 \\ 34 & 0.00 & 0.00 & 0.000 & -9.000 \\ 35 & 0.00 & 0.00 & 0.000 & -9.000 \\ 36 & 0.00 & 0.00 & 0.000 & -9.000\end{array}$


winkler titration values

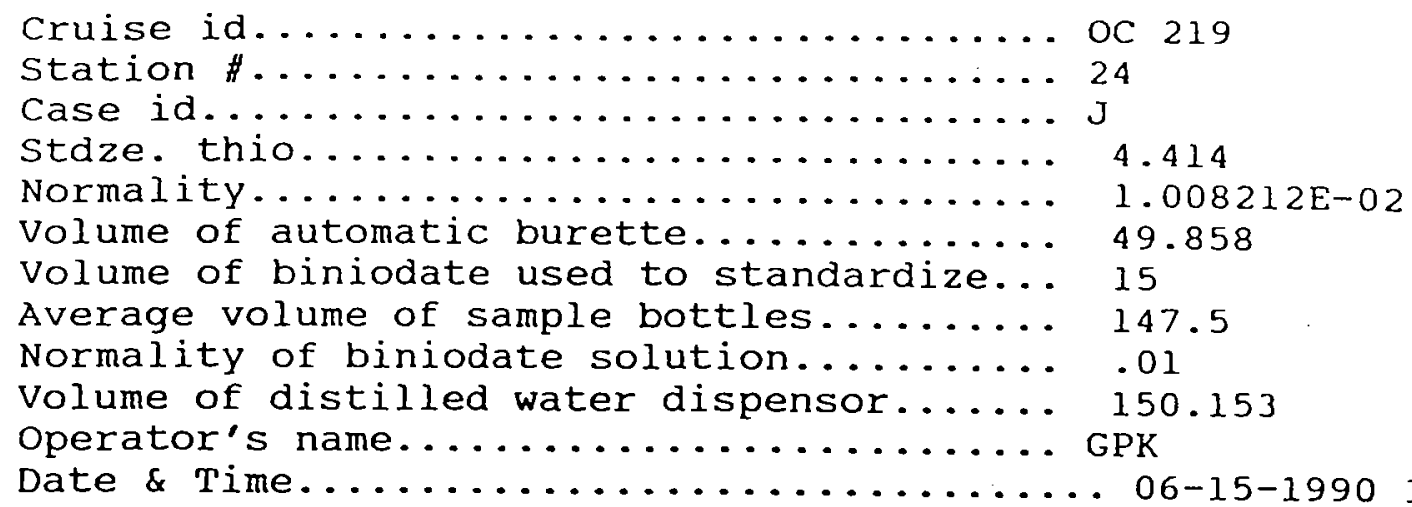

$11: 45: 54$

$\begin{array}{rcccc}\# & \text { Begin volt } & \text { End volt } & \text { thio } & \text { oxygen } \\ 1 & 23.19 & 0.02 & 4.732 & 5.415 \\ 2 & 22.09 & 0.02 & 4.708 & 5.388 \\ 3 & 18.90 & 0.02 & 5.311 & 6.080 \\ 4 & 21.60 & 0.02 & 5.286 & 6.051 \\ 5 & 16.24 & 0.02 & 5.282 & 6.046 \\ 6 & 23.58 & 0.02 & 5.287 & 6.052 \\ 7 & 19.26 & 0.02 & 5.298 & 6.065 \\ 8 & 18.86 & 0.02 & 5.268 & 6.030 \\ 9 & 20.26 & 0.02 & 5.141 & 5.884 \\ 10 & 22.29 & 0.02 & 4.903 & 5.611 \\ 11 & 22.33 & 0.02 & 4.328 & 4.952 \\ 12 & 18.50 & 0.02 & 3.020 & 3.450 \\ 13 & 0.00 & 0.00 & 0.000 & -9.000 \\ 14 & 0.00 & 0.00 & 0.000 & -9.000 \\ 15 & 23.47 & 0.02 & 5.311 & 6.080 \\ 16 & 20.57 & 0.02 & 5.289 & 6.054 \\ 17 & 17.23 & 0.02 & 5.280 & 6.044 \\ 18 & 19.92 & 0.02 & 5.290 & 6.055 \\ 19 & 18.44 & 0.02 & 5.298 & 6.065 \\ 20 & 21.16 & 0.02 & 5.281 & 6.045 \\ 21 & 18.50 & 0.02 & 5.139 & 5.882 \\ 22 & 18.70 & 0.02 & 4.906 & 5.615 \\ 23 & 16.86 & 0.02 & 4.350 & 4.977 \\ 24 & 16.48 & 0.02 & 3.024 & 3.455 \\ 25 & 0.00 & 0.00 & 0.000 & -9.000 \\ 26 & 0.00 & 0.00 & 0.000 & -9.000 \\ 27 & 0.00 & 0.00 & 0.000 & -9.000 \\ 28 & 0.00 & 0.00 & 0.000 & -9.000 \\ 29 & 0.00 & 0.00 & 0.000 & -9.000 \\ 30 & 0.00 & 0.00 & 0.000 & -9.000 \\ 31 & 0.00 & 0.00 & 0.000 & -9.000 \\ 32 & 0.00 & 0.00 & 0.000 & -9.000 \\ 33 & 0.00 & 0.00 & 0.000 & -9.000 \\ 34 & 0.00 & 0.00 & 0.000 & -9.000 \\ 35 & 0.00 & 0.00 & 0.000 & -9.000 \\ 36 & 0.00 & 0.00 & 0.000 & -9.000\end{array}$


Figure 1. Stations occupied during the oxygen intercalibration. $R / V$ Oceanus cruise 219, leg 3.

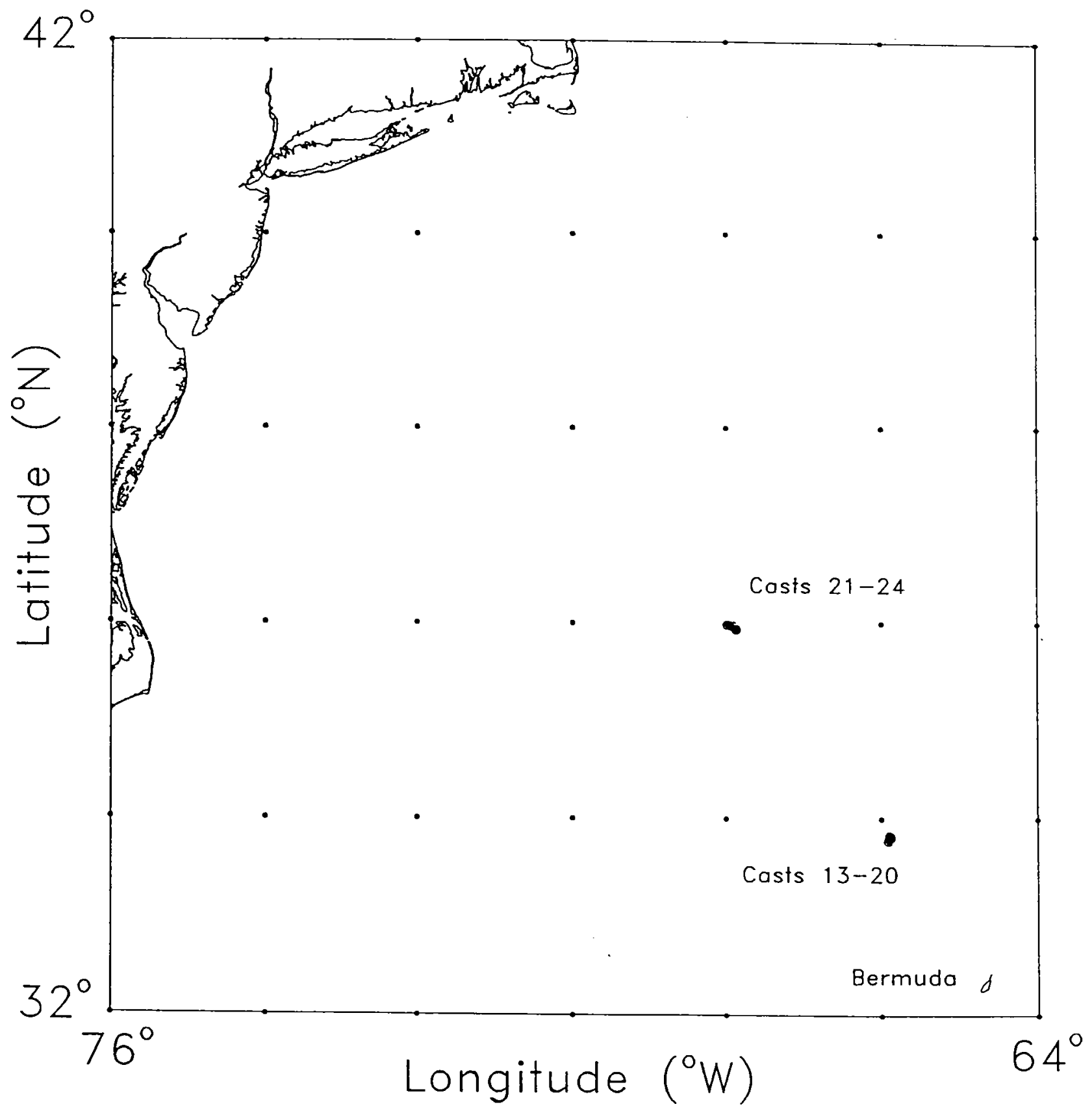


Figure 2. Hydrographic data at Station 1; casts 13, 15,16 , and 20.
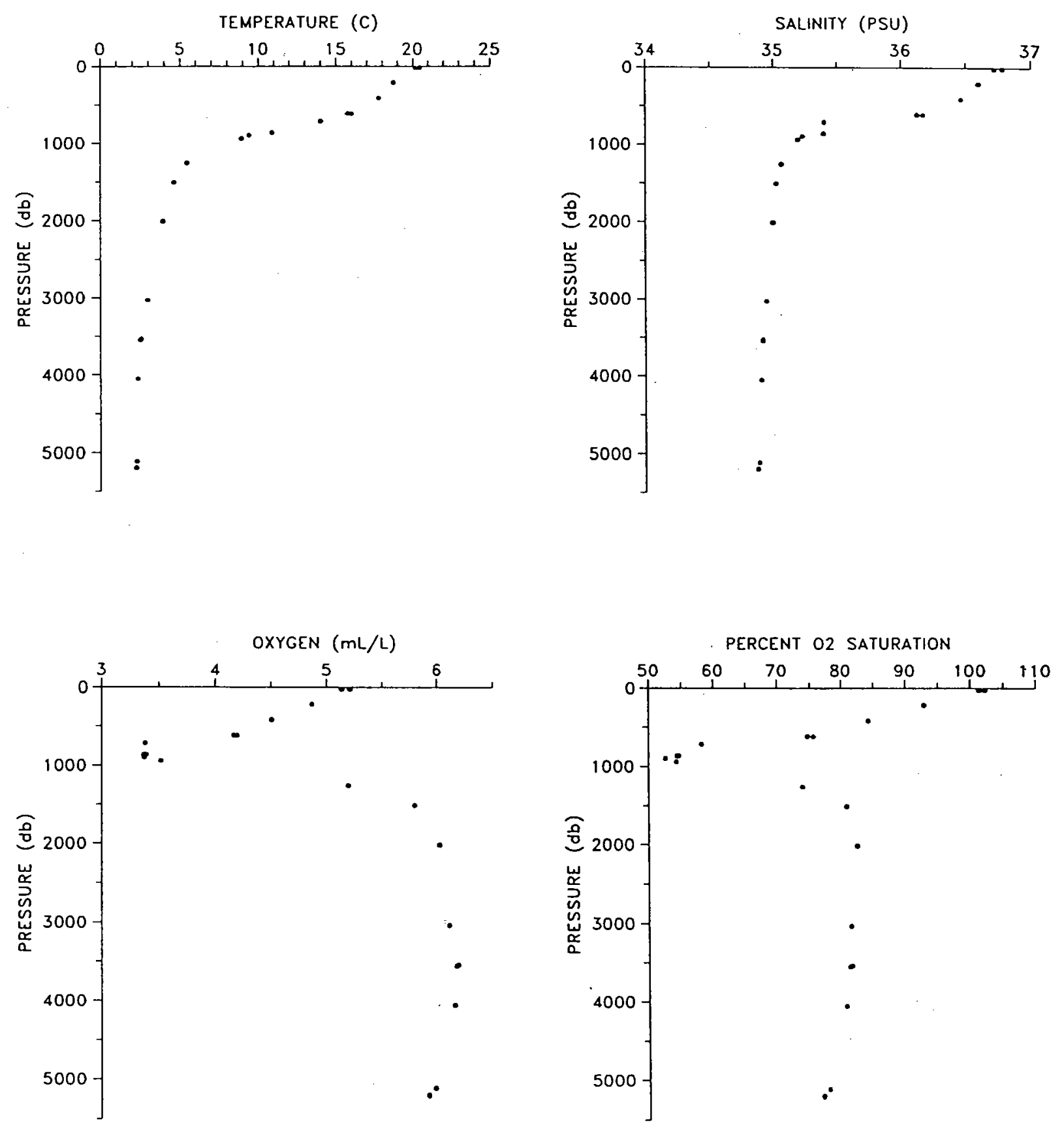
Figure 3. Hydrographic data at Station 2; casts 21 , 23 , and 24.
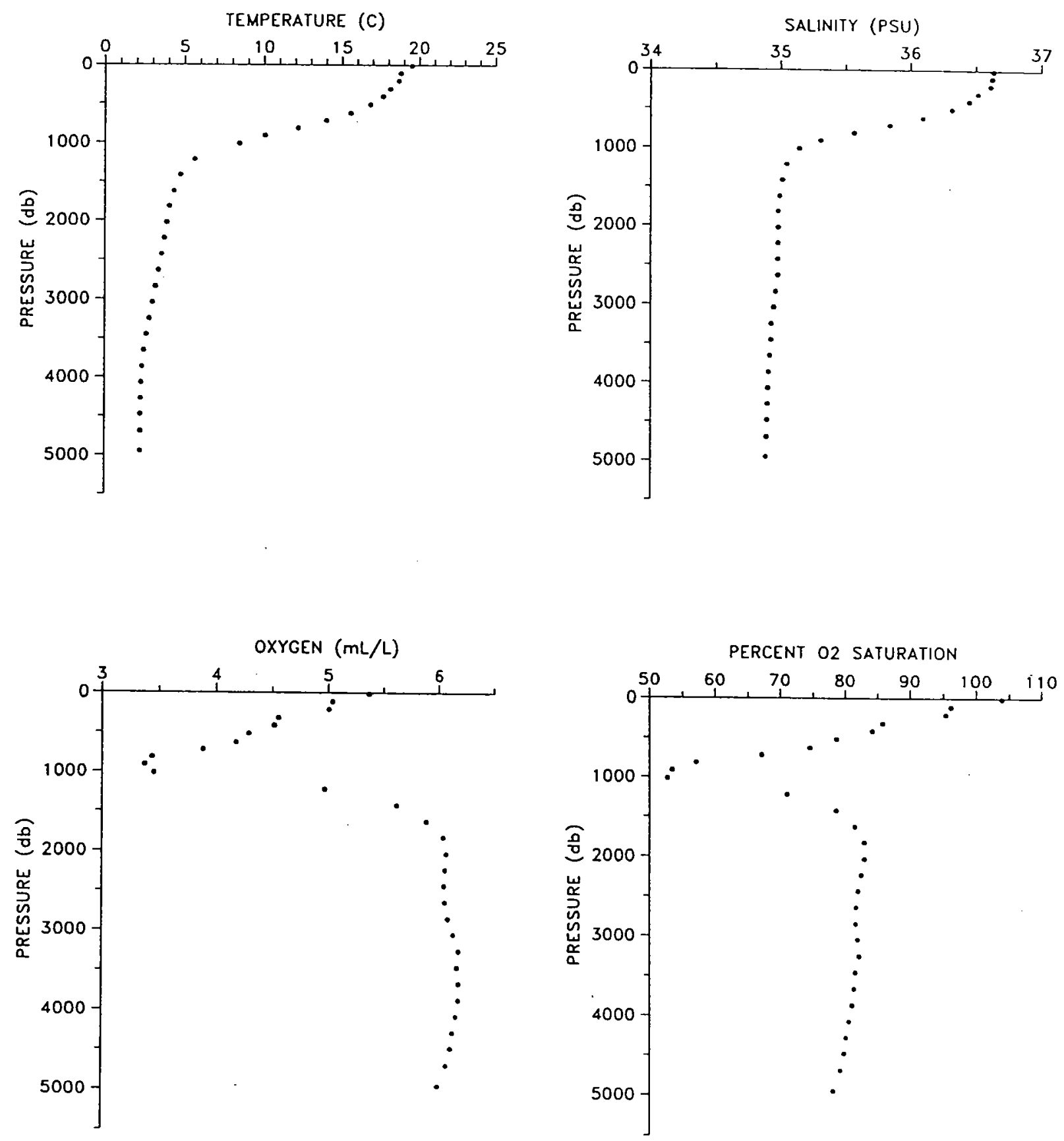

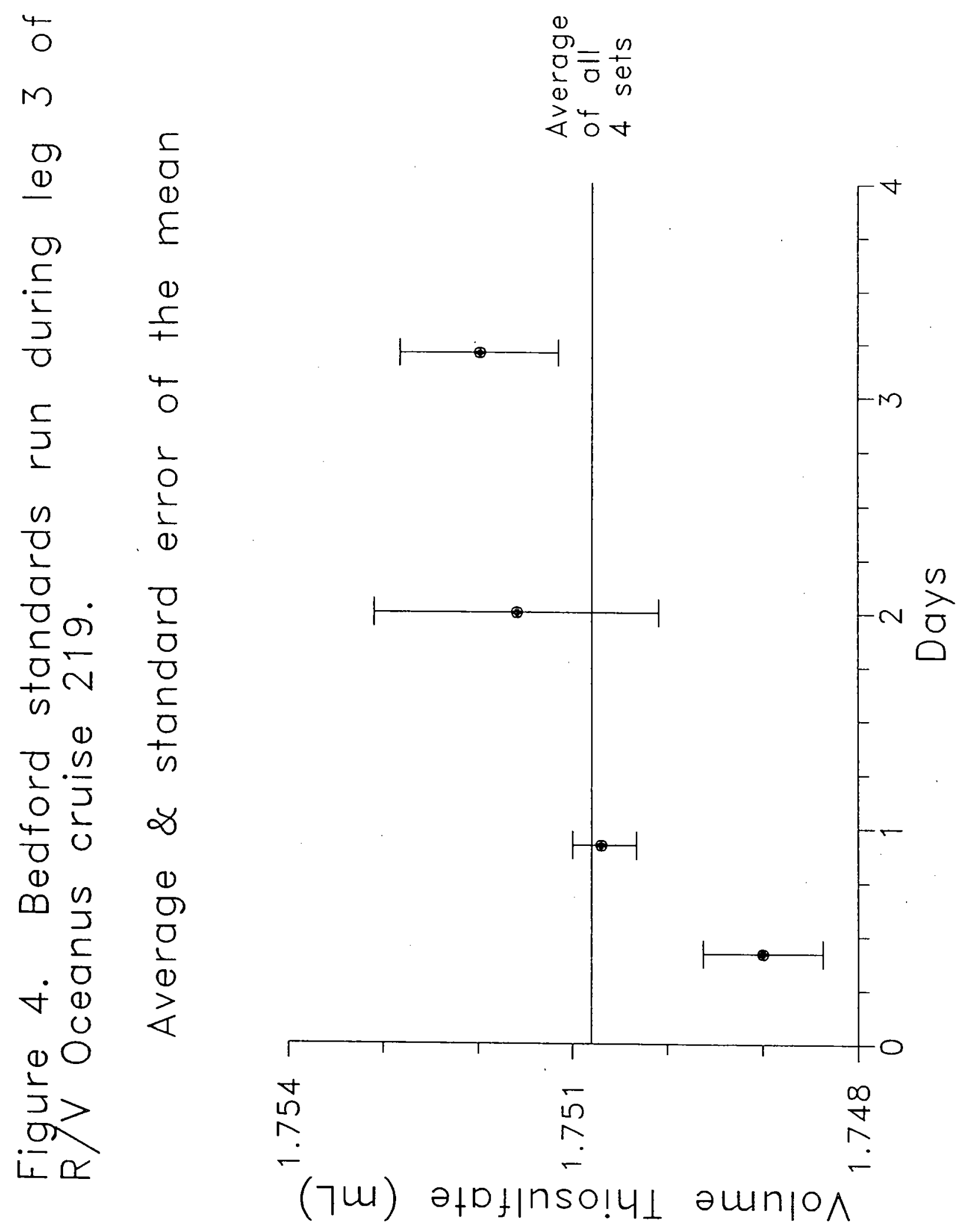


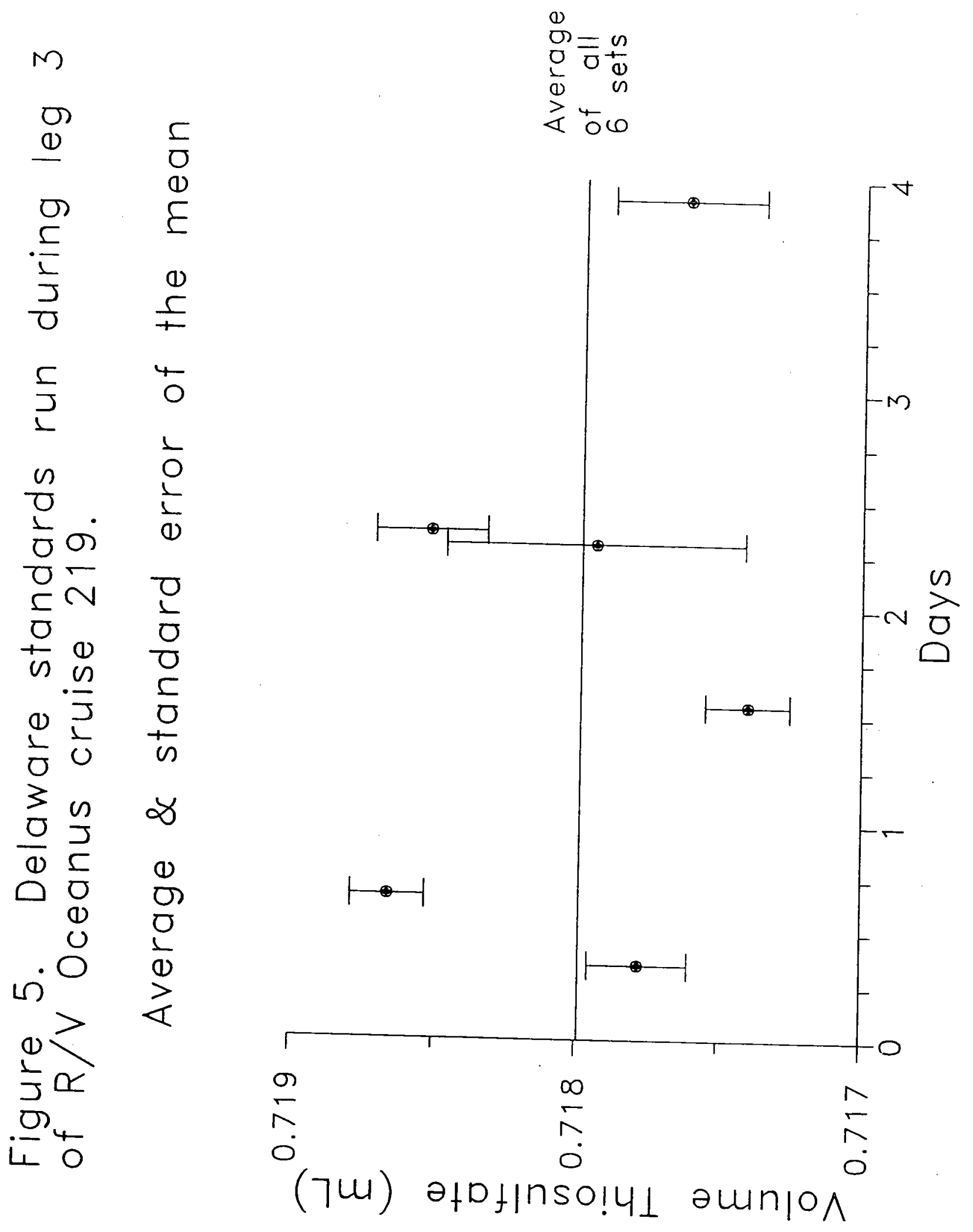



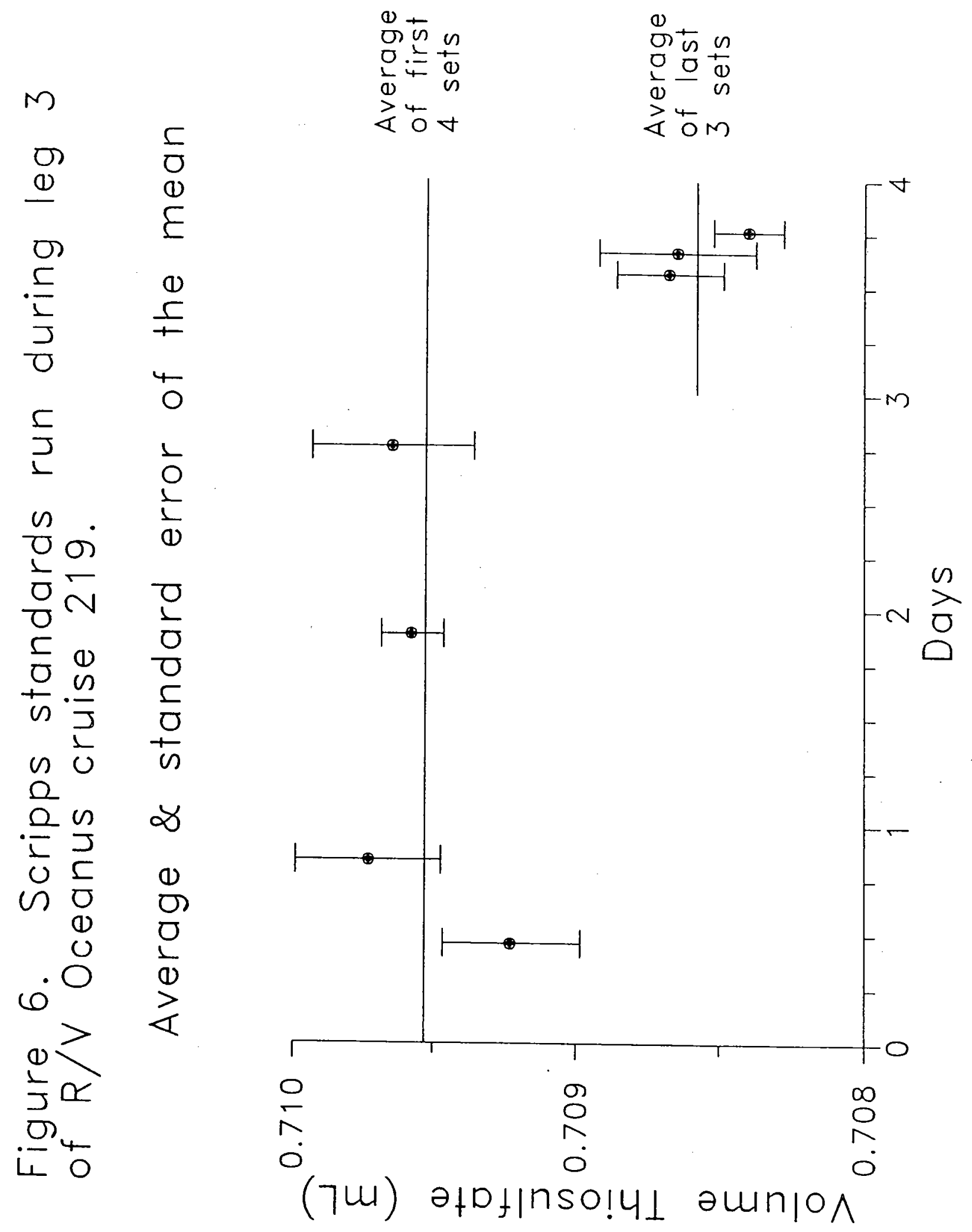


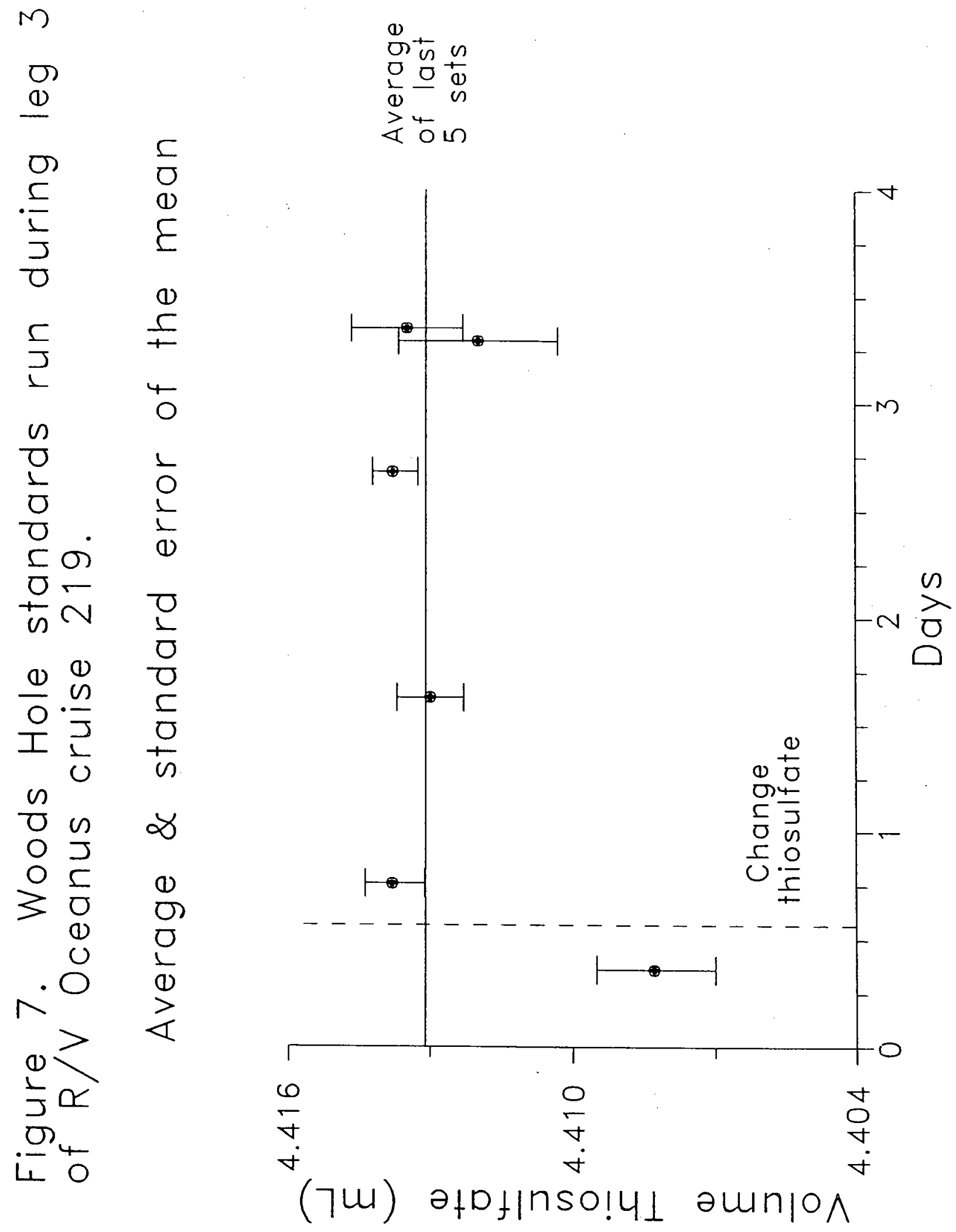


Figure 8. Bedford differences between duplicates (first titration minus second).

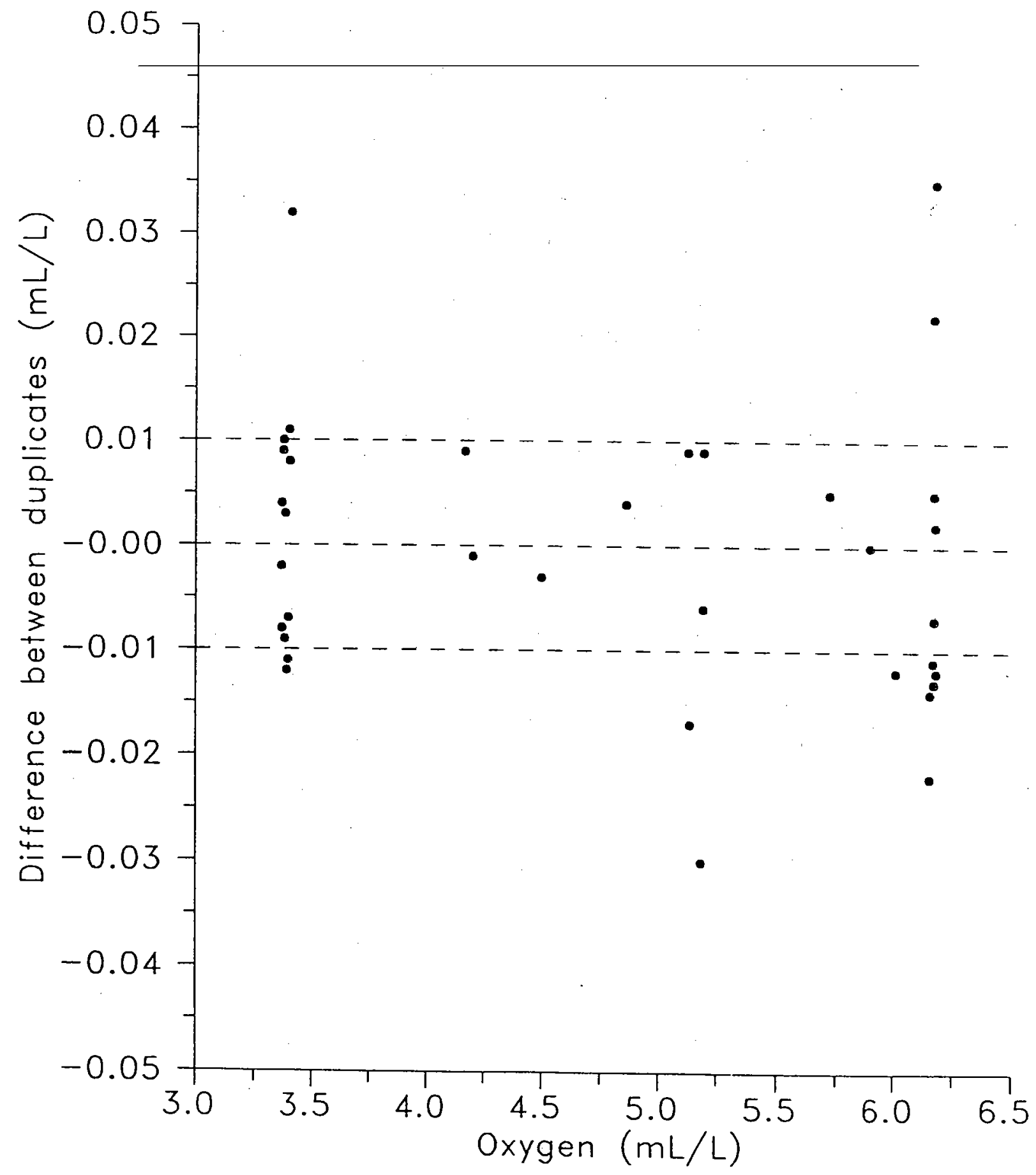


Figure 9. Delaware differences between duplicates (first titration minus second).

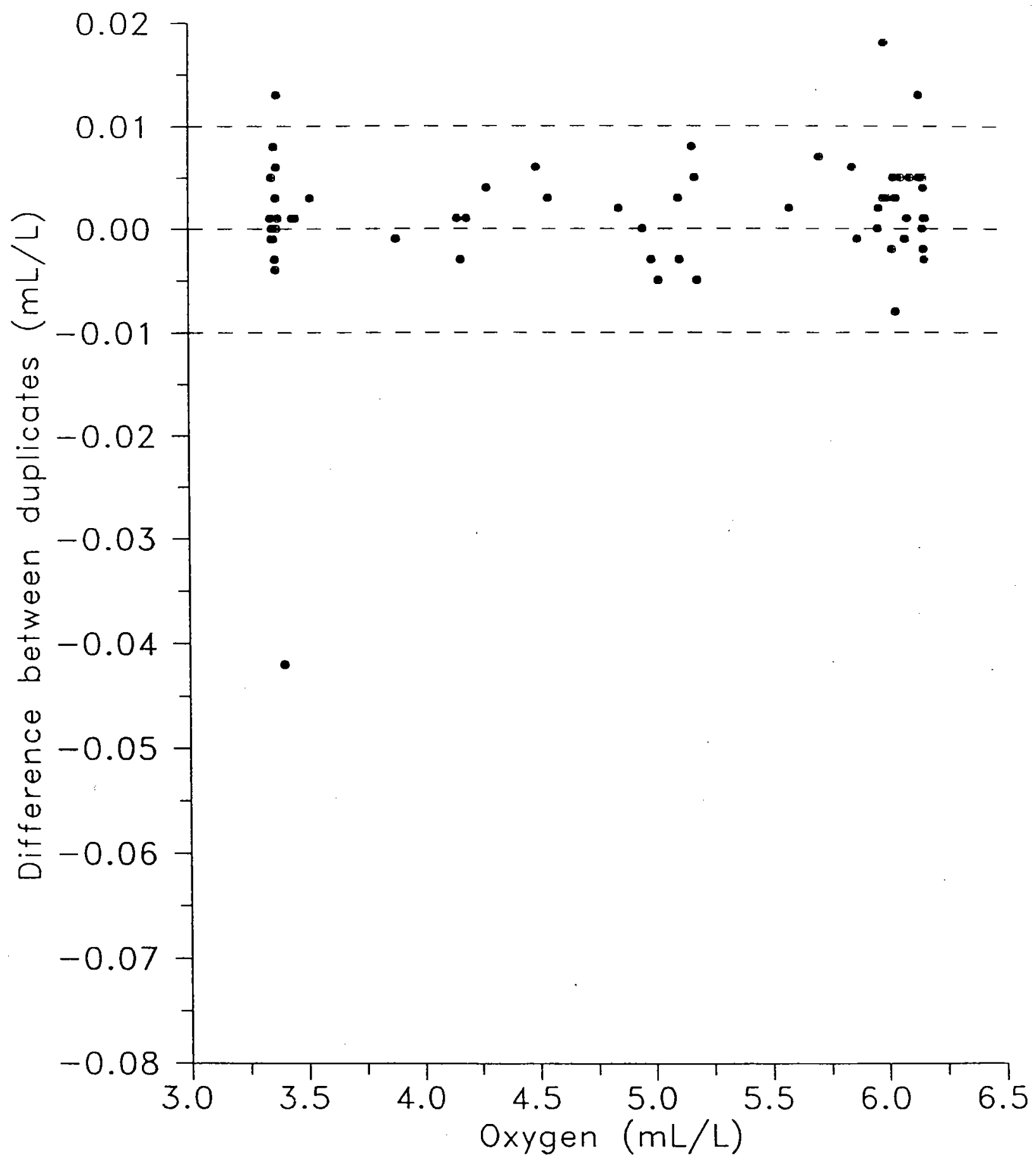


Figure 10. Scripps differences between duplicates (first titration minus second).

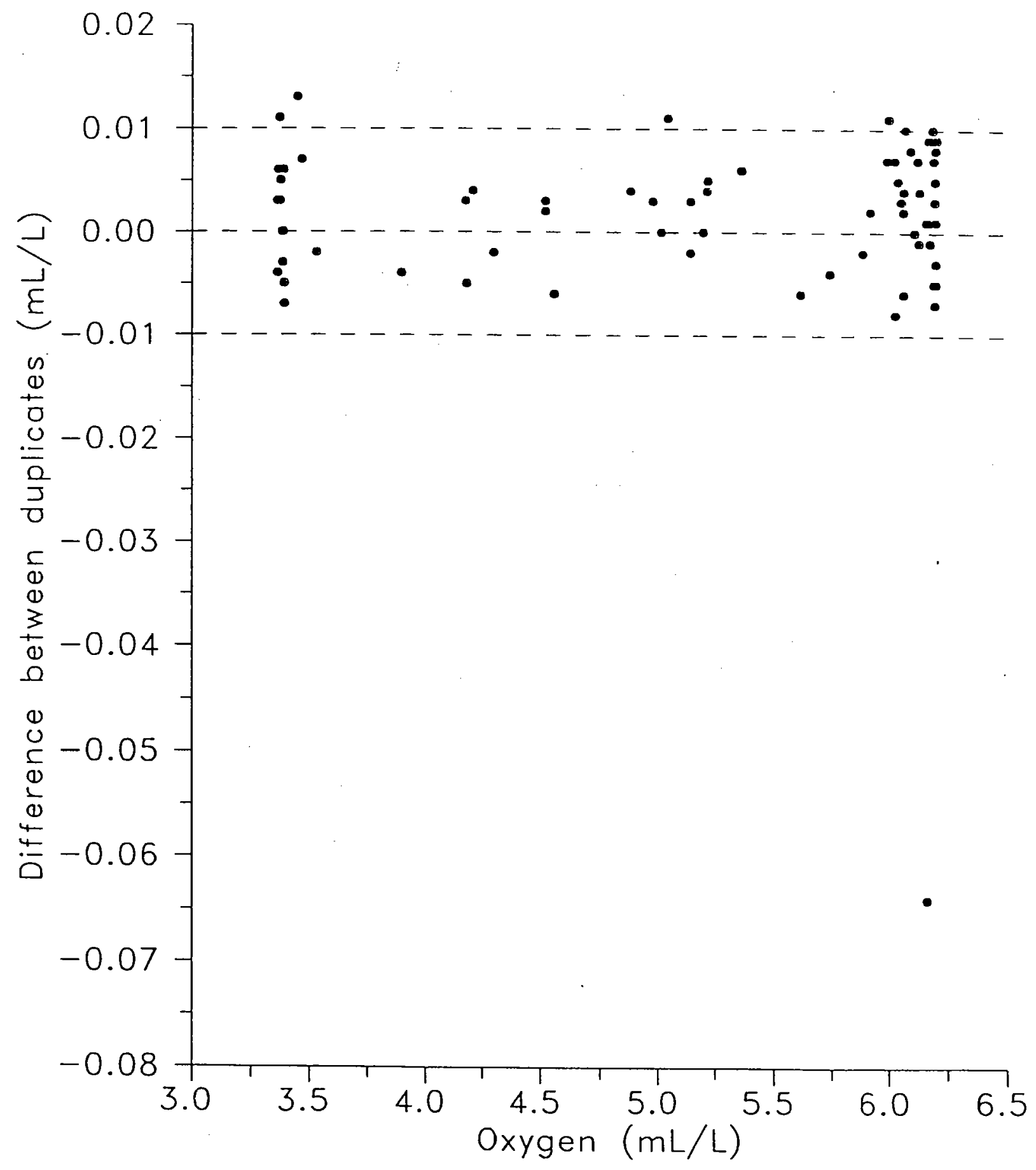


Figure 11. Woods Hole differences between duplicates (first titration minus second).

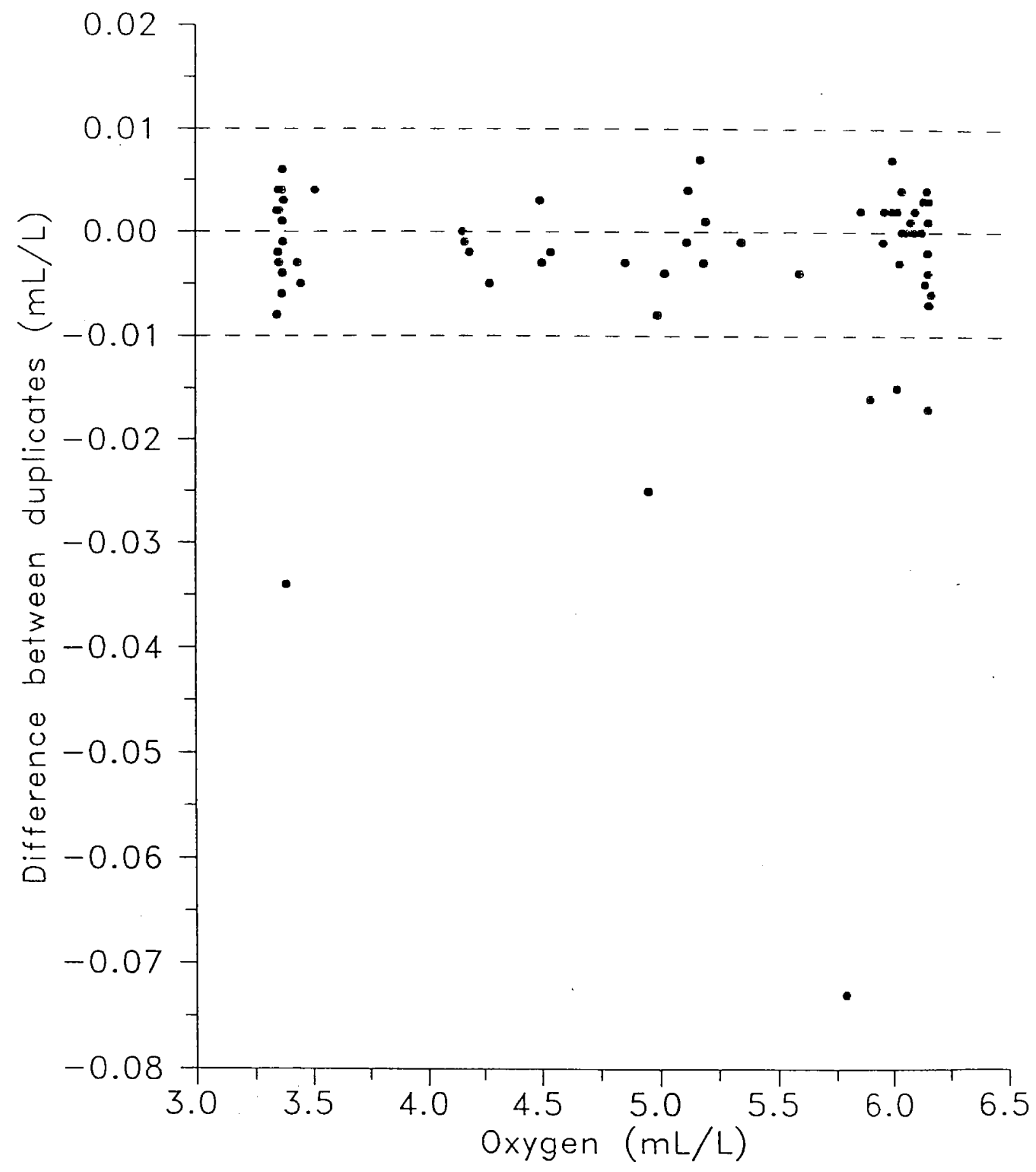


Figure 12. Bedford distribution of differences between duplicates (first titration minus second).

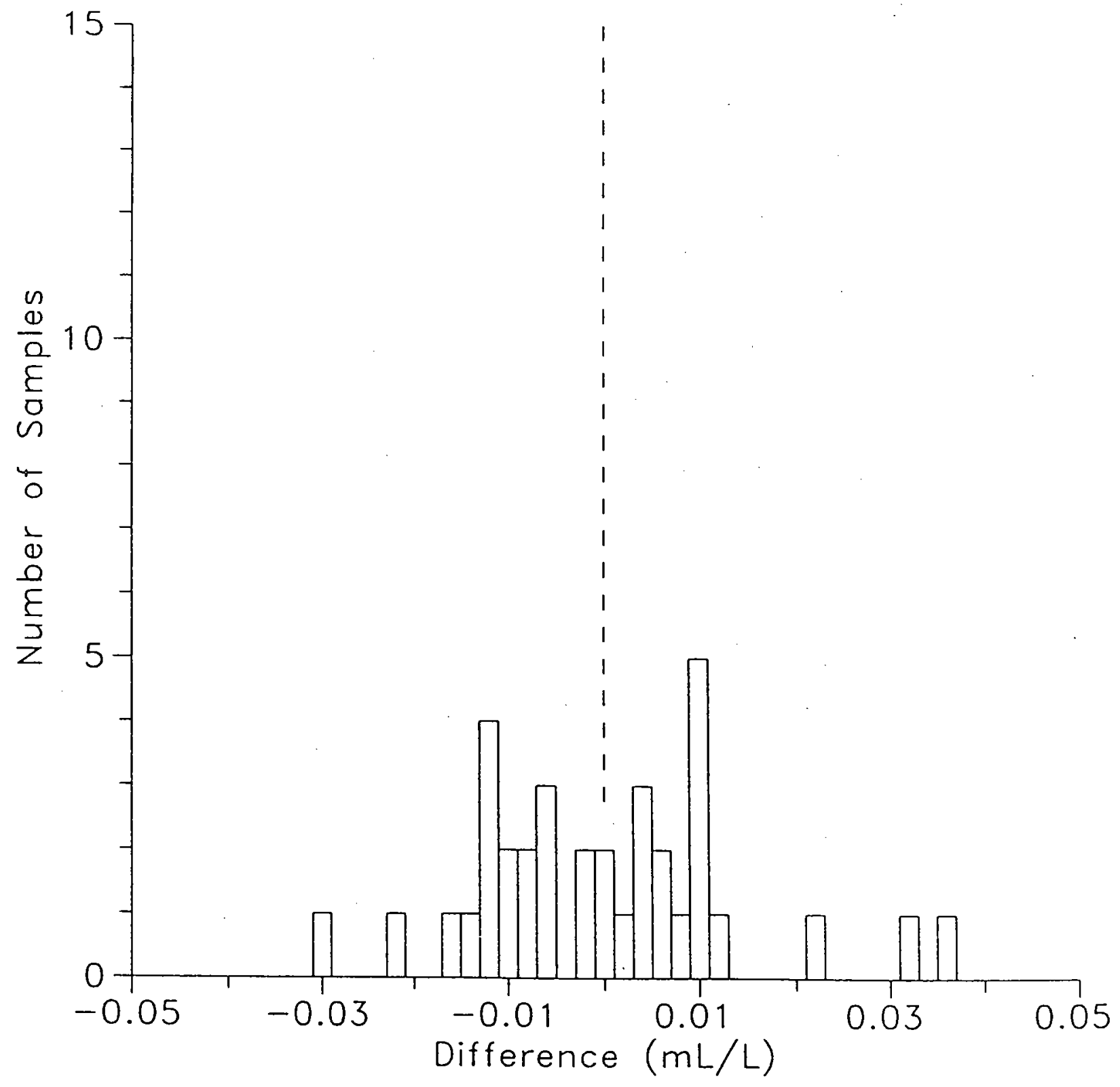


Figure 13. Delaware distribution of differences between duplicates (first titration minus second).

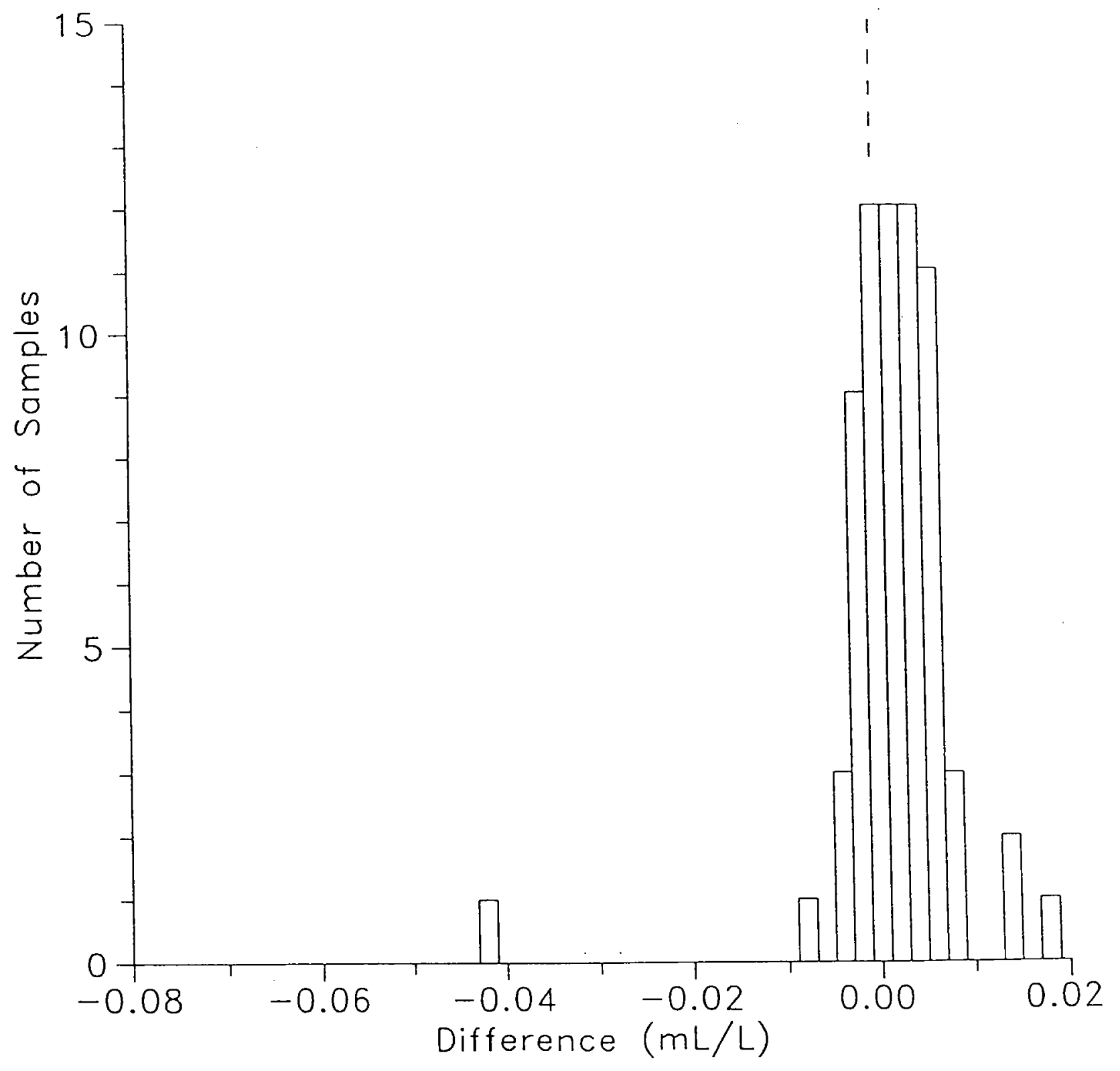


Figure 14. Scripps distribution of differences between duplicates (first titration minus second).

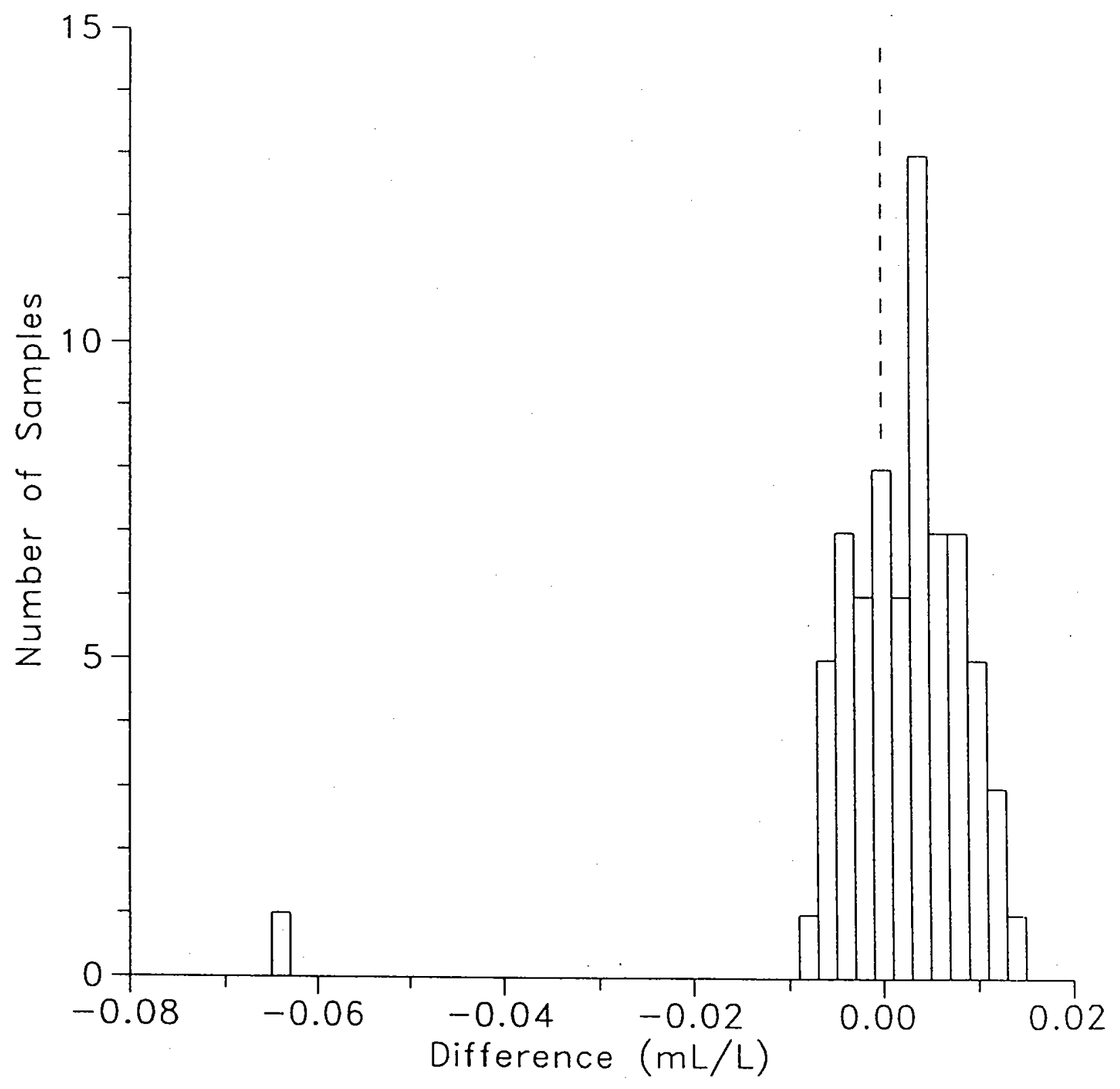


Figure 15. Woods Hole distribution of differences between duplicates (first titration minus second).

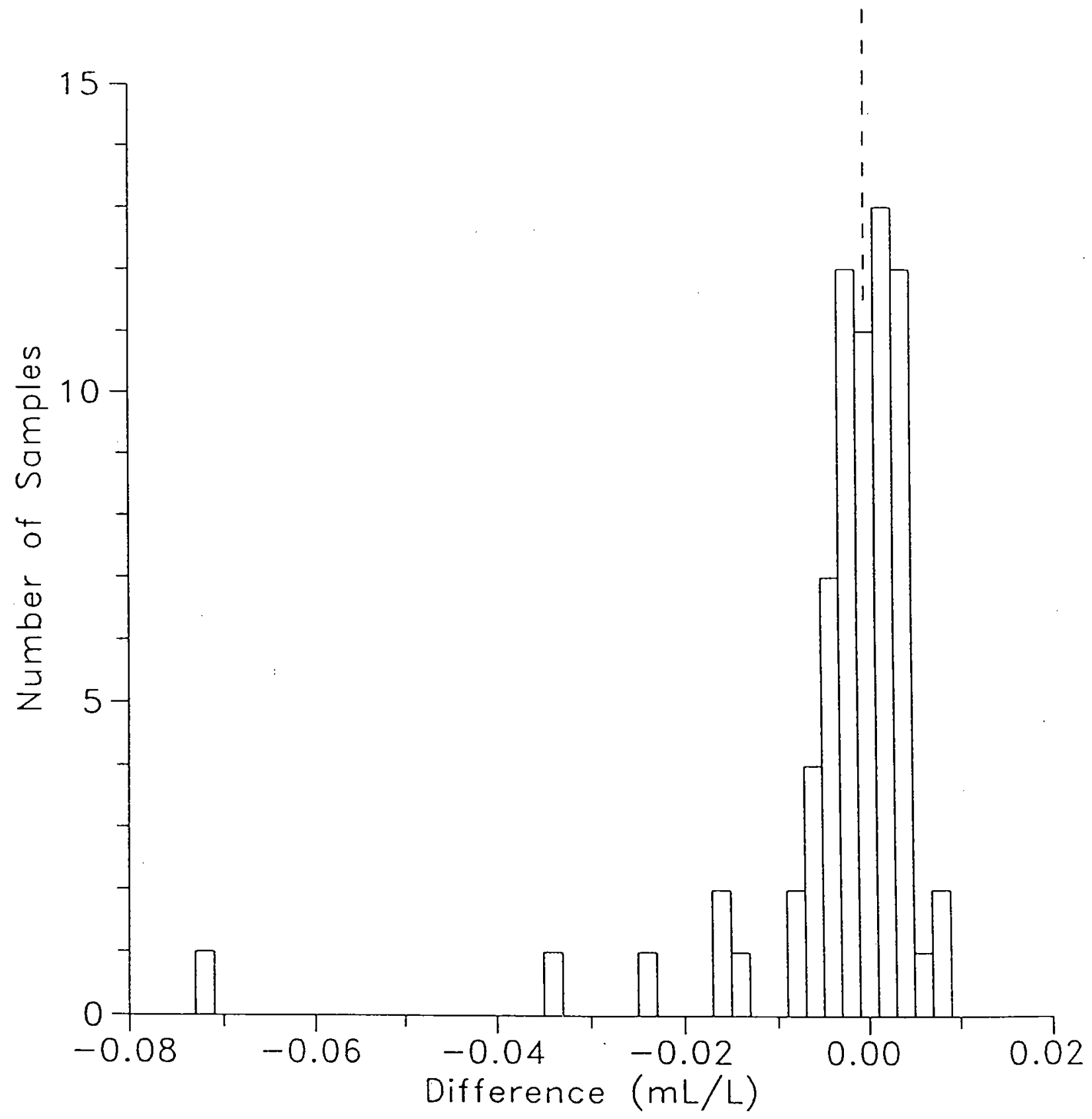


Figure 16. Difference between oxygen concentrations measured by Bedford and Delaware versus the absolute oxygen concentration.

Line: Delta $02=-0.035+0.0054 * 02$

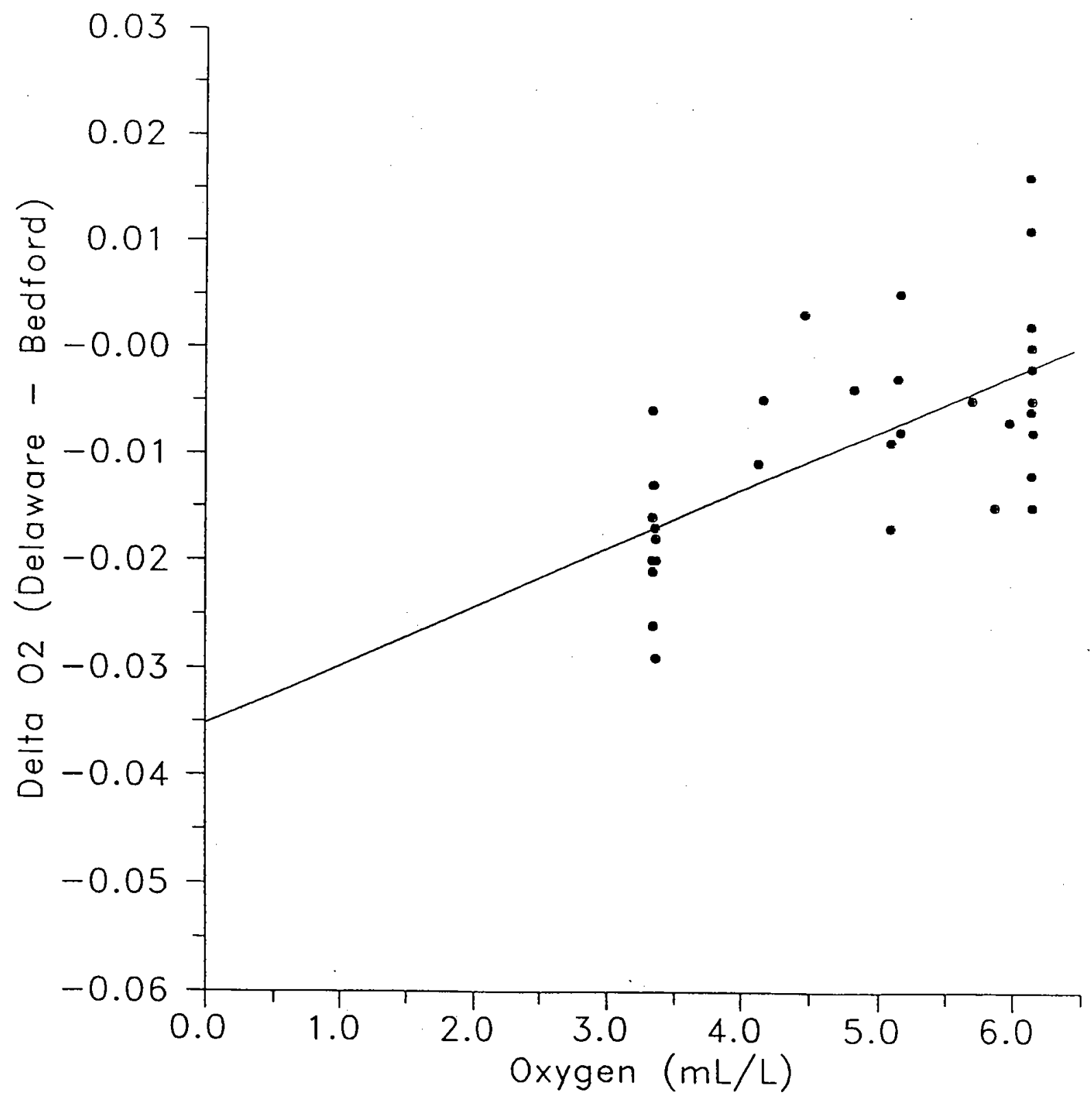


Figure 17. Difference between oxygen concentrations measured by Bedford and Scripps versus the absolute oxygen concentration.

Line: Delta $\mathrm{O} 2=-0.041+0.0113 * \mathrm{O} 2$

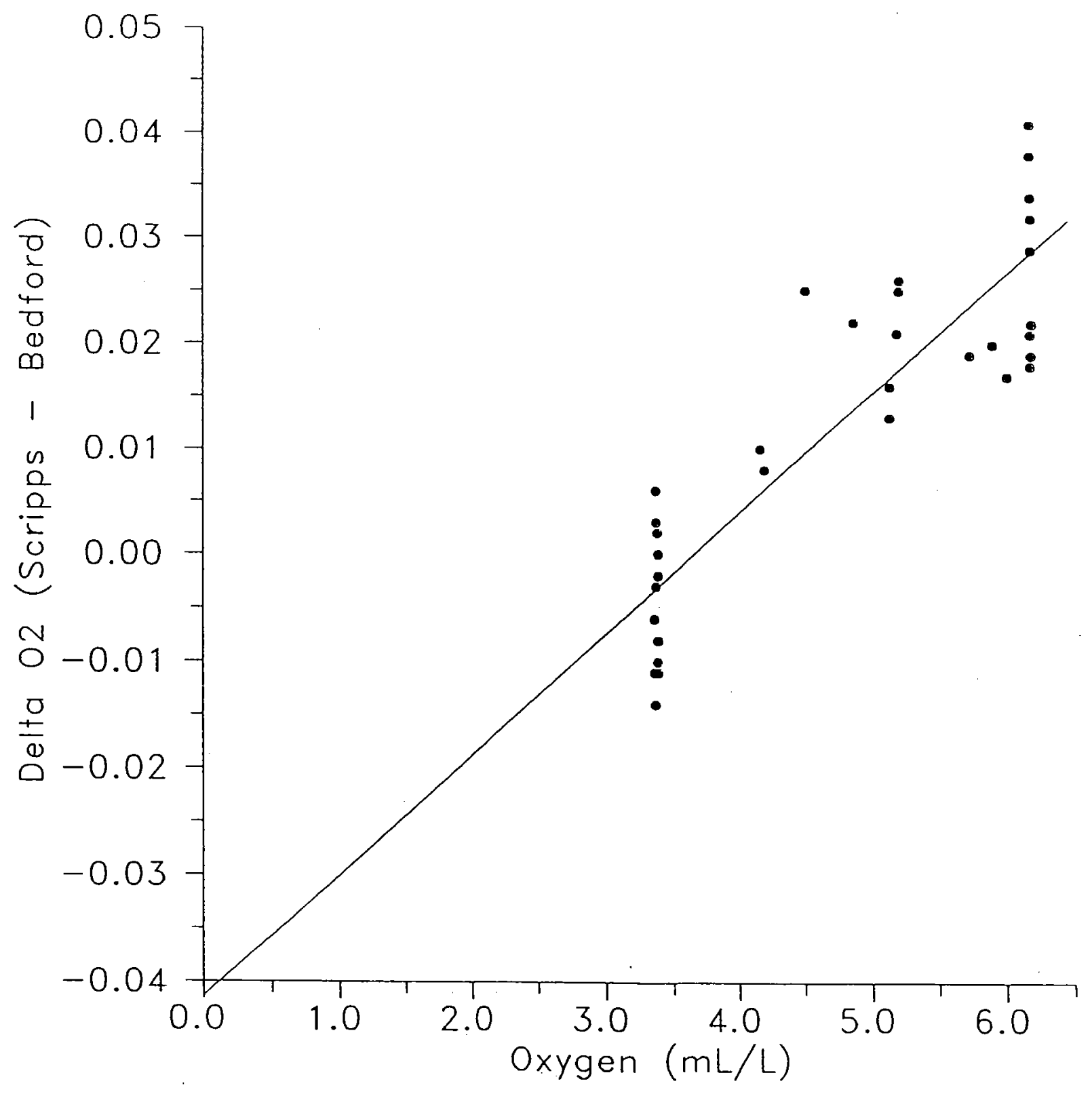


Figure 18. Difference between oxygen concentrations measured by Bedford and Woods Hole versus the absolute oxygen concentration.

Line: Delta $02=-0.051+0.0092 * 02$

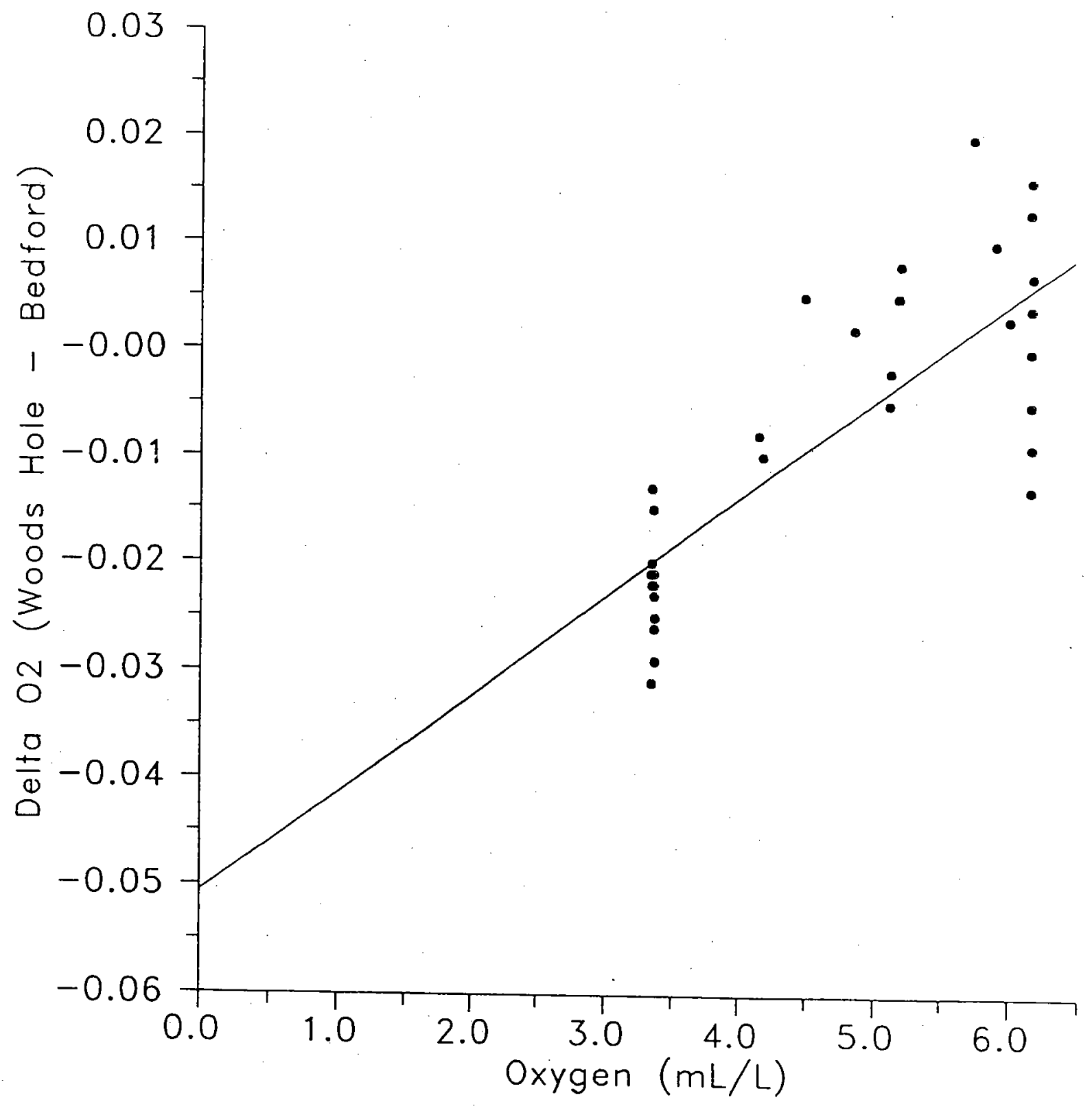


Figure 19. Difference between oxygen concentrations measured by Scripps and Delaware versus the absolute oxygen concentration.

Line: Delta $\mathrm{O} 2=-0.005+0.0050 * 02$

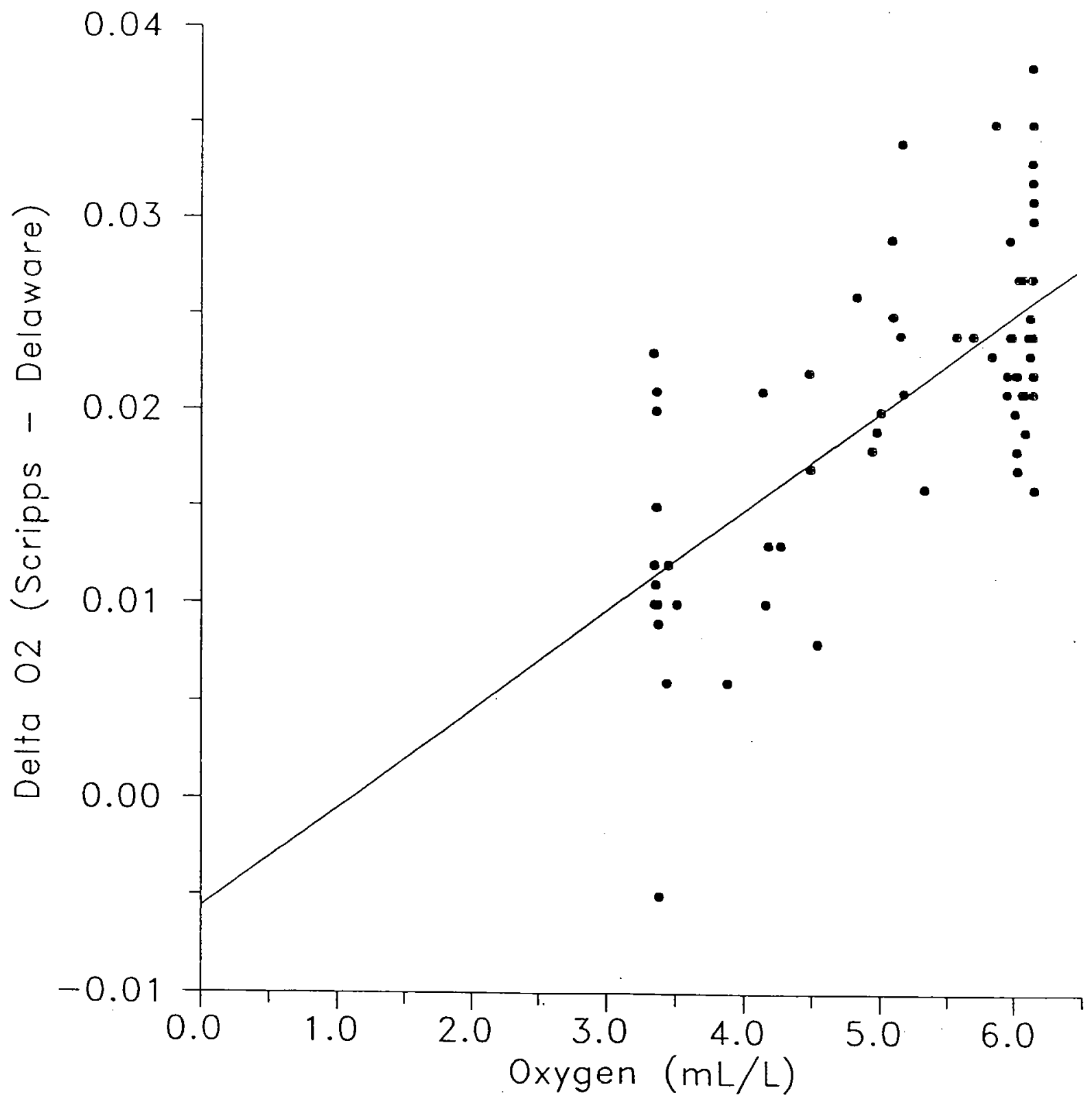


Figure 20. Difference between oxygen concentrations measured by Woods Hole and Delaware versus the absolute oxygen concentration.

Line: Delta $02=-0.015+0.0032 * 02$

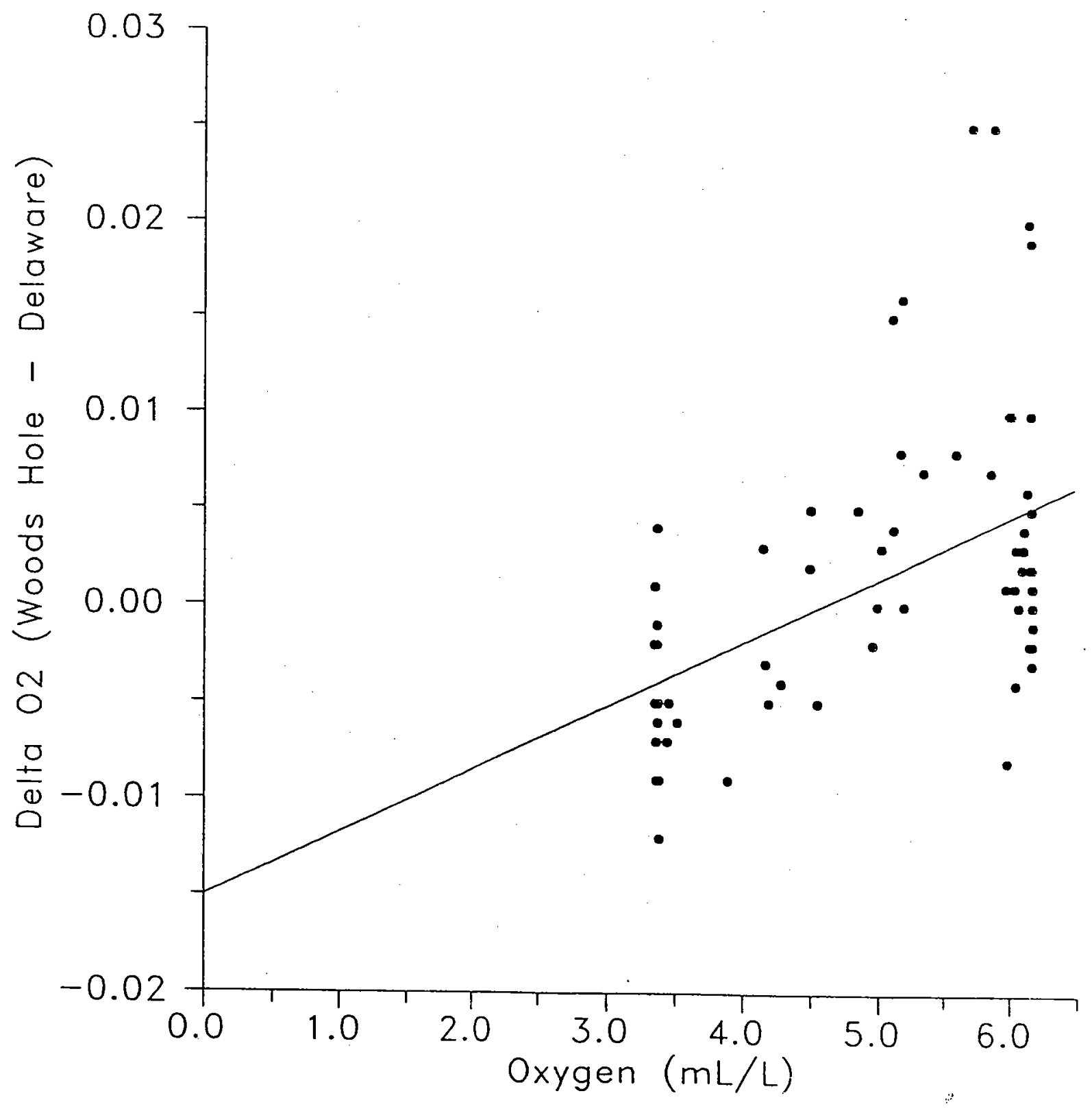


Figure 21. Difference between oxygen concentrations measured by Scripps and Woods Hole versus the absolute oxygen concentration.

Line: Delta $02=0.010+0.0017 * 02$

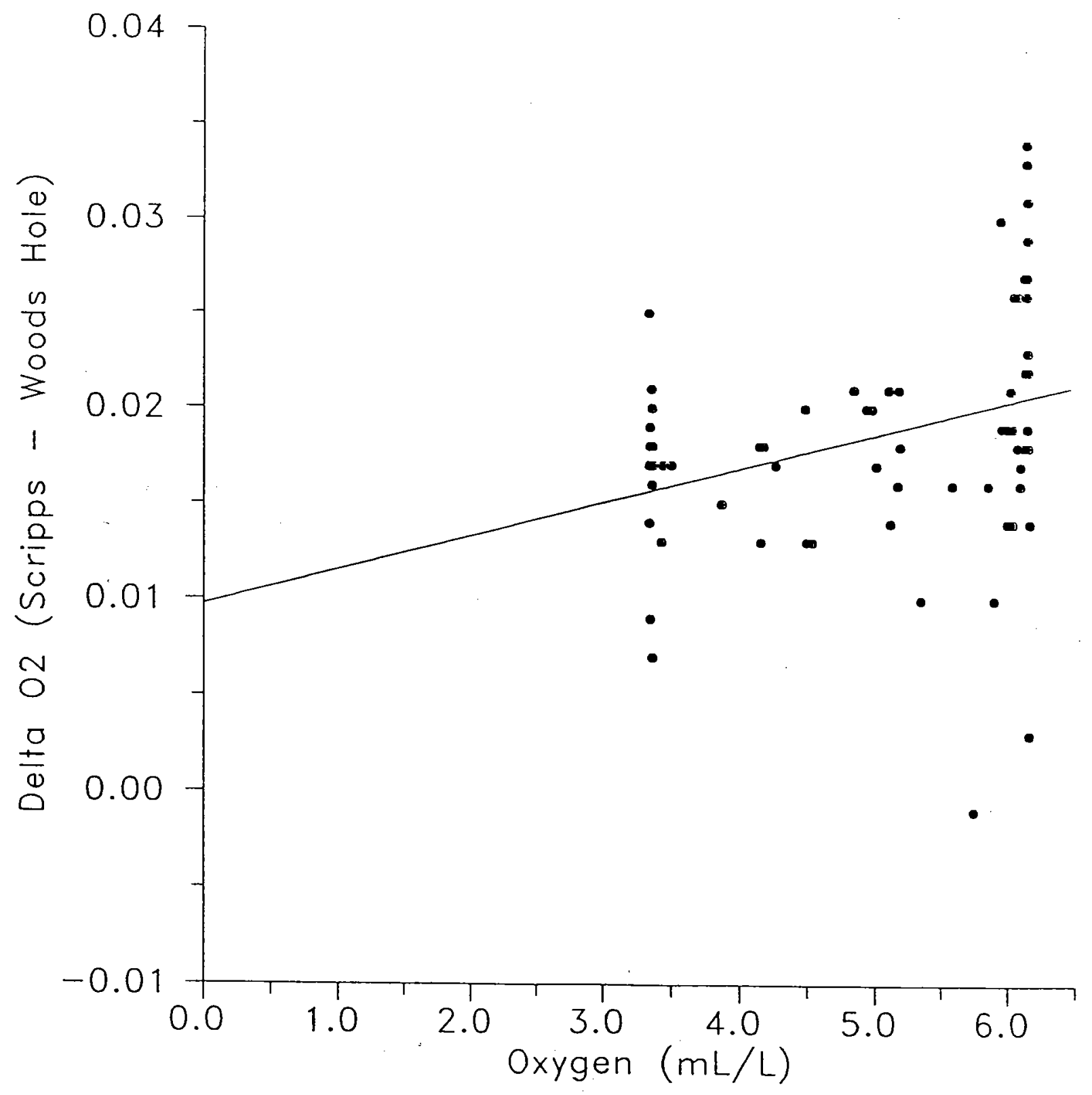


Figure 22. Comparison of regression lines: difference in concentration between institutions versus concentration. Diagonal dashed lines represent errors of \pm 0.5 percent.

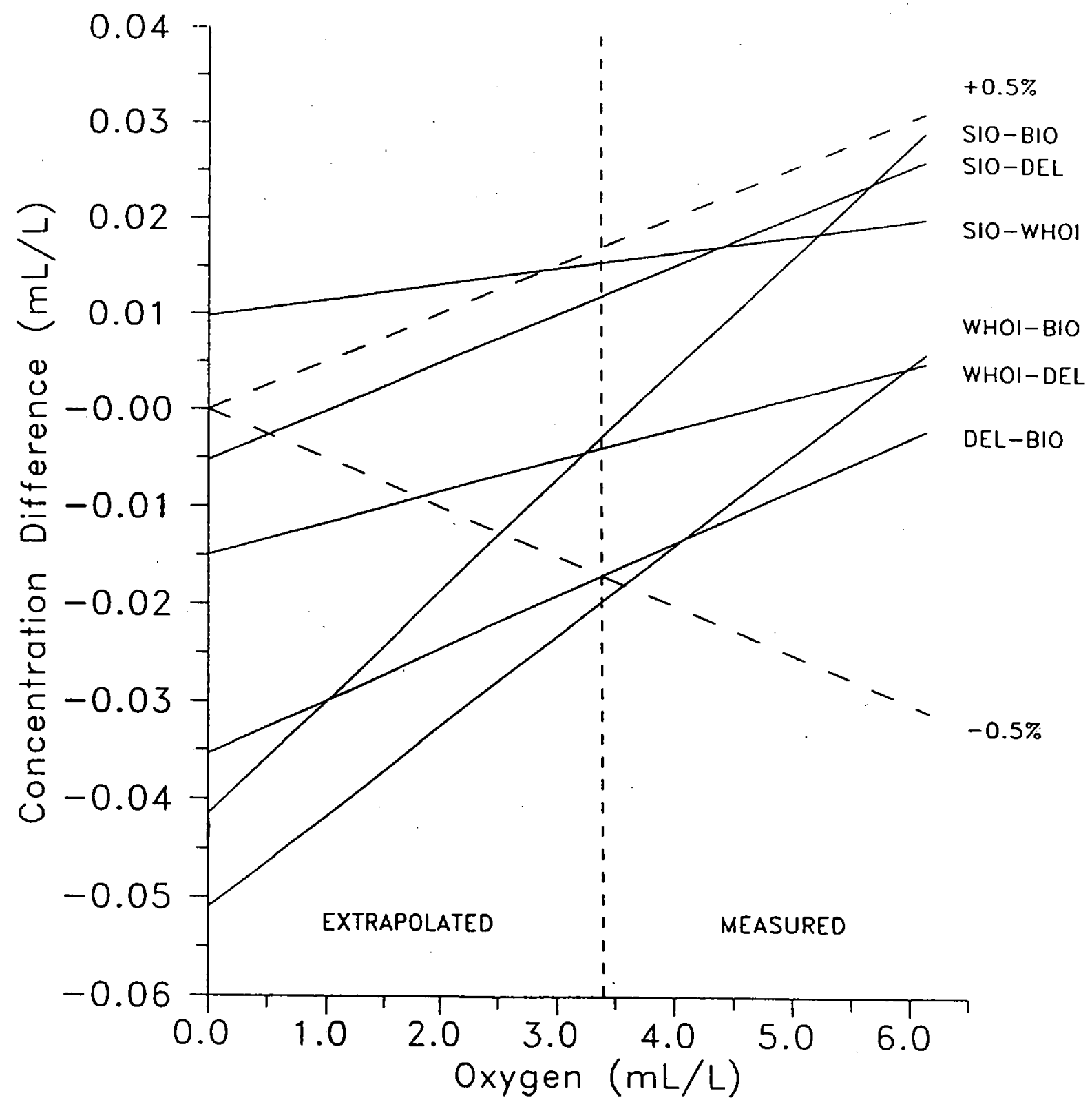


Figure 23. Temperature increase in $10 \mathrm{~L}$. Niskin bottles. Solid circles, temperature when bottle first opened minus potential temperature. Open circles, temperature after last sample drawn minus potential temperature.

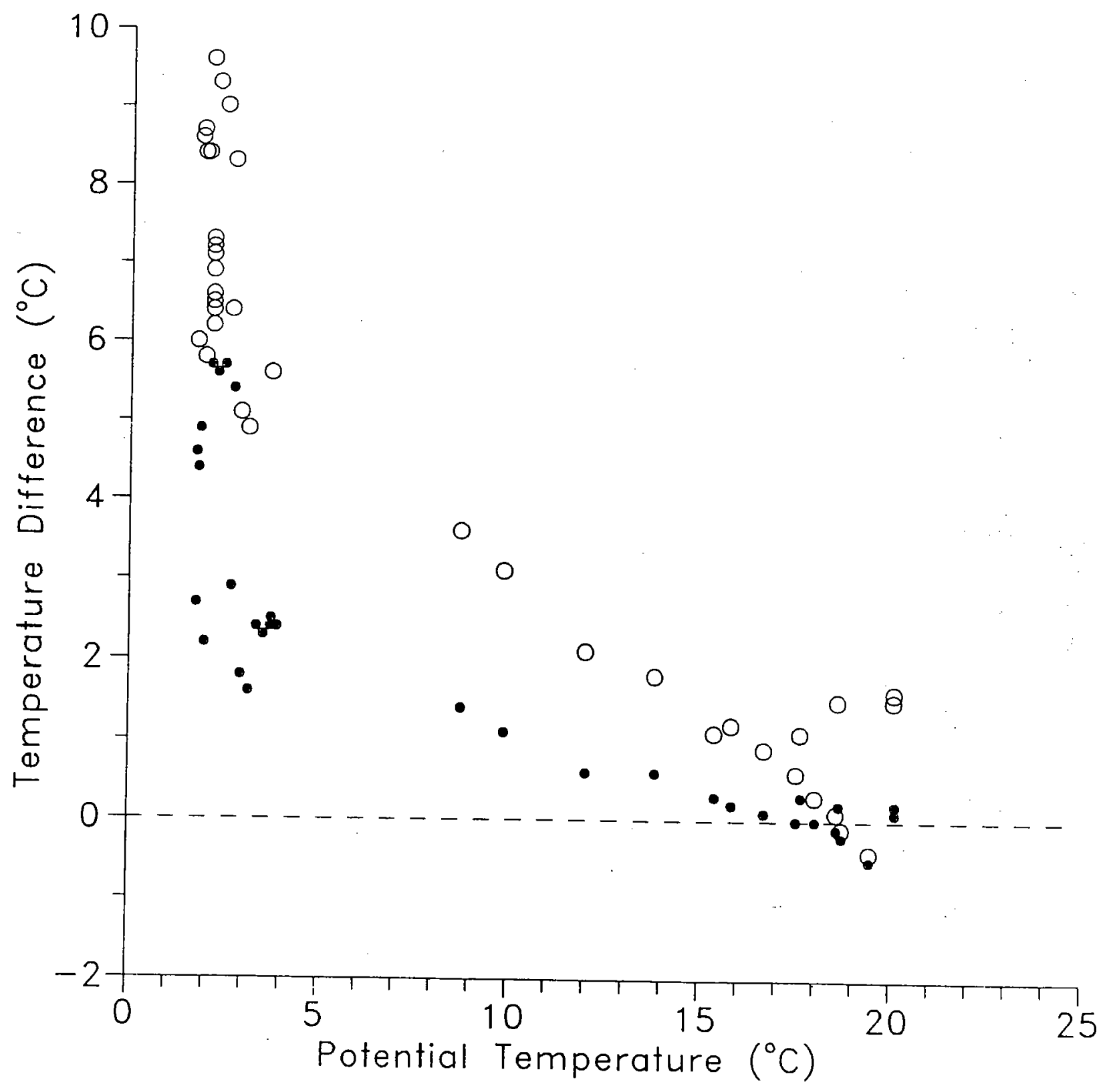


Figure 24. Temperature increase in $10 \mathrm{~L}$ Niskin bottles after bottles were brought on deck. Start temperature is the temperature just before first sample was drawn, end temperature is the temperature after last sample was drawn.

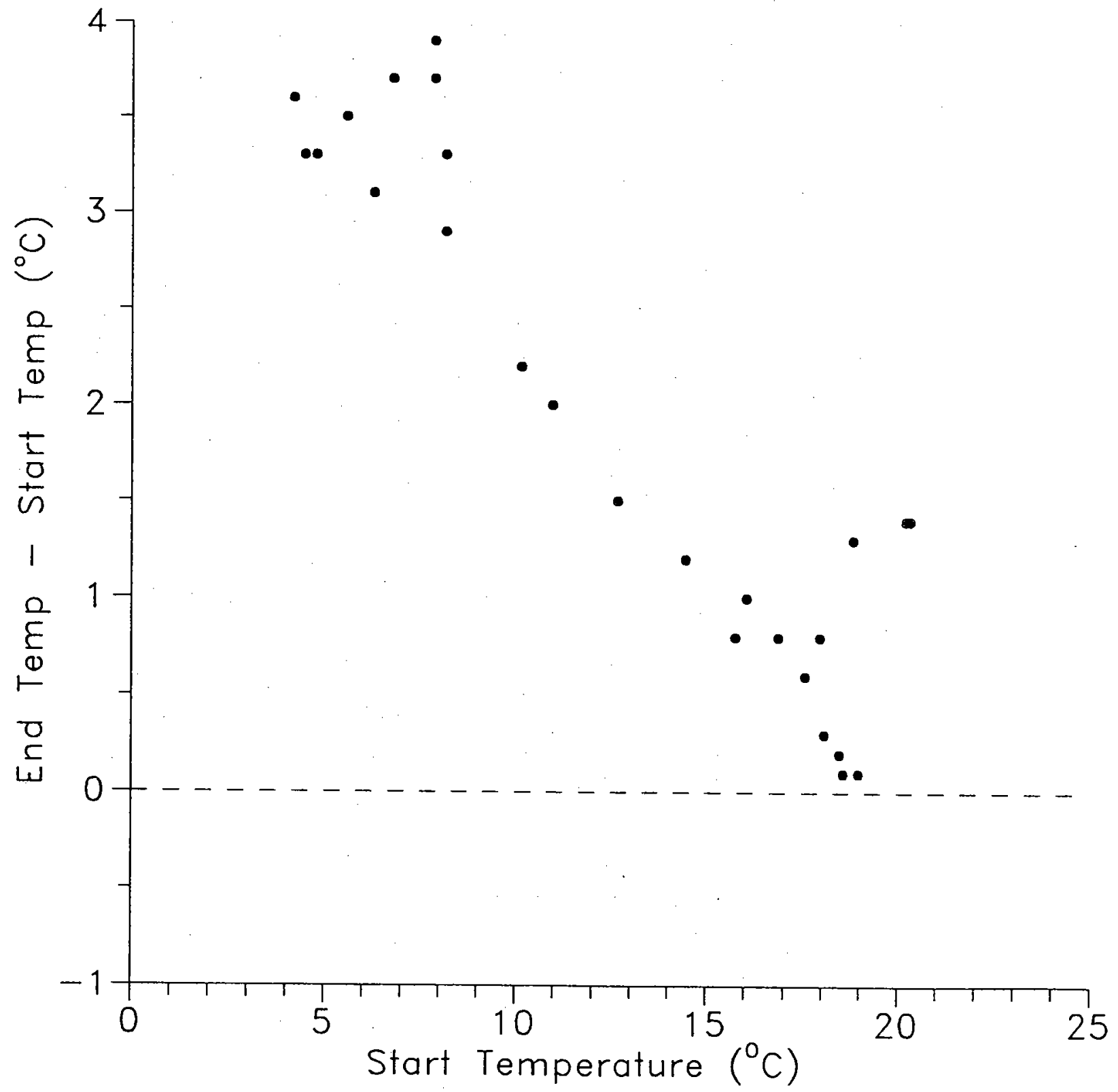


